THE EXPERIENCE OF CHEMOTHERAPY-INDUCED PERIPHERAL NEUROPATHY

\title{
AMONG CHILDHOOD CANCER SURVIVORS
}

\author{
A Dissertation \\ presented to \\ the Faculty of the Graduate School \\ at the University of Missouri-Columbia \\ In Partial Fulfillment \\ of the Requirements for the Degree \\ Doctor of Philosophy \\ by \\ CAROLINE E. MOHRMANN \\ Dr. Jane M. Armer, Dissertation Supervisor \\ July 2017
}


The undersigned, appointed by the dean of the Graduate School, have examined the dissertation entitled

THE EXPERIENCE OF CHEMOTHERAPY-INDUCED PERIPHERAL NEUROPATHY AMONG CHILDHOOD CANCER SURVIVORS

presented by Caroline Mohrmann, a candidate for the degree of doctor of philosophy, and hereby certify that, in their opinion, it is worthy of acceptance.

Professor Jane Armer

Professor Lawrence Ganong

Assistant Professor Urmeka Jefferson

Associate Professor Jennifer Hunter 


\section{Acknowledgements}

As I reflect on my entire doctoral education experience, it is easy to see I did not do this alone. To my advisor, Dr. Jane Armer, I believe you are at the core of this wonderful experience. Your knowledge, support, humanity, and strength have motivated me every step of the way. You are giving to the field of nursing through your own impactful research career, and also, incredibly, by growing the next generation of cancer researchers. I do not know how you accomplish it all with charisma, and a smile. To my committee members Dr. Urmeka Jefferson, Dr. Jennifer Hunter, and Dr. Lawrence Ganong - I cannot express how much I appreciate and value your influence and guidance throughout this entire process. It is easy for me to see you have made my research stronger, and my experience richer.

To my patients, survivors of childhood cancer, thank you for giving your time and efforts to this research. You are my inspiration.

To all the $\mathrm{PhD}$ faculty at the MUSSON, you make me proud to be a graduate of Mizzou (very soon). I look to you all with admiration at what nurses can achieve to improve the lives of those who look to us for care. As a student in the MUSSON, I have felt so much support and encouragement from you all.

I appreciate the generous support from V. James and Verna Adwell Rhodes in the form of their endowed nursing scholarship and the American Cancer Society in the form of their Doctoral Degree Scholarship in Cancer Nursing.

To my colleagues at Washington University and St. Louis Children's Hospital, I appreciate your kind words of encouragement along the way. Dr. Hayashi, thank you for 
your patience and unwavering support. To my Late Effects Clinic Team, thank you for functioning as a sounding board, as you are truly experts in caring for our survivors.

To Ginny Schulz, co-worker and fellow PhD student, you were my lifeline. Thank you.

To my parents and sister, who have supported me in every endeavor in life, thanks for not even blinking an eye when I proposed doctoral education. I am grateful that you continue to build me up every day.

To my daughter, Vera, thank you for being born in the middle of my doctoral studies to teach me that magic is real.

To my husband, Andrew, you are the best. I've learned quite a bit about writing during this program, and I'm convinced there no words to describe your love and support. You believe in me so much, I believe in myself. 


\section{TABLE OF CONTENTS}

Acknowledgements ....................................................... ii

List of Figures, Photographs, and Tables ....................................vii

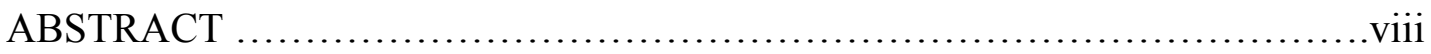

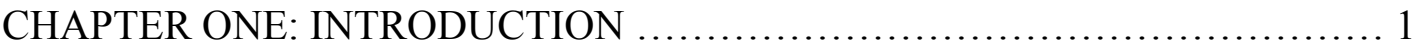

Physical Function and Quality of Life ...................................2

Diagnostic and Management Strategies................................. 4

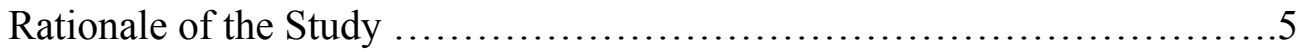

Conclusion ............................................................6

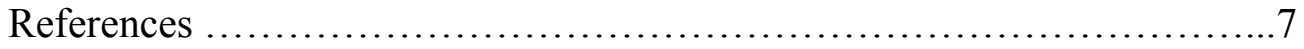

CHAPTER TWO: CHALLENGES EVALUATING CHEMOTHERAPY-INDUCED PERIPHERAL NEUROPATHY IN CHILDHOOD CANCER SURVIVORS: WHICH INSTRUMENT SHOULD NURSES USE? ................................11

Theoretical Guidance ................................................... 13

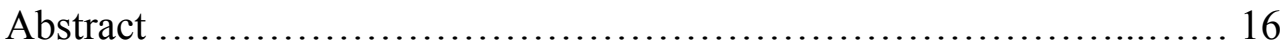

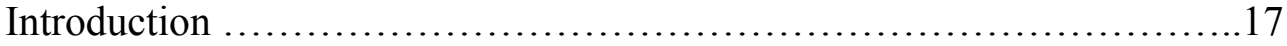

Literature Review .................................................. 18

Review of Measurement Tools ...................................... 21

Recommendations for Future Research ..............................25

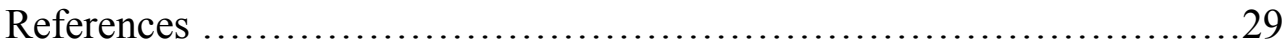

CHAPTER 3: METHODS \& PROPOSAL .................................42

Research Questions and Specific Aims ................................42

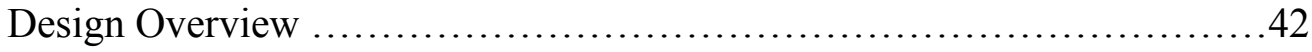




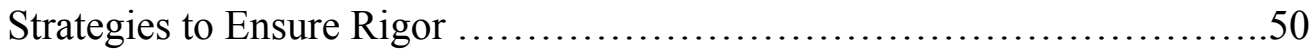

Limitations or Potential Difficulties ......................................50

Protection of Human Subjects ........................................51

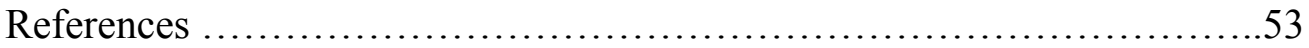

CHAPTER 4: THE EXPERIENCE OF CHEMOTHERAPY-INDUCED PERIPHERAL NEUROPATHY AMONG CHILDHOOD CANCER SURVIVORS ...............56

Abstract.......................................................... 57

Introduction ...................................................... 58

Methods ............................................................ 60

Findings: A Condition of Disconnection ...............................63

Discussion ......................................................... 73

Strength and Limitations .............................................. 75

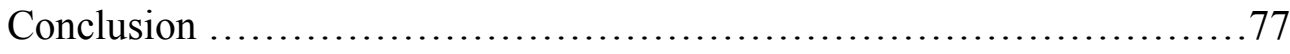

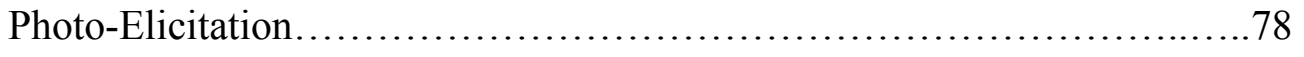

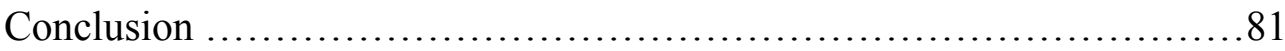

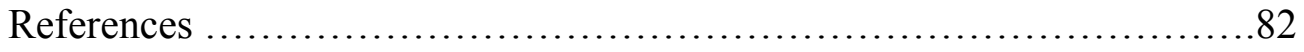

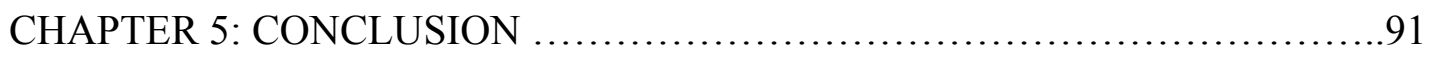

Utilizing the TOUS for CIPN Research ..............................92

A Model of CIPN Among CCS ......................................99

Implications for Future Research, Practice, and Education .................97

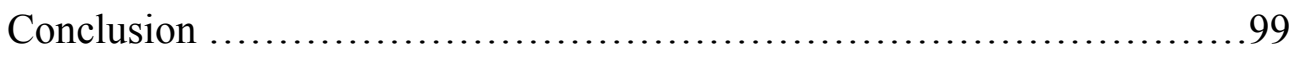

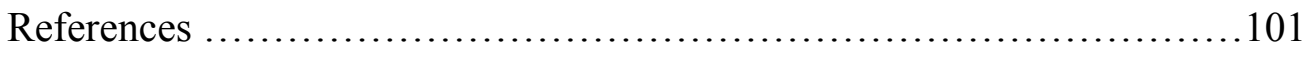

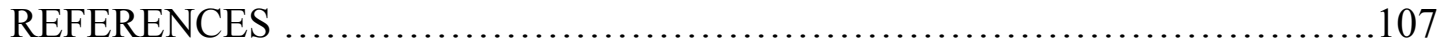




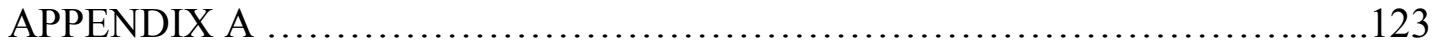

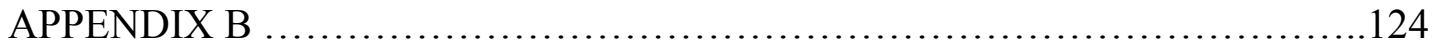

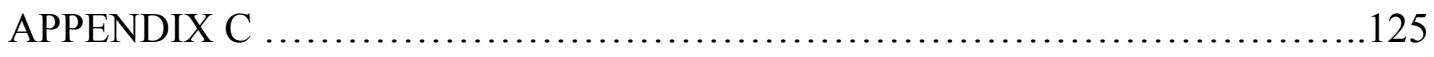

APPENDIX D ......................................................... 127

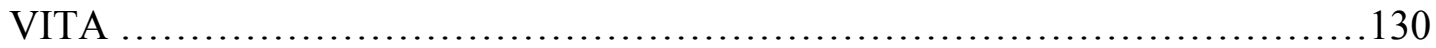


List of Figures, Tables, and Photographs

Figure 1. Literature Search.............................................. 36

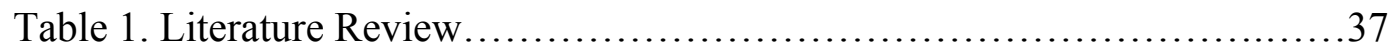

Photograph 1. Cellulitis caused by footwear in presence of CIPN....................66

Photograph 2. Pain caused by simply wearing socks........................67

Photograph 3. Using touch to re-connect mind and body .....................66

Photograph 4. "Am I going to be able to get across today?"..........................69

Photograph 5. Daunting equipment demonstrating the challenges of work........70

Photograph 6. "I'm actually disabled, I'm not using my grandmother's tag" ........72

Figure 2. The Experience of CIPN: A Condition of Disconnection................88

Figure 3. Between- and Within-Participant Symptom Variability.................89

Figure 4. Symptom Quality Word Cloud..................................... 90

Figure 5. Visual Model: The Experience of CIPN among CCS...................106 
The Experience of Chemotherapy-Induced Peripheral Neuropathy Among Childhood Cancer Survivors

\author{
Caroline Mohrmann, RN, MSN, CPNP-AC
}

\begin{abstract}
As the number of childhood cancer survivors (CCS) is increasing, it is imperative to understand the late-effects of childhood cancer therapy to optimize their health and quality of life. Chemotherapy-induced peripheral neuropathy (CIPN) is an unpleasant side effect of chemotherapy which impacts the peripheral nervous system and results in a variety of sensory and motor abnormalities such as numbness, pain, muscle weakness, or impaired coordination. While CIPN is poorly understood in general, there is a particularly poor understanding of the experience of CIPN among CCS, which leads to lack of appropriate support for maximizing physical function and quality of life. This qualitative study used narrative analysis with a phenomenological influence to understand the lived experience of CIPN among five CCS between the ages of 18 and 30. Semi-structured interviews and photo-elicitation were used. Photo-elicitation involves utilizing photographs to enhance the participant's expression of their experience. The lived experience of CIPN is characterized by "a condition of disconnection" with three subthemes: (1) disconnection between mind and body, (2) disconnection between anticipated potential and reality, and (3) disconnection between survivors and support. The condition of disconnection leads to a variety of negative physical and emotional performance outcomes that impact vocation, schooling, and other social roles important in the lives of adolescent and young adult CCS. These findings support the need for the development of interventions to 're-build the connections' CCS are lacking, as well as focused clinical assessments to identify this under-appreciated condition.
\end{abstract}

viii 


\section{CHAPTER ONE INTRODUCTION}

Children diagnosed with cancer today have an almost $80 \%$ chance of survival due to cooperative group clinical trials and advances in anti-cancer treatment over the past few decades (Armenian, Landier, Hudson, Robison, \& Bhatia, 2013). Since survival has increased so significantly, supportive care and survivorship have become increasingly important. Chemotherapy-induced peripheral neuropathy (CIPN) is a serious, yet poorly understood, complication of cancer therapy that can persist into survivorship. Children can develop CIPN as a result of damage to neural tissue due to cancer involvement (compression or infiltration of nerves by a tumor), but more often due to cancer therapy (surgery, chemotherapy, and radiation) (Jacob, 2004). The incidence of CIPN in survivors of childhood cancer is most commonly reported between $25-60 \%$ of those exposed to neurotoxic chemotherapy (Mohrmann, Armer, \& Hayashi, 2016). Signs of CIPN include: numbness and tingling of the hands and feet; painful dysesthesias; sensory loss to temperature, sensation, and proprioception; loss of deep tendon reflexes; poor balance and coordination; distal muscle weakness; and often-times pain (Armstrong et al., 2005; L. Gilchrist, 2012; Smith et al., 2013).

As treatment has advanced and children are living longer after they are diagnosed with cancer, children are more likely to be exposed to neurotoxic chemotherapy (Wickham, 2007). Chemotherapeutic agents known to have nervous system side effects, such as vinca alkaloids, platinum compounds, and taxanes, can affect the three components of the peripheral nervous system comprised of sensory, motor, and 
autonomic (Armstrong et al., 2005). Neuropathic pain is pain specifically of neural tissue that is usually less responsive to standard pain relief measures (Jacob, 2004). In children, the evaluation and treatment of neuropathic pain can be especially challenging due to developmental limitations of the child experiencing the pain; limited guidance available to healthcare providers to identify and treat neuropathic pain; and healthcare provider attitudes towards pain medications in children (Gilchrist, Marais, \& Tanner, 2013; Monteiro Caran, Dias, Seber, \& Petrilli, 2005; Vincent, 2005).

\section{Physical Function and Quality of Life}

There is strong evidence to support that cancer survivors experiencing chronic or long-term CIPN have altered physical functioning, specifically within the adult literature. In addition, patients exposed to chemotherapy report difficulties accepting the consequences of neurotoxicity and indicated that neuropathy had a negative effect on their quality of life (Driessen, de Kleine-Bolt, Vingerhoets, Mols, \& Vreugdenhil, 2012). Although the extent of the data reported is limited, when neuropathic symptoms are present in childhood cancer survivors (CCS), these patients have impaired coordination and other neuromuscular impairments, even 5-46.5 years after exposure to neurotoxic chemotherapy (Ness et al., 2012; van Brussel et al., 2006). The most common physical limitation present in $46.5 \%$ of participants was limited walking efficiency (Ness et al., 2012). Only $15.4 \%$ demonstrated poor balance, but overall $54.5 \%$ of the population had

at least one physical limitation. Although sensory and motor deficits were demonstrated, few studies evaluate upper extremity function, which may result in under-reporting sensory or functional impairments, since some survivors may only be experiencing impairments of the upper extremities (Ness et al., 2012). 
Adult patients report a variety of painful and non-painful symptoms that interfere with their ability to complete activities of daily living or work as they had prior to their cancer diagnosis. In Tofthagen's (2010) study, at least half of the patients report numbness, loss of balance, tingling, and generalized weakness (Tofthagen, 2010). Fortythree percent of the participants required an assistive device for walking due to the development of CIPN; this was often related to lower extremity weakness or sensation changes (Tofthagen, 2010). Patients acknowledged these symptoms caused such impairment that many left their previous place of employment. For example, a physician had to close his practice because he was unable to stand for long periods of time; a lawyer was unable to practice because she became disabled; a mechanic no longer had manual dexterity to work on cars (Tofthagen, 2010). A few patients even reported a negative impact on their sexual functioning and ability to exercise (Tofthagen, 2010). Participants also reported disruption of hobbies, leisure activities, and family roles (Bakitas, 2007).

Some patients perceive CIPN has a significant impact on their physical function, but since the physical symptoms are difficult to quantify, their healthcare providers often overlook the impact of these symptoms (Bakitas, 2007; Tofthagen, 2010). One risk associated with function-altering CIPN is falls or other forms of accidental injury. Patients with chronic peripheral neuropathy are at risk for injury due to sensorimotor abnormalities including weakness, diminished sensation, poor balance, and altered gait (Tofthagen, Overcash, \& Kip, 2012). Patients sometimes injure themselves unknowingly due to their lack of sensation and are only made aware of the injury once they see a bruise, cut or other sign of injury (Tofthagen, 2010). Both quantitative and qualitative 
data supports that adult patients with chronic CIPN experience falls and accidental injuries as a direct result of their unpleasant symptoms and altered physical function (Tofthagen, 2010; Tofthagen et al., 2012).

\section{Diagnostic and Management Strategies}

There is no 'gold standard' for diagnosing peripheral neuropathy in children (Gilchrist et al., 2013). Early studies in children used nerve conduction studies or electromyography (EMG) to identify the presence of abnormal nerve function, although this is less feasible in clinical practice (Chung, Prasad, \& Lloyd, 2014; Vainionpää, Kovala, Tolonen, \& Lanning, 1995). The pediatric-modified total neuropathy score (peds-mTNS) has been recently developed to measure neuropathy in children ages 5-18. The tool was found to be valid and reliable in children with leukemia and extracranial solid tumors (Gilchrist \& Tanner, 2013). The peds-mTNS includes evaluation of sensory symptoms, motor symptoms, autonomic symptoms, light touch sensation, pin sensation, vibration exam, strength, and deep tendon reflexes (Gilchrist \& Tanner, 2013). One item asks children if they hurt, and if so, the examiner is to determine the distribution of pain. Although there are many standardized pain measures in children, none are specific to neuropathic pain. The lack of a standard diagnostic tool contributes to the challenge of diagnosing and treating children with neuropathic pain. In addition, less is known about this condition in children and young adults than in the adult population (Gilchrist et al., 2013).

Providers have commonly referred patients to rehabilitation services such as physical therapy or occupational therapy in attempts to improve physical functioning. Providers have encouraged patients to focus on strength, stretching, and maintaining as 
much physical activity as possible. Social services may also be necessary to support patients who require a major role change as a result of their CIPN symptoms. Adult patients report a variety of self-care strategies such as looking up information on the internet, seeking support, walking, exercise, orthotics for shoes, transcutaneous nerve stimulation, acupuncture, or assistive ambulation devices (Bakitas, 2007). Patients also report using medications, prescribed or over the counter, but there are not data to support the efficacy of medications to significantly improve symptoms (De Grandis, 2007; Kottschade et al., 2010).

\section{Rationale of the Study}

Within clinical practice, healthcare providers need to appreciate that CIPN can present in a variety of sensory, functional, or emotional ways. As patient reports have shown, clinical measures are often insensitive to the depth of global symptoms patients are experiencing. There is strong evidence that further research is needed to better understand the symptom experience of chronic CIPN in CCS. Due to the limited information available the reported incidence of CIPN in CCS varies, but more importantly, the impact of CIPN on their quality of life is largely unknown. Once researchers understand the clinical significance of CIPN on the physical functioning and quality of life of cancer survivors, focused interventions must be developed and tested. Again, the difficulty will be lack of a standardized assessment for CIPN to determine the effectiveness of developed interventions. It will be important to use clinically significant functioning and quality of life measures to evaluate effectiveness. The population of CCS is growing each year due to improved treatment. Therefore, providers and researchers need to be ready to support these survivors experiencing life-altering long-term 
complications. The purpose of this dissertation research is to inform those caring for CCS living with CIPN in order to provider more focused health assessments, and eventually, more impactful management strategies for CIPN.

\section{Conclusion}

Chapter 2 is comprised of a review of the Theory of Unpleasant Symptoms as the theoretical guidance for this research. This chapter also includes a manuscript which reviews the literature regarding CIPN among CCS, specifically focusing on appropriate symptom evaluation and reported incidence of CIPN. Chapter 3 describes the methods and procedures for this dissertation work. Methodological considerations, as well as the use of photo-elicitation, are detailed. Chapter 4 is comprised of a manuscript reporting the research findings on the experience of CIPN among CCS, including a reflection on the use of photo-elicitation as a method of inquiry with adolescents and young adults. Chapter 5 concludes with a discussion of the research findings and recommendations for future research, education, and clinical practice. A visual model of CIPN among CCS is presented. 


\section{References}

Armenian, S. H., Landier, W., Hudson, M. M., Robison, L. L., \& Bhatia, S. (2013). Children's Oncology Group's 2013 blueprint for research: Survivorship and outcomes. Pediatric Blood \& Cancer, 60(6), 1063-1068. https://doi.org/10.1002/pbc. 24422

Armstrong, T., Almadrones, L., \& Gilbert, M. (2005). Chemotherapy-Induced Peripheral Neuropathy. Oncology Nursing Forum, 32(2), 305-311. https://doi.org/10.1188/05.ONF.305-311

Bakitas, M. A. (2007). Background noise: the experience of chemotherapy-induced peripheral neuropathy. Nursing Research, 56(5), 323-331. https://doi.org/10.1097/01.NNR.0000289503.22414.79

Chung, T., Prasad, K., \& Lloyd, T. E. (2014). Peripheral neuropathy: clinical and electrophysiological considerations. Neuroimaging Clinics of North America, 24(1), 49-65.

De Grandis, D. (2007). Acetyl-L-Carnitine for the Treatment of Chemotherapy-Induced Peripheral Neuropathy: A Short Review. CNS Drugs, 21, 39.

Driessen, C. M. L., de Kleine-Bolt, K. M. E., Vingerhoets, A., Mols, F., \& Vreugdenhil, G. (2012). Assessing the impact of chemotherapy-induced peripheral neurotoxicity on the quality of life of cancer patients. Supportive Care in Cancer, 20(4), 877-881.

Gilchrist, L. (2012). Chemotherapy-Induced Peripheral Neuropathy in Pediatric Cancer Patients. Seminars in Pediatric Neurology, 19(1), 9-17. https://doi.org/10.1016/j.spen.2012.02.011 
Gilchrist, L., Marais, L., \& Tanner, L. (2013). Comparison of two chemotherapy-induced peripheral neuropathy measurement approaches in children. Supportive Care in Cancer, 1-8. https://doi.org/10.1007/s00520-013-1981-6

Gilchrist, L., \& Tanner, L. (2013). The pediatric-modified total neuropathy score: a reliable and valid measure of chemotherapy-induced peripheral neuropathy in children with non-CNS cancers. Supportive Care in Cancer, 21(3), 847-856. https://doi.org/10.1007/s00520-012-1591-8

Jacob, E. (2004). Neuropathic pain in children with cancer. Journal of Pediatric Oncology Nursing: Official Journal of the Association of Pediatric Oncology Nurses, 21(6), 350-357. https://doi.org/10.1177/1043454204270251

Kottschade, L. A., Sloan, J. A., Mazurczak, M. A., Johnson, D. B., Murphy, B. P., Rowland, K. M., ... Loprinzi, C. L. (2010). The use of vitamin E for the prevention of chemotherapy-induced peripheral neuropathy: results of a randomized phase III clinical trial. Supportive Care in Cancer, 19(11), 17691777. https://doi.org/10.1007/s00520-010-1018-3

Mohrmann, C., Armer, J., \& Hayashi, R. J. (2016). Challenges Evaluating Chemotherapy-Induced Peripheral Neuropathy in Childhood Cancer Survivors Which Instrument Should Nurses Use? Journal of Pediatric Oncology Nursing, $34(2), 1-9$.

Monteiro Caran, E. M., Dias, C. G., Seber, A., \& Petrilli, A. S. (2005). Clinical aspects and treatment of pain in children and adolescents with cancer. Pediatric Blood \& Cancer, 45(7), 925-932. https://doi.org/10.1002/pbc.20523

Ness, K. K., Hudson, M. M., Pui, C.-H., Green, D. M., Krull, K. R., Huang, T. T., ... 
Morris, E. B. (2012). Neuromuscular impairments in adult survivors of childhood acute lymphoblastic leukemia. Cancer, 118(3), 828-838. https://doi.org/10.1002/cncr.26337

Smith, E. M. L., Li, L., Hutchinson, R. J., Ho, R., Burnette, W. B., Wells, E., ... Renbarger, J. (2013). Measuring Vincristine-Induced Peripheral Neuropathy in Children With Acute Lymphoblastic Leukemia. Cancer Nursing September/October 2013, 36(5). https://doi.org/10.1097/NCC.0b013e318299ad23

Tofthagen, C. (2010). Patient perceptions associated with chemotherapy-induced peripheral neuropathy. Clinical Journal of Oncology Nursing, 14(3), E22-28. https://doi.org/10.1188/10.CJON.E22-E28

Tofthagen, C., Overcash, J., \& Kip, K. (2012). Falls in persons with chemotherapyinduced peripheral neuropathy. Supportive Care in Cancer, 20(3), 583-589.

Vainionpää, L., Kovala, T., Tolonen, U., \& Lanning, M. (1995). Vincristine therapy for children with acute lymphoblastic leukemia impairs conduction in the entire peripheral nerve. Pediatric Neurology, 13(4), 314-318.

van Brussel, M., Takken, T., Net, J. van der, Engelbert, R. H., Bierings, M., Schoenmakers, M. A., \& Helders, P. J. (2006). Physical function and fitness in long-term survivors of childhood leukaemia. Developmental Neurorehabilitation, 9(3), 267-274.

Vincent, C. V. H. (2005). Nurses' knowledge, attitudes, and practices: Regarding children's pain. MCN: The American Journal of Maternal/Child Nursing, 30(3), $177-183$.

Wickham, R. (2007). Chemotherapy-Induced Peripheral Neuropathy: A Review and 
Implications for Oncology Nursing Practice. Clinical Journal of Oncology Nursing, 11(3), 361-376. https://doi.org/10.1188/07.CJON.361-376 


\section{CHAPTER TWO}

\section{REVIEW OF THE LITERATURE}

Existing literature has successfully described the variety of presentations of CIPN in adult cancer survivors of different diagnoses and a multitude of neurotoxic chemotherapy agents. Distinct features of CIPN presentation, as they differ by chemotherapeutic agents, are also better known among adult cancer patients. Patients exposed to platinum-containing compounds are likely to experience more sensory symptoms when compared to patients exposed to vinca alkaloids (Ness et al., 2013). Oxaliplatin has long-lasting symptoms such as tingling, aching, burning, and numbness (Beijers et al., 2015; Mols et al., 2013; Tofthagen, Donovan, Morgan, Shibata, \& Yeh, 2013, p.). Patients experiencing toxicity from taxanes can experience painful sensory symptoms (frequently tingling in the hands and feet), poor motor function, and sometimes even autonomic symptoms, such as dizziness (Eckhoff, Knoop, Jensen, \& Ewertz, 2015; Ezendam et al., 2014; Wampler et al., 2007). Bortezomib, a newlydeveloped proteasome inhibitor, also has mainly sensory neuropathic symptoms in the stocking-glove distribution that is described as numbness, tingling, burning, sharp, cold, and electrical (Cata et al., 2007). Long-term survivors of cancer exposed to vinca alkaloids are more likely to experience motor dysfunction than sensory symptoms (De Luca et al., 2013; Ness et al., 2012; van Brussel et al., 2006).

Existing literature has also well-described the impact of these symptoms in adult cancer survivors. There is evidence to support CIPN effects vocation and other life roles, emotional health, social interactions, sleep, and sexual functioning. This literature 
represents patients with a multitude of primary cancer diagnoses and chemotherapeutic exposures, indicating that neurotoxic chemotherapy can have a lasting and oftentimes global impact on an adult cancer survivor. Even though this impact is known, existing literature frequently reports the lack of available interventions to improve physical functioning or quality of life in patients living with chronic CIPN.

The pediatric literature is more homogeneous in terms of populations and chemotherapeutic agents studied. The primary population studied is survivors of childhood leukemia. The primary agent studied is vincristine, although some studies have included platinum-containing agents as well. All studies involving children have been quantitative in methodology, which naturally limits the richness of the findings in this difficulty to evaluate phenomenon. To date, no patient-reported outcomes or qualitative investigations regarding CIPN in a pediatric population have been found. Studies involving children have focused on functional measures, but not functional outcomes. For example, studies evaluate standardized movement scores or commonly-used physical therapy evaluations such as dorsiflexion, but the impact of these findings in the everyday lives of children is unknown. Importantly, the impact on school performance, work performance, emotional health, and social interactions is largely unknown. The focus within the pediatric literature has been on statistical significance, but not clinical significance. As demonstrated by the adult qualitative studies, even when symptoms are less severe, these symptoms can have clinically significant impact on a patient's quality of life. This chapter includes a review of the Theory of Unpleasant Symptoms (TOUS) as a guide for this research, as well as a manuscript which reviews the existing literature on CIPN among CSS. 


\section{Theoretical Guidance}

The TOUS was developed to "improve the understanding of the symptom experience in various contexts and to provide information useful for designing effective interventions to prevent, ameliorate, or manage unpleasant symptoms and their negative effects" (Smith \& Liehr, 2013, p. 166). The authors propose that antecedents (physiologic, psychologic, and situational) influence patient's symptoms, and the patient's symptoms result in a functional outcome (Lenz, Pugh, Milligan, Gift, \& Suppe, 1997). Symptoms are described as a multidimensional experience that includes intensity, timing, level of distress perceived, and quality (Lenz et al., 1997).

\section{Underlying Assumptions}

The major underlying assumption of the TOUS is that a variety of symptoms experienced across patient populations and clinical situations have similarities (Smith \& Liehr, 2013). The theorists initially came to this conclusion after years of clinical practice and research regarding their specific symptoms of interest: dyspnea and fatigue. Pugh and Milligan worked together to produce a fatigue model for child-bearing women. Later, Gift and Pugh combine efforts with Milligan when they realized concepts involved in the experience of dyspnea had similar concepts to the model on fatigue (Lenz, Suppe, Gift, Pugh, \& Milligan, 1995). One of the major modifications made to the original theory in 1997 accounted for the presence of symptoms that can be experienced in isolation or in combination with other symptoms. The theorists assume that since patients may experience more than one related symptom at a time, interventions may be effective in alleviating more than one symptom due to their commonalities (Lenz et al., 1997). This update allows symptom clusters, defined as three or more concurrent symptoms, to be 
evaluated using this theory (Dodd, Miaskowski, \& Lee, 2003; Motl \& McAuley, 2009). The other major modification of the updated theory is the recognition that the flow between the symptoms experienced and the patient's performance is bi-directional, rather than unidirectional (Myers, 2009).

\section{Philosophical and Theoretical Antecedents}

The theorists have identified three categories of interrelated antecedents: physiologic, psychologic, and situational (Lenz et al., 1997). The previous version of the model did not consider the interaction between each antecedent and how these interactions may influence the patient's symptoms (Lenz et al., 1995). Physiologic factors consist of underlying pathology or healthy body systems. Examples of physiologic factors include nutritional status, hydration status, and existing trauma (Lenz et al., 1997). Obviously, some physiologic factors are identified by the presence of the patient's symptoms, which leads the authors to acknowledge the reciprocal nature of symptoms and physiologic factors. Psychologic factors are anything that affects the patient's mental state. Examples of psychologic factors are depression, anxiety, and uncertainty (Lenz et al., 1997). Situational factors include aspects of the patient's environment; this includes their social and physical environment (Lenz et al., 1997). Examples of social environment include marital status, living situation, and employment status. Examples of the patient's physical environment include temperature, lighting, and space (Lenz et al., 1997).

\section{Major Concepts}

As the updated theory is proposed, the influencing factors, the symptoms, and the patient's outcome have many relationships. It is proposed that initially a patient's 
influencing factors affect symptoms that result in the patient's performance - which can be either functional and/or cognitive. In turn, that performance can then affect a patient's influencing factors or the symptoms themselves, which can result in a different level of performance. Their description of chronic pain displays the relationship well. A patient with chronic pain (symptom) may not be motivated (psychologic factor) to eat a healthy diet (physiologic factor) leading to new symptoms, as well as a new performance outcome (Lenz et al., 1997).

\section{TOUS as a Guide for CIPN Research}

Lenz et al (1995) argue middle-range theories need to be developed to strengthen the relationship between theory, research, and nursing practice (Lenz et al., 1995). The middle-range TOUS provides a framework for studying neuropathic symptoms in childhood cancer survivors in a way that has not been done previously. The theory is easily adaptable across populations, but to date has not been used in this population. The theory's level of abstraction and comprehensiveness allow for the development of theoretically-framed data analysis. There is also potential for further development of the framework that may be identified through application of the theory with this new population that will strengthen the theory for future use. CIPN is indeed an unpleasant symptom of cancer therapy. The TUOS provides a model for further investigation, as it guides the researcher to carefully consider the theoretical antecedents, as well as the complex relationship between antecedents with the symptoms and outcomes. Following this discussion of the theoretical foundation for this study, the second section of Chapter 2 is comprised of the manuscript on nursing assessment of CIPN in childhood cancer survivors. 


\title{
CHALLENGES EVALUATING CHEMOTHERAPY-INDUCED PERIPHERAL NEUROPATHY IN CHILDHOOD CANCER SURVIVORS: WHICH INSTRUMENTS SHOULD NURSES USE?
}

\author{
Mohrmann, C., Armer, J., \& Hayashi, R. J. (2016). Challenges Evaluating \\ Chemotherapy-Induced Peripheral Neuropathy in Childhood Cancer Survivors Which \\ Instrument Should Nurses Use? Journal of Pediatric Oncology Nursing,
} 1043454216651016.

\begin{abstract}
Children treated for cancer are exposed to a variety of chemotherapeutic agents with known toxicity to the peripheral nervous system. The side effect of peripheral neuropathy can cause changes in sensation, function, and even cause pain. Although peripheral neuropathy is recognized by pediatric oncology nurses as an important and significant side effect, measuring neuropathy can be quite complex for clinical care and research efforts. With more children surviving a cancer diagnosis today, this issue is increasingly important for childhood cancer survivors. This article has reviewed existing literature examining peripheral neuropathy in childhood cancer survivors with particular interest paid to measurement tools available and needs for future research. It is important for nurses to choose appropriate measures for clinical care and research methods in order to have an impact on patients experiencing this condition.
\end{abstract}




\section{Introduction}

Pediatric oncology nurses are often responsible for the assessment of patients that have received chemotherapeutic agents that increase their risk for peripheral neuropathy, especially in clinics focused on the care of survivors of childhood cancer. Although most nurses believe chemotherapy-induced peripheral neuropathy (CIPN) is a significant problem, most nurses rate their assessment skills either fair or poor (Binner, Ross, \& Browner, 2011). Beyond their role of assessment for this condition, they are also involved in patient education, symptom management, and care coordination of these patients (Wickham, 2007). One of the greatest challenges in providing care for this population is a lack of a nursing assessment guidelines or standard of care evaluations for children experiencing chemotherapy-induced peripheral neuropathy (Binner et al., 2011). This also presents a great challenge for nurses intending to study peripheral neuropathy in pediatric or adolescent survivors of childhood cancer through formal research studies. Without reliable standardized measures, the ideal evaluation criteria and the approach to subsequent management is unclear.

Almost $80 \%$ of children diagnosed with cancer become long-term survivors and the study of long-term complications is becoming increasingly important (Armenian, Landier, Hudson, Robison, \& Bhatia, 2013). CIPN is a serious, yet poorly understood complication of cancer therapy. Signs of CIPN include numbness and tingling of the hands and feet; painful dysesthesias; sensory loss to temperature, sensation, and proprioception; loss of deep tendon reflexes; poor balance and coordination; distal muscle weakness; and oftentimes pain (Armstrong, Almadrones, \& Gilbert, 2005; Gilchrist, 2012; Smith et al., 2013). Unfortunately, little is known about the incidence of 
long-term chemotherapy-induced peripheral neuropathy in children and adolescents. Even less is known about appropriate interventions for survivors who experience this condition. This article will discuss a brief review of the literature regarding CIPN in survivors of childhood cancer, review measurement tools available for use in the pediatric cancer population, and provide recommendations for future research with a focus on survivorship.

\section{Literature Review}

\section{Methods}

There are fewer than fifteen identified studies that evaluate the incidence of neuropathy in childhood cancer survivors in the past 20 years. A review of the literature was performed to evaluate the current evidence regarding peripheral neuropathy in survivors of pediatric cancer (Figure 1). Criteria required by each article to be included in the review was a study population consisting of childhood cancer survivors currently at any age, history of exposure to neurotoxic chemotherapy, use of evaluation criteria of peripheral neuropathy or motor functioning as a proxy for motor neuropathy, written in the English language, and published within the past 20 years. A PubMed search using the MESH terms "peripheral nervous systems diseases, neoplasms, and survivors" was performed, and the resultant list was then searched using "survivors", "CIPN", and "(child or adolescent)". An analogous search was performed on OVID, Cumulative Index of Nursing and Allied Health Literature (CINAHL), and Scopus with similar findings. Using the "berry picking" method of literature searching, 99 related articles from PubMed were identified and reviewed (Barroso et al., 2003). From the initial 194 results, 
17 met the inclusion criteria after review of the titles and abstracts. The titles of each article cited in the citation list from each of the 17 articles that met the search criteria were reviewed with no additional articles identified that met the search criteria. After full text review, three of the articles were excluded because the majority of the study population consisted of patients on active therapy leaving a total of 14 articles. Each article was reviewed with particular interest in the instrumentation selection and other methods used to determine the incidence of neuropathy in the childhood cancer survivor population (Table 1).

\section{Summary of Results}

The overall incidence of CIPN reported among survivors of childhood cancer varies widely between studies. The incidence is most commonly reported between $25-$ 60\% (De Luca et al., 2013; Harila-Saari, Huuskonen, Tolonen, Vainionpää, \& Lanning, 2001; Jain et al., 2013; Lehtinen et al., 2002; Ramchandren et al., 2009; ReindersMesselink et al., 1996). Articles reporting this incidence have populations that vary in age and time since neurotoxic chemotherapy exposure. Overall incidence ranged from 12.8$100 \%$ depending on the measures used (Ness et al., 2012; Ramchandren et al., 2009). It is clear that children treated for leukemia continue to have abnormal electrophysiological exams after the completion of therapy when compared to age- and sex-matched healthy volunteers (Gomber, Dewan, \& Chhonker, 2010; Harila-Saari et al., 2001; Harila-Saari, Vainionpää, Kovala, Tolonen, \& Lanning, 1998; Lehtinen et al., 2002). There is also strong evidence that the cumulative dose of vincristine is not associated with the incidence of neuropathy in long-term cancer survivors (Hartman, van den Bos, Stijnen, \& Pieters, 2006; Lehtinen et al., 2002; Ness et al., 2013; Ramchandren et al., 2009; 
Reinders-Messelink et al., 1996). Other generalizations are difficult to make due to the challenges discussed below

\section{Challenges}

There are a few distinct features of the existing literature that will further challenge instrumentation selection for future research as well as evaluation methods for pediatric nurses in clinical practice with survivors of childhood cancer. First, most of the research studies (78.5\%) only include patients with a history of leukemia, with other cancer diagnoses significantly under-represented in the literature (Aytaç, Yetgin, \& Tavil, 2006; De Luca et al., 2013; Harila-Saari et al., 1998; Lehtinen et al., 2002, 2002; Leone et al., 2013; Ness et al., 2012; Wright, Halton, Martin, \& Barr, 1998). Leukemia is the most common childhood cancer with a high survival rate, which makes it an important population of survivors to study (Aytaç et al., 2006). However, other diagnoses are exposed to neurotoxic chemotherapy in a variety of intensities and the outcomes in these populations are also important. The current lack of available information regarding longterm CIPN in solid-tumor patients makes determining appropriate measures and interventions challenging. A revealing study by Ness et al. (2013) reports the incidence of neuropathic symptoms in a population of solid-tumor childhood cancer survivors, yet the age of this population is much older than other studies (ages $18.7-63.8$ years) and therefore difficult to compare (Ness et al., 2013). Only one other study in this review included patients with a current age greater than 24 years, with the vast majority of the studies including only those under age 18 . Another limitation is that almost all of the studies evaluated the effect of vincristine only (92.8\%). Although vincristine is a commonly-used chemotherapeutic agent in children and has known neurotoxic effects, 
other agents such as platinum compounds, taxanes, and proteasome inhibitors are also known to cause CIPN (Armstrong et al., 2005). The long-term effects of these additional agents are much better understood in the adult population, particularly in regards to breast cancer survivors (Reyes-Gibby, Morrow, Bennett, Jensen, \& Shete, 2010; Speck et al., 2012; Stubblefield, McNeely, Alfano, \& Mayer, 2012). Unfortunately, none of the measurement tools used in the reviewed studies included a pain measure, despite that it is a known manifestation of peripheral neuropathy (Anghelescu et al., 2011). Finally, there was variance in the different types of neuropathy evaluated between studies. Some studies focus on motor neuropathy, some on sensory neuropathy, and some studies focus on a combination of sensory and motor neuropathy. Furthermore, there was no consensus measure used by all the studies, thus, results from one report were difficult to compare to another.

\section{Review of Measurement Tools}

Within the group of articles that met criteria for the literature review, only a few measures were used in more than one article. Evaluators of peripheral neuropathy for each study vary in many ways from report to report. Some evaluators require a specified certification, background, or training. For example, some measures of peripheral neuropathy may only be performed by neurologists, occupational therapists, or physical therapists due to their expertise or training with certain tools. Other measures are designed to evaluate only certain types of nerve fiber injury. Different symptoms will be experienced based on the type of nerve fiber affected. Chung, Prasad, and Lloyd (2014) explain that affected "motor fibers can cause weakness, fasciculations, or muscle atrophy, whereas sensory involvement causes numbness, tingling, and/or altered perception of 
pain" (Chung, Prasad, \& Lloyd, 2014). Thus, a clinician with the skills to assess the entire scope of symptoms and signs associated with peripheral neuropathy is needed to perform a study that fully captures and characterizes the population. Also of interest, is the lack of use of common standardized tools for toxicity monitoring used in clinical practice such as the Common Terminology Criteria for Adverse Events (CTCAE) version 4.0 or the Balis grading scale (Smith et al., 2013; US Department of Health and Human Services, 2009). The CTCAE includes descriptive terminology to grade adverse events experienced by cancer patients. Peripheral motor neuropathy and peripheral sensory neuropathy adverse events are graded on a 1-5 scale with more severe symptoms earning a higher score. Scoring is determined by the provider's description of the patient's symptoms. The Balis grading scale is a commonly used tools in pediatric practice used to determine peripheral motor neuropathy and peripheral sensory neuropathy. Similar to the CTCAE, the Balis scale scores are determined by the provider's description of the patient's symptoms on a scale of 1-4, with higher scores indicating more severe neuropathy symptoms. Neuropathy measures commonly used in the adult population, such as the Functional Assessment of Cancer Therapy/Gynecologic Oncology Group Neurotoxicity (FACT/GOG-Ntx), were also lacking. The FACT/GOG-Ntx is an 11-item, self-reported instrument "created to evaluate health-related quality of life associated with chemotherapy-induced neurotoxicity" (Calhoun et al., 2003). Reliability and validity testing of the FACT/GOG-Ntx has only been performed in adult populations (Calhoun et al., 2003). Instruments used in the various articles reviewed for this study will be discussed below in regards to their accuracy and consistency, but also in regards to their practicality of application within pediatric oncology nursing practice. 


\section{Specialized Neurological Evaluations}

Electromyograms (EMG) and Nerve Conduction Studies (NCS) were used in 43\% of the reviewed studies $(n=6)$ as either the primary method of evaluation or in combination with other measures of neuropathy (Aytaç et al., 2006; Gomber et al., 2010; Harila-Saari et al., 2001, 1998; Jain et al., 2013; Lehtinen et al., 2002). Both EMG and NCS are focused examinations requiring specialized equipment and performed by a neurologist. Electromyography testing requires insertional electrodes to measure muscle electrical activity at rest and with exertion (Chung et al., 2014). Nerve conduction studies assist in differentiating between an axonal loss lesion and a demyelination lesion (Chung et al., 2014). Although these studies help identify the type of lesion or severity of nerve injury, which is helpful in diagnosing and characterizing peripheral neuropathy, they are impractical in the clinical setting since they are more time-consuming and more expensive. In regards to using such tools for clinical research efforts, the pediatric oncology nurse may not be familiar with the administration these exams, making them the lowest level of practicality.

\section{Standardized Neuropathy Evaluations}

The instrument most commonly utilized to measure peripheral neuropathy that included a sensory measure was the Total Neuropathy Score (TNS) or an updated variant of the TNS. The TNS is a widely used valid and reliable measure of neuropathy. Early testing of the instrument revealed high intra-rater and inter-rater reliability $(0.973$ and 0.938 respectively) (Cornblath et al., 1999). Cross sectional validation revealed the TNS was highly correlated to other standardized measures of neuropathy (Cornblath et al., 1999). Overall, this measure was used in around $20 \%$ of reviewed articles $(n=3)$ (Jain et 
al., 2013; Ness et al., 2013; Ramchandren et al., 2009). The TNS originally included nerve conductions studies when developed in 1994, but subsequent versions have developed a scoring system without nerve conduction studies to improve ease of use (Vasquez et al., 2014). More recently, the pediatric-modified Total Neuropathy Scale (peds-mTNS) has been developed and tested in a population of children with cancer with acceptable inter-rater reliability, test-retest reliability, and internal consistency (Gilchrist \& Tanner, 2013). The TNS measures include sensory, motor, and autonomic symptoms; pin sensation exam; vibration exam; sometimes deep tendon reflex exam; and sometimes nerve conduction studies (Gilchrist, 2012). Nurses do not often perform these exams due to lack of training with this particular specialized equipment.

\section{Standardized Motor Evaluations}

To start, none of the motor evaluations used in current studies were designed to measure chemotherapy-induced motor neuropathy in children. They were designed to measure motor performance in children. Disturbances in motor performance may be a manifestation of peripheral neuropathy, but may also represent a sign of disturbances within the muscle, or in the central nervous system. The most commonly used standardized motor evaluation was the Movement and Assessment Battery (MABC) and the updated Movement and Assessment Battery for Children-2 (MABC-2). Both tools are designed to identify motor impairments in children, with the updated version spanning ages 3-17 years (Brown \& Lalor, 2009). The three areas evaluated include manual dexterity, aiming and catching, and balance, with normal values available for three age groups within the 3-17 year age-span (Brown \& Lalor, 2009). The MABC has been heavily used in populations of children with developmental disorders, cognitive 
disorders, and some complex chronic health conditions (Brown \& Lalor, 2009). Within the literature reviewed, around $20 \%(\mathrm{n}=3)$ used the MABC or MABC- 2 to evaluate motor functioning after exposure to neurotoxic chemotherapy. This test can be administered by physical therapists as well as those outside the medical field - such as teachers - with appropriate training and equipment. With training, the test can be administered by oncology nurses. Challenges would include acquiring appropriate training, extended visit time needed for testing, and purchase of equipment. There are also no validation studies in a population of childhood cancer patients, so the accuracy of the reported incidence of neuropathy is unclear. Other tools, such as the Bruininks-Oseretsky Test of Motor Proficiency (BOT-2), were used in less than $20 \%$ of studies. The BOT-2 is a reliable and valid tool used to characterize fine and gross motor performance in children ages 4-21 years (Deitz, Kartin, \& Kopp, 2007). Tools such as the BOT-2 are primarily used by physical therapists and occupational therapists and also require special training, space, time, and sometimes equipment (Deitz et al., 2007).

\section{Recommendations for Future Research}

After reviewing tools used for the evaluation of CIPN in survivors of childhood cancer, no tools appear to be practical for the pediatric oncology nurse to use in the clinical setting without the assistance of other disciplines, increased cost, prolonged appointment times, and occasionally additional supplies. Due to the limitations presented, using currently available instruments to evaluate CIPN results in arbitrary scores which have limited clinical utility. Even toxicity grading commonly used in practice, such as the CTCAE, are known to be rather insensitive and may fail to detect neuropathy when present (Gilchrist, Marais, \& Tanner, 2013). The modified version of the TNS, the peds- 
mTNS, has been validated in a population of childhood cancer patients, but has not yet been used in a population of childhood cancer survivors ( Gilchrist \& Tanner, 2013). Further testing of this tool is needed in this population. Due to the lack of appropriate measures, the overall understanding of this condition in survivors of childhood cancer is limited.

The existing literature on CIPN in survivors of childhood cancer also lacks patient-reported outcomes measures. Increasingly, patient-reported outcome measures are being developed in order to aid providers in understanding the clinical significance of the problems patients experience. Moreover, the existing literature lacks studies utilizing qualitative methods and longitudinal studies evaluating the relationship between CIPN experienced during and after cancer therapy. Qualitative studies may provide details about survivor's experiences with long-term peripheral neuropathy that cannot be measured due to lack of appropriate quantitative measures. Within the adult literature, qualitative studies evaluating the impact of peripheral neuropathy on cancer survivors have reported that even when neuropathic symptoms might not be severe, they still may be highly distressing to the patient (Tofthagen, 2010). Adult cancer survivors have also reported neuropathy symptoms bleed into many facets of their life including functional, social, and emotional (Bakitas, 2007). In regards to longitudinal studies, such a design would provide insight into the natural course of the disease over time. A longitudinal design would also allow for the identification of risk factors for the development of longterm CIPN in childhood cancer survivors. It would be important to target those at risk for long-term CIPN for early intervention, especially once interventions are developed and tested. 
Clearly the evaluation of neuropathy is complicated and collaboration with other disciplines will be beneficial, if not currently necessary. The development of a screen for peripheral neuropathy would be significantly helpful for nursing practice. A good screen should be simple, rapid, inexpensive, safe, and acceptable (Friis \& Sellers, 2013, p. 461489). As discussed in the review, no screen currently available meets all these criteria to meet nursing or patient needs. Some measures are acceptable (such as EMG), but not simple, rapid, and inexpensive. While the development and testing of a new tool is a significant undertaking, there is clearly a need for such a tool to assist nurses in the assessment of children with long-term CIPN.

Based on the available literature, future researchers will need to make special considerations when designing studies to evaluate peripheral neuropathy in pediatric cancer survivors. Future studies would be strengthened by the following strategies: focus on patient-reported and clinically significant outcomes, use of diverse and innovative methods, heterogeneous sample by diagnosis and chemotherapeutic exposure, and more sensitive and specific instrumentation for quantitative studies when they are available. Researchers should carefully choose instruments to include measures that assess the presence of signs and symptoms of sensory and motor neuropathy, and also include pain. Once researchers and clinicians understand the clinical significance of CIPN, interventions can be developed that can assist the patient in coping with this problem to improve their function and quality of life.

\section{Declaration of Conflicting Interests}

The author(s) declare no conflicts of interest with respect to the research, authorship, and/or publication of this article. 


\section{Funding}

The author(s) disclosed receipt of the following financial support for the research, authorship, and/or publication of this article: Caroline Mohrmann is supported by the Doctoral Degree Scholarship in Cancer Nursing 127294-DSCN-15-080-01-SCN from the American Cancer Society. 


\section{References}

Anghelescu, D. L., Faughnan, L. G., Jeha, S., Relling, M. V., Hinds, P. S., Sandlund, J. T., ... Pui, C.-H. (2011). Neuropathic pain during treatment for childhood acute lymphoblastic leukemia. Pediatric Blood \& Cancer, 57(7), 1147-1153. http://doi.org/10.1002/pbc.23039

Armenian, S. H., Landier, W., Hudson, M. M., Robison, L. L., \& Bhatia, S. (2013). Children's Oncology Group's 2013 blueprint for research: Survivorship and outcomes. Pediatric Blood \& Cancer, 60(6), 1063-1068.

http://doi.org/10.1002/pbc.24422

Armstrong, T., Almadrones, L., \& Gilbert, M. (2005). Chemotherapy-Induced Peripheral Neuropathy. Oncology Nursing Forum, 32(2), 305-311. http://doi.org/10.1188/05.ONF.305-311

Aytaç, S., Yetgin, S., \& Tavil, B. (2006). Acute and long-term neurologic complications in children with acute lymphoblastic leukemia. The Turkish Journal of Pediatrics, $48(1), 1-7$.

Bakitas, M. A. (2007). Background noise: the experience of chemotherapy-induced peripheral neuropathy. Nursing Research, 56(5), 323-331. http://doi.org/10.1097/01.NNR.0000289503.22414.79

Barroso, J., Gollop, C. J., Sandelowski, M., Meynell, J., Pearce, P. F., \& Collins, L. J. (2003). The Challenges of Searching for and Retrieving Qualitative Studies. Western Journal of Nursing Research, 25(2), 153-178. http://doi.org/10.1177/0193945902250034

Binner, M., Ross, D., \& Browner, I. (2011). Chemotherapy-Induced Peripheral 
Neuropathy: Assessment of Oncology Nurses' Knowledge and Practice.

Oncology Nursing Forum, 38(4), 448-454.

Brown, T., \& Lalor, A. (2009). The Movement Assessment Battery for ChildrenSecond Edition (MABC-2): A Review and Critique. Physical \& Occupational Therapy in Pediatrics, 29(1), 86-103. http://doi.org/10.1080/01942630802574908

Calhoun, E. A., Welshman, E. E., Chang, C.-H., Lurain, J. R., Fishman, D. A., Hunt, T. L., \& Cella, D. (2003). Psychometric evaluation of the Functional Assessment of Cancer Therapy/Gynecologic Oncology Group-Neurotoxicity (Fact/GOG-Ntx) questionnaire for patients receiving systemic chemotherapy. Journal of Gynecological Cancer November, 13(6), 741-748.

Chung, T., Prasad, K., \& Lloyd, T. E. (2014). Peripheral Neuropathy. Neuroimaging Clinics of North America, 24(1), 49-65. http://doi.org/10.1016/j.nic.2013.03.023

Cornblath, D. R., Chaudhry, V., Carter, K., Lee, D., Seysedadr, M., Miernicki, M., \& Joh, T. (1999). Total neuropathy score validation and reliability study. Neurology, 53(8), 1660-1660.

Deitz, J. C., Kartin, D., \& Kopp, K. (2007). Review of the Bruininks-Oseretsky Test of Motor Proficiency, Second Edition (BOT-2). Physical \& Occupational Therapy in Pediatrics, 27(4), 87-102. http://doi.org/10.1080/J006v27n04_06

De Luca, C. R., McCarthy, M., Galvin, J., Green, J. L., Murphy, A., Knight, S., \& Williams, J. (2013). Gross and fine motor skills in children treated for acute lymphoblastic leukaemia. Developmental Neurorehabilitation, 16(3), 180-187. http://doi.org/10.3109/17518423.2013.771221

Friis, R. H., \& Sellers, T. (2013). Epidemiology for Public Health Practice. Burlington, 
MA: Jones \& Bartlett Publishers.

Gilchrist, L. (2012). Chemotherapy-Induced Peripheral Neuropathy in Pediatric Cancer Patients. Seminars in Pediatric Neurology, 19(1), 9-17. http://doi.org/10.1016/j.spen.2012.02.011

Gilchrist, L., Marais, L., \& Tanner, L. (2013). Comparison of two chemotherapy-induced peripheral neuropathy measurement approaches in children. Supportive Care in Cancer, 1-8. http://doi.org/10.1007/s00520-013-1981-6

Gilchrist, L., \& Tanner, L. (2013). The pediatric-modified total neuropathy score: a reliable and valid measure of chemotherapy-induced peripheral neuropathy in children with non-CNS cancers. Supportive Care in Cancer, 21(3), 847-856. http://doi.org/10.1007/s00520-012-1591-8

Gomber, S., Dewan, P., \& Chhonker, D. (2010). Vincristine induced neurotoxicity in cancer patients. The Indian Journal of Pediatrics, 77(1), 97-100. http://doi.org/10.1007/s12098-009-0254-3

Harila-Saari, A. H., Huuskonen, U. E. J., Tolonen, U., Vainionpää, L. K., \& Lanning, B. M. (2001). Motor nervous pathway function is impaired after treatment of childhood acute lymphoblastic leukemia: A study with motor evoked potentials. Medical and Pediatric Oncology, 36(3), 345-351. http://doi.org/10.1002/mpo.1084

Harila-Saari, A. H., Vainionpää, L. K., Kovala, T. T., Tolonen, E. U., \& Lanning, B. M. (1998). Nerve lesions after therapy for childhood acute lymphoblastic leukemia. Cancer, 82(1), 200-207. http://doi.org/10.1002/(SICI)10970142(19980101)82:1<200::AID-CNCR25>3.0.CO;2-5 
Hartman, A., van den Bos, C., Stijnen, T., \& Pieters, R. (2006). Decrease in motor performance in children with cancer is independent of the cumulative dose of vincristine. Cancer, 106(6), 1395-1401. http://doi.org/10.1002/cncr.21706

Jain, P., Gulati, S., Seth, R., Bakhshi, S., Toteja, G. S., \& Pandey, R. M. (2013). Vincristine-induced Neuropathy in Childhood ALL (Acute Lymphoblastic Leukemia) Survivors Prevalence and Electrophysiological Characteristics. Journal of Child Neurology, 0883073813491829. http://doi.org/10.1177/0883073813491829

Lehtinen, S. S., Huuskonen, U. E., Harila-Saari, A. H., Tolonen, U., Vainionpää, L. K., \& Lanning, B. M. (2002). Motor nervous system impairment persists in long-term survivors of childhood acute lymphoblastic leukemia. Cancer, 94(9), 2466-2473. http://doi.org/10.1002/cncr.10503

Leone, M., Viret, P., Bui, H. T., Laverdière, C., Kalinova, É., \& Comtois, A.-S. (2013). Assessment of gross motor skills and phenotype profile in children 9-11 years of age in survivors of acute lymphoblastic leukemia. Pediatric Blood \& Cancer, n/an/a. http://doi.org/10.1002/pbc.24731

Ness, K. K., Hudson, M. M., Pui, C.-H., Green, D. M., Krull, K. R., Huang, T. T., ... Morris, E. B. (2012). Neuromuscular impairments in adult survivors of childhood acute lymphoblastic leukemia. Cancer, 118(3), 828-838. http://doi.org/10.1002/cncr.26337

Ness, K. K., Jones, K. E., Smith, W. A., Spunt, S. L., Wilson, C. L., Armstrong, G. T., ... Gurney, J. G. (2013). Chemotherapy-Related Neuropathic Symptoms and Functional Impairment in Adult Survivors of Extracranial Solid Tumors of 
Childhood: Results From the St. Jude Lifetime Cohort Study. Archives of Physical Medicine and Rehabilitation. http://doi.org/10.1016/j.apmr.2013.03.009

Ramchandren, S., Leonard, M., Mody, R. J., Donohue, J. E., Moyer, J., Hutchinson, R., \& Gurney, J. G. (2009). Peripheral neuropathy in survivors of childhood acute lymphoblastic leukemia. Journal of the Peripheral Nervous System, 14(3), 184189. http://doi.org/10.1111/j.1529-8027.2009.00230.x

Reinders-Messelink, H. A., Schoemaker, M. M., Hofte, M., Göeken, L. N. H., Kingma, A., van den Briel, M. M., \& Kamps, W. A. (1996). Fine motor and handwriting problems after treatment for childhood acute lymphoblastic leukemia. Medical and Pediatric Oncology, 27(6), 551-555. http://doi.org/10.1002/(SICI)1096911X(199612)27:6<551::AID-MPO8>3.0.CO;2-K

Reyes-Gibby, C., Morrow, P. K., Bennett, M. I., Jensen, M. P., \& Shete, S. (2010). Neuropathic Pain in Breast Cancer Survivors: Using the ID Pain as a Screening Tool. Journal of Pain and Symptom Management, 39(5), 882-889. http://doi.org/10.1016/j.jpainsymman.2009.09.020

Smith, E. M. L., Li, L., Hutchinson, R. J., Ho, R., Burnette, W. B., Wells, E., ... Renbarger, J. (2013). Measuring Vincristine-Induced Peripheral Neuropathy in Children With Acute Lymphoblastic Leukemia. Cancer Nursing September/October 2013, 36(5). http://doi.org/10.1097/NCC.0b013e318299ad23

Speck, R. M., DeMichele, A., Farrar, J. T., Hennessy, S., Mao, J. J., Stineman, M. G., \& Barg, F. K. (2012). Scope of symptoms and self-management strategies for chemotherapy-induced peripheral neuropathy in breast cancer patients. Supportive Care in Cancer, 20(10), 2433-2439. http://doi.org/10.1007/s00520-011-1365-8 
Stubblefield, M. D., McNeely, M. L., Alfano, C. M., \& Mayer, D. K. (2012). A prospective surveillance model for physical rehabilitation of women with breast cancer. Cancer, 118(S8), 2250-2260. http://doi.org/10.1002/cncr.27463

Tofthagen, C. (2010). Patient perceptions associated with chemotherapy-induced peripheral neuropathy. Clinical Journal of Oncology Nursing, 14(3), E22-28. http://doi.org/10.1188/10.CJON.E22-E28

US Department of Health and Human Services. (2009). Common terminology criteria for adverse events (CTCAE) version 4.0. National Institutes of Health. Retrieved from http://evs.nci.nih.gov/ftp1/CTCAE/CTCAE_4.03_2010-06-

14_QuickReference_5x7.pdf

Vainionpää, L., Kovala, T., Tolonen, U., \& Lanning, M. (1995). Vincristine therapy for children with acute lymphoblastic leukemia impairs conduction in the entire peripheral nerve. Pediatric Neurology, 13(4), 314-318.

Vasquez, S., Guidon, M., McHugh, E., Lennon, O., Grogan, L., \& Breathnach, O. S. (2014). Chemotherapy induced peripheral neuropathy: the modified total neuropathy score in clinical practice. Irish Journal of Medical Science, 183(1), 53-58. http://doi.org/10.1007/s11845-013-0971-5

Wickham, R. (2007). Chemotherapy-Induced Peripheral Neuropathy: A Review and Implications for Oncology Nursing Practice. Clinical Journal of Oncology Nursing, 11(3), 361-376. http://doi.org/10.1188/07.CJON.361-376

Wright, M. J., Halton, J. M., Martin, R. F., \& Barr, R. D. (1998). Long-term gross motor 
performance following treatment for acute lymphoblastic leukemia. Medical and Pediatric Oncology, 31(2), 86-90. http://doi.org/10.1002/(SICI)1096-

911X(199808)31:2<86::AID-MPO7>3.0.CO;2-V 
Figure 1. Literature Search

\section{Literature Search}

Criteria: Survivors of Childhood Cancer, Sensory Neuropathy or Motor

Neuropathy, English Language, Published within the last 20 years

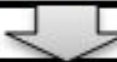

PubMed, Ovid, CINAHL, Scopus

$\mathrm{N}=194$

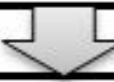

Screen $1(N=194)$

Review of titles and abstracts for inclusion criteria

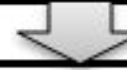

\section{Citation Search $(\mathrm{N}=17)$}

Reviewed the citations from 17 articles that met inclusion criteria, no new articles identified

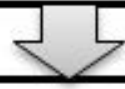

Screen 2 (N=17)

Reviewed full text of each article for inclusion criteria, 3 articles excluded

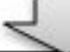

Articles meeting all criteria to be included in review $(\mathrm{N}=14)$ 
Table 1. Literature Review

\begin{tabular}{|c|c|c|c|c|c|c|c|}
\hline Author/year & Title & Design & $\begin{array}{l}\text { Patients/Neurotoxic } \\
\text { Exposure }\end{array}$ & Measures/Tools & $\begin{array}{l}\text { Strengths/ } \\
\text { Weaknesses }\end{array}$ & $\begin{array}{l}\text { PN or } \\
\text { Motor }\end{array}$ & $\begin{array}{l}\text { CIPN } \\
\text { Prevalence }\end{array}$ \\
\hline Aytac/2006 & $\begin{array}{l}\text { Acute and } \\
\text { long-term } \\
\text { neurologic } \\
\text { complications } \\
\text { in children } \\
\text { with acute } \\
\text { lymphoblastic } \\
\text { leukemia }\end{array}$ & $\begin{array}{l}\text { Retrospectiv } \\
\text { e chart } \\
\text { review }\end{array}$ & $\begin{array}{l}256 \text { children with } \\
\text { ALL, }<17 \text { years of } \\
\text { age/ Vincristine }\end{array}$ & $\begin{array}{l}\text { EEG, EMG, CT } \\
\text { and/or MRI, } \\
\text { metabolic exam }\end{array}$ & $\begin{array}{l}\text { (-): Only ALL } \\
\text { patients. Do not } \\
\text { specify length of long- } \\
\text { term follow up. Focus } \\
\text { more on seizures, } \\
\text { infections, not } \\
\text { specifically PN. }\end{array}$ & $\mathrm{PN}$ & $\begin{array}{l}\text { Not specific } \\
\text { to post- } \\
\text { therapy }\end{array}$ \\
\hline De Luca/2013 & $\begin{array}{l}\text { Gross and fine } \\
\text { motor skills in } \\
\text { children } \\
\text { treated for } \\
\text { acute } \\
\text { lymphoblastic } \\
\text { leukaemia }\end{array}$ & $\begin{array}{l}\text { Cross- } \\
\text { sectional } \\
\text { study design }\end{array}$ & $\begin{array}{l}36 \text { children with } \\
\text { ALL, } 5-12.1 \text { years } \\
\text { of age/ Vincristine }\end{array}$ & MABC-2, BOT-2 & $\begin{array}{l}\text { (-): Only ALL } \\
\text { patients. MABC-2 not } \\
\text { developed for the } \\
\text { oncology population. } \\
\text { Very small window } \\
\text { for age and time from } \\
\text { treatment. }\end{array}$ & Motor & $\begin{array}{l}27 \% \\
\text { impaired on } \\
\text { the MABC- } \\
2,16 \% \\
\text { impaired on } \\
\text { BOT-2, but } \\
\text { represents a } \\
\text { very small } \\
\text { population }\end{array}$ \\
\hline Gomber/2010 & $\begin{array}{l}\text { Vincristine } \\
\text { induced } \\
\text { neurotoxicity } \\
\text { in cancer } \\
\text { patients }\end{array}$ & $\begin{array}{l}\text { Retrospectiv } \\
\text { e chart } \\
\text { review }\end{array}$ & $\begin{array}{l}20 \text { children with } \\
\text { ALL, NHL, HD, } \\
\text { NBL, LCH, } 2 \text { months } \\
-12 \text { years of age/ } \\
\text { Vincristine }\end{array}$ & $\begin{array}{l}\text { Electrophysiological } \\
\text { eval, nerve } \\
\text { conduction velocity }\end{array}$ & $\begin{array}{l}\text { (-): Higher incidence } \\
\text { of neuropathy, likely } \\
\text { due to malnourished } \\
\text { population (India). }\end{array}$ & $\mathrm{PN}$ & $\begin{array}{l}50 \% \text { (not } \\
\text { all off } \\
\text { therapy) }\end{array}$ \\
\hline
\end{tabular}




\begin{tabular}{|c|c|c|c|c|c|c|c|}
\hline $\begin{array}{l}\text { Harila- } \\
\text { Saari/1998 }\end{array}$ & $\begin{array}{l}\text { Nerve lesions } \\
\text { after therapy } \\
\text { for childhood } \\
\text { acute } \\
\text { lymphoblastic } \\
\text { leukemia }\end{array}$ & $\begin{array}{l}\text { Longitudinal } \\
\text { study }\end{array}$ & $\begin{array}{l}31 \text { children with } \\
\text { ALL; age-, gender- } \\
\text { and height-matched } \\
\text { controls, } 3.6-17.7 \\
\text { years of age/ } \\
\text { Vincristine }\end{array}$ & $\begin{array}{l}\text { SEP, neurological } \\
\text { exam }\end{array}$ & $\begin{array}{l}\text { (-): Only ALL } \\
\text { patients, small study. }\end{array}$ & PN & $\begin{array}{l}\text { Unable to } \\
\text { clearly } \\
\text { define what } \\
\text { is PN, } \\
\text { population } \\
\text { has just } \\
\text { finished } \\
\text { therapy, not } \\
\text { long-term }\end{array}$ \\
\hline $\begin{array}{l}\text { Harila- } \\
\text { Saari/2001 }\end{array}$ & $\begin{array}{l}\text { Motor nervous } \\
\text { pathway } \\
\text { function is } \\
\text { impaired after } \\
\text { treatment for } \\
\text { childhood } \\
\text { acute } \\
\text { lymphoblastic } \\
\text { leukemia: A } \\
\text { study with } \\
\text { motor evoked } \\
\text { potentials }\end{array}$ & $\begin{array}{l}\text { Cross- } \\
\text { sectional } \\
\text { study design }\end{array}$ & $\begin{array}{l}32 \text { children with } \\
\text { ALL; age- and } \\
\text { gender- matched } \\
\text { controls, } 4.6-15.5 \\
\text { years of age/ } \\
\text { Vincristine }\end{array}$ & $\begin{array}{l}\text { MRI, MEP, } \\
\text { neurological exam }\end{array}$ & $\begin{array}{l}\text { (-): Only ALL } \\
\text { patients. Recently } \\
\text { completed therapy, } \\
\text { unclear the effect of } \\
\text { IT methotrexate. Did } \\
\text { not define what } \\
\text { constitutes peripheral } \\
\text { neuropathy. }\end{array}$ & PN & $\begin{array}{l}\text { Not } \\
\text { defined. } \\
\text { Using } \\
\text { motor } \\
\text { deficits } \\
\text { incidence is } \\
\text { between } \\
31-63 \% \text {. }\end{array}$ \\
\hline $\begin{array}{l}\text { Hartman/200 } \\
6\end{array}$ & $\begin{array}{l}\text { Decrease in } \\
\text { motor } \\
\text { performance } \\
\text { in children } \\
\text { with cancer is } \\
\text { independent of } \\
\text { the cumulative } \\
\text { dose of } \\
\text { vincristine }\end{array}$ & $\begin{array}{l}\text { Cross- } \\
\text { sectional } \\
\text { study design }\end{array}$ & $\begin{array}{l}128 \text { children with } \\
\text { ALL, Wilm's Tumor, } \\
\text { NHL, and Malignant } \\
\text { Mesenchymal Tumor } \\
\text {, } 4-12 \text { years of age/ } \\
\text { Vincristine }\end{array}$ & MABC & $\begin{array}{l}(+) \text { : Includes a variety } \\
\text { of tumors, many years } \\
\text { from completion of } \\
\text { therapy. } \\
(-) \text { : only one measure } \\
\text { of motor movement, } \\
\text { not specific to cancer } \\
\text { patients or } \\
\text { neuropathy. }\end{array}$ & Motor & $\begin{array}{l}65 \% \text { of } \\
\text { children } \\
\text { below } 50 \text { th } \\
\text { percentile. } \\
10 \% \text { had } \\
\text { sensory } \\
\text { loss, but } \\
\text { procedure } \\
\text { not } \\
\text { described }\end{array}$ \\
\hline
\end{tabular}




\begin{tabular}{|c|c|c|c|c|c|c|c|}
\hline Jain/2013 & $\begin{array}{l}\text { Vincristine- } \\
\text { induced } \\
\text { Neuropathy in } \\
\text { Childhood } \\
\text { ALL } \\
\text { Survivors } \\
\text { Prevalence } \\
\text { and Electro- } \\
\text { physiological } \\
\text { Characteristics }\end{array}$ & $\begin{array}{l}\text { Cross- } \\
\text { sectional } \\
\text { study design }\end{array}$ & $\begin{array}{l}80 \text { children with } \\
\text { ALL, 5-18 years of } \\
\text { age/ Vincristine }\end{array}$ & $\begin{array}{l}\text { Clinical eval, } \\
\text { electrophysiological } \\
\text { eval, TNSr }\end{array}$ & $\begin{array}{l}\text { (-): Only ALL } \\
\text { survivors, in-depth } \\
\text { evaluation with } \\
\text { multiple measures. }\end{array}$ & PN & $\begin{array}{l}33.7 \% \text { in } \\
\text { survivors of } \\
\text { ALL }\end{array}$ \\
\hline $\begin{array}{l}\text { Lehtinen/200 } \\
2\end{array}$ & $\begin{array}{l}\text { Motor nervous } \\
\text { system } \\
\text { impairment } \\
\text { persists in } \\
\text { long-term } \\
\text { survivors of } \\
\text { childhood } \\
\text { acute } \\
\text { lymphoblastic } \\
\text { leukemia }\end{array}$ & $\begin{array}{l}\text { Cross- } \\
\text { sectional } \\
\text { study design }\end{array}$ & $\begin{array}{l}27 \text { patients with } \\
\text { ALL; age-, gender-, } \\
\text { height-matched } \\
\text { controls, } 8-24 \text { years } \\
\text { of age/ Vincristine }\end{array}$ & $\begin{array}{l}\text { Brain MRI, clinical } \\
\text { exam, MEP }\end{array}$ & $\begin{array}{l}\text { (-): Only ALL } \\
\text { survivors; did not } \\
\text { clearly describe } \\
\text { evaluation of fine and } \\
\text { gross motor skills. }\end{array}$ & $\mathrm{PN}$ & $\begin{array}{l}\text { Approximat } \\
\text { ely 33\% }\end{array}$ \\
\hline Leone/2013 & $\begin{array}{l}\text { Assessment of } \\
\text { gross motor } \\
\text { skills and } \\
\text { phenotype } \\
\text { profile in } \\
\text { children 9-11 } \\
\text { years of age in } \\
\text { survivors of } \\
\text { acute } \\
\text { lymphoblastic } \\
\text { leukemia }\end{array}$ & $\begin{array}{l}\text { Cross- } \\
\text { sectional } \\
\text { study design }\end{array}$ & $\begin{array}{l}20 \text { children with } \\
\text { ALL, 9-11 years of } \\
\text { age/ Vincristine }\end{array}$ & $\begin{array}{l}\text { UQAC-UQAM, a } \\
\text { test of gross motor } \\
\text { skills }\end{array}$ & $\begin{array}{l}\text { (-): Only ALL } \\
\text { survivors, lack of } \\
\text { treatment info, limited } \\
\text { ages, small sample. }\end{array}$ & Motor & $\mathrm{N} / \mathrm{A}$ \\
\hline
\end{tabular}




\begin{tabular}{|c|c|c|c|c|c|c|c|}
\hline Ness/2012 & $\begin{array}{l}\text { Neuromuscula } \\
\mathrm{r} \text { impairments } \\
\text { in adult } \\
\text { survivors of } \\
\text { childhood } \\
\text { acute } \\
\text { lymphoblastic } \\
\text { leukemia }\end{array}$ & Cohort study & $\begin{array}{l}415 \text { patients with } \\
\text { ALL, } 21.9-52.3 \\
\text { years of age/ } \\
\text { Vincristine }\end{array}$ & $\begin{array}{l}\text { Ankle tendon } \\
\text { reflexes, Semmes- } \\
\text { Weinstein } \\
\text { monofilament for } \\
\text { sensation, Bio- } \\
\text { Thesiometer for } \\
\text { vibration, Ankle } \\
\text { ROM, Strength, } \\
\text { Balance by the SOT, } \\
\text { TUG, 6MW }\end{array}$ & $\begin{array}{l}(+) \text { : extensive records } \\
\text { about treatment and } \\
\text { comorbid conditions. } \\
(-) \text { : Only ALL } \\
\text { survivors. }\end{array}$ & Motor & $12.80 \%$ \\
\hline Ness/2013 & $\begin{array}{l}\text { Chemotherapy } \\
\text {-Related } \\
\text { Neuropathic } \\
\text { Symptoms and } \\
\text { Functional } \\
\text { Impairment in } \\
\text { Adult } \\
\text { Survivors of } \\
\text { Extracranial } \\
\text { Solid Tumors } \\
\text { of Childhood: } \\
\text { Results from } \\
\text { the St. Jude } \\
\text { Lifetime } \\
\text { Cohort Study }\end{array}$ & Cohort study & $\begin{array}{l}\text { 531 patients with } \\
\text { Carcinoma, Ewing } \\
\text { Sarcoma, NBL, } \\
\text { Osteosarcoma, RBL, } \\
\text { RMS, Wilm's } \\
\text { Tumor, other, } 18.7 \text { - } \\
\text { 63.8 years of age/ } \\
\text { Vincristine, } \\
\text { Vinblastine, } \\
\text { Carboplatin, } \\
\text { Cisplatin }\end{array}$ & $\begin{array}{l}\text { mTNS, ankle } \\
\text { dorsiflexion, TUG, } \\
\text { 6MW, balance with } \\
\text { SOT }\end{array}$ & $\begin{array}{l}(+) \text { : includes larges } \\
\text { sample of a variety of } \\
\text { solid tumors; only } \\
\text { study that includes } \\
\text { more than one } \\
\text { neurotoxic } \\
\text { chemotherapeutic } \\
\text { agent. } \\
(-) \text { : No formal } \\
\text { neurological exam, } \\
\text { nerve conduction } \\
\text { studies. }\end{array}$ & $\mathrm{PN}$ & $\begin{array}{l}17.2-20 \% \\
\text { in long } \\
\text { term solid } \\
\text { tumor } \\
\text { survivors }\end{array}$ \\
\hline $\begin{array}{l}\text { Ramchandren } \\
/ 2009\end{array}$ & $\begin{array}{l}\text { Peripheral } \\
\text { neuropathy in } \\
\text { survivors of } \\
\text { childhood } \\
\text { acute } \\
\text { lymphoblastic } \\
\text { leukemia }\end{array}$ & $\begin{array}{l}\text { Cross- } \\
\text { sectional } \\
\text { study design }\end{array}$ & $\begin{array}{l}37 \text { children with } \\
\text { ALL, } 8-18 \text { years of } \\
\text { age /Vincristine }\end{array}$ & $\begin{array}{l}\text { TNSr, Michigan } \\
\text { autonomic symptom } \\
\text { survey, BOT, } \\
\text { PedsQL, } \\
\text { Neuropathy } \\
\text { impairment score }\end{array}$ & $\begin{array}{l}(+) \text { : includes many } \\
\text { measurement tools, } \\
\text { had treatment data } \\
\text { available. } \\
(-) \text { : Only ALL } \\
\text { survivors. }\end{array}$ & $\mathrm{PN}$ & $\begin{array}{l}29.7-100 \% \\
\text { depending } \\
\text { on } \\
\text { measureme } \\
\text { nt }\end{array}$ \\
\hline
\end{tabular}




\begin{tabular}{|c|c|c|c|c|c|c|}
\hline $\begin{array}{l}\text { Reinders- } \\
\text { Messelink/ } \\
1996\end{array}$ & $\begin{array}{l}\text { Fine motor } \\
\text { and } \\
\text { handwriting } \\
\text { problems after } \\
\text { treatment for } \\
\text { childhood } \\
\text { acute } \\
\text { lymphoblastic } \\
\text { leukemia }\end{array}$ & $\begin{array}{l}\text { Cross- } \\
\text { sectional } \\
\text { study design }\end{array}$ & $\begin{array}{l}18 \text { children with } \\
\text { ALL, } 7.1-12.05 \\
\text { years of age/ } \\
\text { Vincristine }\end{array}$ & $\begin{array}{l}\text { MABC, a } \\
\text { computerized } \\
\text { writing task }\end{array}$ & $\begin{array}{l}(+) \text { : very creative } \\
\text { measurement of } \\
\text { handwriting. } \\
(-) \text { : Only ALL } \\
\text { survivors, small age } \\
\text { range. }\end{array}$ & $\begin{array}{l}25 \% \\
\text { leukemia } \\
\text { survivors } \\
\text { have } \\
\text { handwriting } \\
\text { difficulties }\end{array}$ \\
\hline Wright/1998 & $\begin{array}{l}\text { Long-Term } \\
\text { Gross Motor } \\
\text { Performance } \\
\text { Following } \\
\text { Treatment for } \\
\text { Acute } \\
\text { Lymphoblastic } \\
\text { Leukemia }\end{array}$ & $\begin{array}{l}\text { Cross- } \\
\text { sectional } \\
\text { study design }\end{array}$ & $\begin{array}{l}36 \text { children with } \\
\text { ALL; age- and sex- } \\
\text { matched controls, } 5.5 \\
-14.5 \text { years of age / } \\
\text { Vincristine }\end{array}$ & $\begin{array}{l}\text { GMFM, BOT-MP, } \\
\text { grip strength, } \\
\text { passive ankle } \\
\text { dorsiflexion }\end{array}$ & $\begin{array}{l}\text { (-): Only ALL } \\
\text { survivors, high } \\
\text { amount received } \\
\text { cranial radiation. }\end{array}$ & Not noted \\
\hline \multicolumn{7}{|c|}{$\begin{array}{l}\text { Abbreviations: } \\
\text { ALL - Acute Lymphocytic Leukemia; BOT-MP - Bruininks-Osteretsky Test of Motor Proficiency; BOT-2 - Bruininks-Osteretsky Test } \\
\text { of Motor Proficiency, Second Edition; CT - Computerized Tomography Scan ; EEG - electroencephalography; EMG - } \\
\text { electromyography; GMFM - Gross Motor Function Measure; HD - Hodgkin Lymphoma; IT - Intrathecal; LCH - Langerhans Cell } \\
\text { Histiocytosis; MABC - Movement Assessment Battery for Children ; MABC-2 - Movement Assessment Battery for Children-Second } \\
\text { Edition ; MEP - Motor Evoked Potentials; MRI - Magnetic Resonance Imaging; mTNS - Modified Total Neuropathy Score; NBL - } \\
\text { Neuroblastoma; NHL - Non-Hodgkin Lymphoma; PedsQL - Pediatric Quality of Life Inventory; PN - Peripheral Neuropathy; RBL - } \\
\text { Retinoblastoma; RMS - Rhabdomyosarcoma; ROM - range of motion; SEP - Sensory Evoked Potentials; SOT - sensory organization } \\
\text { test; TNSr - Total Neuropathy Score-reduced; TUG - timed-up-and-go; UQAC-UQAM - University of Quebec Chicoutimi-University } \\
\text { of Quebec Montreal motor skills battery test; 6MW - 6-minute walk test }\end{array}$} \\
\hline
\end{tabular}

Table 1. Literature Review 


\section{CHAPTER THREE}

\section{METHODS \& PROPOSAL}

\section{Research Questions and Specific Aims}

The primary aim of this study was to examine the lived experience of childhood cancer survivors (CCS) at least one year or more after the completion of cancer therapy between 14-30 years old living with chronic chemotherapy-induced peripheral neuropathy (CIPN). Results of this study provided details of the lived experience of chronic CIPN in CCS, which was currently unknown, in order to develop more appropriate assessments and interventions to improve functioning and quality of life in CCS living with this chronic condition. Research questions included: (1) What is the lived experience of painful or function-altering CIPN after the completion of therapy for childhood cancer?; (2) How does chronic CIPN affect school and/or vocational performance after the completion of therapy for childhood cancer?; (3) How does chronic CIPN affect the quality of life of childhood cancer survivors?

\section{Design Overview}

A qualitative, narrative design with a phenomenological influence was used to describe the lived experience of adolescent and young adult CCS who are experiencing CIPN. Narrative inquiry is founded on the belief that humans are natural story-tellers, and these stories can help us understand how people experience the world. In this study, participants were asked to tell their experience living with CIPN after the treatment for cancer. Phenomenological studies aim to understand the lived experience of a certain phenomenon from the perspective of those living that certain experience, since Husserl proposed that the human experience is valuable and worthy of scientific study (Lopez \& 
Willis, 2004). The phenomenological method and philosophy developed by Edmund Husserl in the beginning of the 20th century is a wonderful fit for nursing inquiry (Tuohy, Cooney, Dowling, Murphy, \& Sixsmith, 2013). Both narrative and phenomenology methods were included to address the scope of the primary aim of the research. Phenomenology aids in the understanding of the phenomenon of CIPN, where narrative methods aid in the understanding of the participant's stories and the broader meaning of the CIPN experience. This research also utilized photo-elicitation interviews (PEI) as guided by Hermeneutical photography. Hermeneutical photography is an innovative technique that uses participant-taken photographs to capture the essence of the lived experience. Photographs can also capture symbols of a person's reality that have the potential to become meaning (Hagedorn, 1994). In Hermeneutical photography, "the images captured with photography invite human beings to speak about these experiences with reflective depth. Photographs not only gather interpretations of images of experience, but also enrich and extend the communications of those experiences" (Hagedorn, 1994, p. 46).

Participants were given a disposable camera with the prompt to take pictures that capture what it is like to live with peripheral neuropathy and were sent home with these prompts in writing as a reference (Appendix A). Participants were given two month to take pictures with a disposable, single-use camera with 27 exposures. Each patient was instructed on how to use the camera during their office visit (or over the phone) and was sent home with written instructions. Two weeks after the participant had received the camera, a member of the study team called the participant to check on their progress and 
see if they had any questions or concerns regarding the pictures to be taken. Patients did not need to use all 27 exposures and were able to stop taking photographs at any point. Once the patient was done taking their photographs, they placed the camera is a preaddressed, pre-stamped envelope to return to the study team. Photos were developed in duplicate upon the camera's return and an in-person interview was scheduled. In order to obtain data regarding the lived experience, interviews were conducted with survivors of childhood cancer themselves, rather than their parents or others in their community. Inhospital interviews were conducted in a private room in the Hematology/Oncology clinic. In-home interviews were not offered in order to guarantee the safety of the interviewer who would otherwise possibly be at risk traveling to nearby areas with high rates of violent crime. Phone interviews were allowed, and screen-sharing software was available, as needed, to view the photographs.

\section{Sampling}

Purposive sampling was used to identify patients that exemplified the characteristics needed to understand the lived experience of CIPN in a population of CCS currently between the ages of 14-30. Participants were identified through a long-term follow-up clinic for CCS in a large academic medical center in the Midwest region of the United States. This clinic draws patients from across the region since it is the largest multi-disciplinary clinic for CCS across many states, with a wide variety of demographic characteristics. This clinic cares for over 400 children, adolescent, and young-adult CCS annually. Approximately 90 patients are within the eligible age range. Previous data collected from this clinic revealed the prevalence of CIPN was $23 \%$. Thus, approximately 18 CCS with CIPN comprised the pool of potential participants at this institution. 
Survivors with a diagnosis of CIPN, as noted within their medical record, were eligible for this study and were approached by a member of the research team.

The following inclusion criteria were considered: patient has a history of childhood cancer diagnosed before the age of 21; patient has completed therapy for cancer at least 1 year prior to study enrollment; patient is currently between the ages of 14-30; patient's previous cancer treatment included neurotoxic chemotherapy such as a vinca alkaloids, platinum containing compounds, taxanes, and/or proteasome inhibitors; and participant cognitively able to participate in an in-depth interview. Exclusion criteria included: patients with a diagnosis of neuropathy prior to cancer diagnosis; and patients with concurrent diagnosis of diabetes or Charcot-Marie-Tooth disease. The number of participants was not driven by statistical methods, but was driven by the richness of the data. The sample size was determined during the research process at the point the interviewer has reached saturation of the data, meaning no new themes were generated and there were no new emergent patterns (Sandelowski, 1995).

\section{Instruments}

The researcher used an interview guide developed with open-ended questions focusing on what the life experience was like with CIPN (Appendix B). The interview questions focused on the daily lived experience of CIPN as an adolescent or young adult CCS. Sample questions included, "In your own words, what does CIPN feel like?", and "Tell me about any of the ways CIPN makes you feel emotionally." Interviews were conversational between researcher and research subject. While using the interview guide, the interviewer needed to be flexible, keenly aware of conversational cues from research participants, and poised to explore those cues through further questioning (Bevan, 2014; 
Richards \& Morse, 2012). In addition to the interview guide, each photograph was viewed and participants were asked to explain the photograph in their own words. Follow-up questions, including questions regarding the meaning of the photograph, occurred, as appropriate. Interviews lasted 30-60 minutes. Interviews were audiorecorded and transcribed verbatim by a contracted transcriptionist.

\section{Data Collection}

CSS with CIPN took photographs that demonstrated the lived experience of CIPN and subsequently participated in one-on-one, in-depth interviews. To understand the experience of chronic CIPN in a population of CSS, the principal investigator completed the data collection. Since the process of collecting data and reflection on the data overlapped, having one interviewer assisted in providing in-depth interviews for analysis. To understand the lived experience of a cancer survivor, a time point was established that the patients must be at least one year from the completion of therapy to participate. Two major types of data were used to answer the research questions: transcripts of the in-depth interviews and photographs.

\section{Photographs as Data}

In terms of photographs taken for the purpose of healthcare research, data are not limited to the photographs themselves, but may also include the participants' reflections on the photographs, participants' guidance to the researcher, or the researcher's reflection's on the image (Drew \& Guillemin, 2014). Transparency regarding what are considered data when using visual methods is key to improving trustworthiness. For this research project, the participants' reflections on the photograph and guidance to the researcher were discussed during the in-depth interview and subsequently became a part 
of the interview transcripts. The photographs were used to stimulate conversation and were also analyzed as independent data. The SHOWeD method was used as a guide to generate photographic data. SHOWeD stands for: "What do you SEE here? What's really HAPPENING here? How does this relate to OUR lives? Why does this problem, concern, or strength EXIST? What can we DO about it?" (Catalani \& Minkler, 2010). A benefit to using photographs along with transcripts is it allowed for triangulation (Catalani \& Minkler, 2010).

\section{Data Analysis}

Specific strategies were required to analyze the variety of data produced. The development of the research question was guided by phenomenological methods and these methods were used for data analysis, as well. The concept of bracketing within phenomenological studies is a debated and sometimes polarizing topic (van Manen, 2011). Husserl believed successful phenomenological study should achieve "transcendental subjectivity" or lack of researchers' influence on the object of the study (Lopez \& Willis, 2004). Therefore, Husserl believes researchers need to "bracket" prior knowledge at the beginning of the research process. This includes writing out all prior knowledge on the topic in order to reduce influence on the exploration of the phenomenon of interest (Richards \& Morse, 2012). Subsequent phenomenologists, including Husserl's student and contemporary, Martin Heidegger, disagreed with the process of bracketing and argued that prior knowledge of the phenomenon and review of the literature is what has helped the researcher identify a certain phenomenon as worthy of study (Lopez \& Willis, 2004). Again later, van Manen's beliefs about phenomenological study are that a human within their individual context conducts the 
research, and thus is not able to separate from their personal context-therefore bracketing is unnecessary (Miller, 2003). My personal axiological belief is that values should be acknowledged, but not intimately be made a part of the research process. Therefore, I explored my thoughts and beliefs regarding the research topic through reflective journaling in order to be aware of my own biases, but did not attempt bracketing since I did not believe I could rid myself of this knowledge altogether (Ortlipp, 2008). I believe my previous knowledge of the phenomenon is what has driven the development of this study and the interview questions.

Analysis of the participant interview. In a phenomenological study, data analysis is an ongoing process throughout during data collection. During the interviews, while data are generated, the researcher is analyzing the research participants' expressions of their lived experiences and then asking focused questions to generate more data (Richards \& Morse, 2012). Past phenomenologists recommend many processes for data analysis, similar to the way they have different recommendations in regard to bracketing (Miller, 2003). Colaizzi and van Manen each had "steps" or "activities" of their analysis (Miller, 2003). Steps for analysis of this study were determined by what was appropriate for my interpretive paradigm, aims for the research study, and population under evaluation. The steps I followed included: immersing myself within the data by reading and re-reading interview transcripts and corresponding photographs; identifying interpretive statements and extracting meaning; sorting data into categories or themes; developing an exhaustive description of the phenomenon; and validating findings by allowing participant review (Miller, 2003). Transcripts were imported into NVivo qualitative data analysis software for data management and coding. 
Analysis of photographs. The photographic data were analyzed as guided by the proposed 'interpretive engagement' framework. This framework was developed to analyze participant-generated images. The framework includes three stages of meaningmaking: "meaning-making through participant engagement, through researcher-driven engagement, and through re-contextualizing" (Drew \& Guillemin, 2014, p.58 ). The first stage of analysis focuses on the participants' view of the research, including their reflections of the images they have produced. In the second stage, the researcher documents the images and establishes themes and connections between the themes (Drew \& Guillemin, 2014). In this stage, the researcher's reflections become additional data. Stage two of analysis builds on stage one and meaning-making begins. During the third phase, data are reviewed once more to re-contextualize interpretations as they are congruent with theoretical frameworks. Drew and Guillemin (2014) find asking interpretive questions at this stage, such as "whose knowledges are excluded from this representation?" allows for further analysis. This framework is proposed to improve the rigor and transparency in the analysis of images used as research data.

There are aspects of analyzing photographic data where the researchers must be particularly careful and reflective. When using photographs as primary data, the researcher needs to be wary of the ability of the photographer to manipulate and influence an image. Cautious discussion of the photograph with the photographer is necessary to avoid hasty interpretations. Interpretations should be systematic rather than passive. The duality of photographic data is that it may be concrete and have more abstract representation simultaneously (Drew \& Guillemin, 2014). The researcher also needs to consider that there may be 'missing photographs'. Participants may have significant 
experiences to share that they are unable to photograph and the researcher should address this potential, which was a planned part of the in-depth interview (Frith \& Harcourt, 2007).

\section{Strategies to Ensure Rigor}

To increase transparency, and therefore the study's validity, once the principal investigator felt saturation had been met, attempts were made for one more participant to be enrolled in order to determine if another interview provided new or discrepant data (O’Reilly \& Parker, 2012). At the point where no new or discrepant data were found, data saturation was assumed. To improve the trustworthiness of the data, participants were able to review the data prior to publication, either during a routine clinic visit or during a phone call, as a form of member checking. Expert review of the final themes was provided by healthcare providers in the long-term follow-up clinic who work closely with CCS who experience CIPN. Disagreement regarding the findings was discussed in detail until a shared understanding developed and the data were found to be representative of the phenomenon. The researcher remained open and flexible while coding data and analytic memos were made in order to track how codes were created and subsequent larger themes emerged.

\section{Limitations or Potential Difficulties}

The sample in this study presented a unique challenge as the range of ages in this population of CCS spans a large period of development from childhood through adulthood. Survivors of varying ages have different experiences and tasks in their daily life, which will affect how they report their experience of peripheral neuropathy. This larger span of development was chosen in order to be more representative of the 
population of childhood cancer survivors currently in long-term follow-up care. The principal investigator made the assumption, guided by the Theory of Unpleasant Symptoms, that regardless of age or development, there will be similarities across the symptom experience that should support the validity of the data (Lenz, Pugh, Milligan, Gift, \& Suppe, 1997). A second potential challenge was ensuring the participants were completing the photographic portion of the research while away from the researcher, since this has been a historic problem with other photographic research projects with children and adolescents (Coad, 2007; Drew, Duncan, \& Sawyer, 2010). In anticipation of this potential challenge, participants received a reminder call to address questions or concerns with the photographic assignment.

\section{Protection of Human Subjects}

Institutional review board approval was obtained at the participating institution (Appendix C). Consent or assent was obtained in a private exam room (or over the phone) with clear explanation of the risks and benefits of the study (Appendix D). All participants were provided with a clear explanation that participation is voluntary and they may withdraw consent/assent at any time. There were minimal direct benefits to the participants. Data support that cancer survivors are motivated by altruism to participate in research, knowing research results in a greater understanding of their disease, and

patients like themselves may find direct benefit in the future (Keusch et al., 2014). Data collection techniques in this study were of minimal risk to the participants. The importance of the knowledge to be gained from the results of this study and the potential to design interventions that can improve the physical function and quality of life of cancer survivors outweighed the minimal risk to the participants. Steps were taken to 
ensure privacy and anonymity. Transcripts, audio recordings, and photographs from each interview were stored on a secure server within password-protected software. 


\section{References}

Bevan, M. T. (2014). A Method of Phenomenological Interviewing. Qualitative Health Research, 24(1), 136-144. https://doi.org/10.1177/1049732313519710

Catalani, C., \& Minkler, M. (2010). Photovoice: A Review of the Literature in Health and Public Health. Health Education \& Behavior, 37(3), 424-451. https://doi.org/10.1177/1090198109342084

Coad, J. (2007). Using art-based techniques in engaging children and young people in health care consultations and/or research. Journal of Research in Nursing, 12(5), 487-497. https://doi.org/10.1177/1744987107081250

Dodd, M. J., Miaskowski, C., \& Lee, K. A. (2004). Occurrence of Symptom Clusters. JNCI Monographs, 2004(32), 76-78. https://doi.org/10.1093/jncimonographs/lgh008

Drew, Duncan, \& Sawyer. (2010). Visual Storytelling: A Beneficial But Challenging Method for Health Research With Young People. Qualitative Health Research, 20(12), 1677-1688. https://doi.org/10.1177/1049732310377455

Drew, S., \& Guillemin, M. (2014). From photographs to findings: visual meaningmaking and interpretive engagement in the analysis of participant-generated images. Visual Studies, 29(1), 54-67.

https://doi.org/10.1080/1472586X.2014.862994

Frith, H., \& Harcourt, D. (2007). Using photographs to capture women's experiences of chemotherapy: Reflecting on the method. Qualitative Health Research, 17(10), $1340-1350$.

Hagedorn, M. R. (1994). Hermeneutic photography: An innovative esthetic technique for 
generating data in nursing research. Advances in Nursing Science Esthetics and the Art of Nursing, 17(1), 44-50.

Keusch, F., Rao, R., Chang, L., Lepkowski, J., Reddy, P., \& Choi, S. W. (2014).

Participation in clinical research: perspectives of adult patients and parents of pediatric patients undergoing hematopoietic stem cell transplantation. Biology of Blood and Marrow Transplantation: Journal of the American Society for Blood and Marrow Transplantation, 20(10), 1604-1611.

https://doi.org/10.1016/j.bbmt.2014.06.020

Lenz, E. R., Pugh, L. C., Milligan, R. A., Gift, A., \& Suppe, F. (1997). The MiddleRange Theory of Unpleasant Symptoms: An Update. Advances in Nursing Science, 19(3), 14-27.

Lenz, E. R., Suppe, F., Gift, A., Pugh, L., \& Milligan, R. (1995). Collaborative development of middle-range nursing theories: toward a theory of unpleasant symptoms. ANS. Advances in Nursing Science, 17(3), 1-13.

Lopez, K. A., \& Willis, D. G. (2004). Descriptive Versus Interpretive Phenomenology: Their Contributions to Nursing Knowledge. Qualitative Health Research, 14(5), 726-735. https://doi.org/10.1177/1049732304263638

Miller, S. (2003). Analysis of phenomenological data generated with children as research participants. Nurse Researcher, 10(4), 68.

Motl, R. W., \& McAuley, E. (2009). Symptom Cluster as a Predictor of Physical Activity in Multiple Sclerosis: Preliminary Evidence. Journal of Pain and Symptom Management, 38(2), 270-280. https://doi.org/10.1016/j.jpainsymman.2008.08.004

Myers, J. S. (2009). A Comparison of the Theory of Unpleasant Symptoms and the 
Conceptual Model of Chemotherapy-Related Changes in Cognitive Function. Oncology Nursing Forum, 36(1), E1-E10. https://doi.org/10.1188/09.ONF.E1E10

Ortlipp, M. (2008). Keeping and Using Reflective Journals in the Qualitative Research Process. The Qualitative Report, 13(4), 695-705.

Richards, L., \& Morse, J. M. (2012). README FIRST for a User's Guide to Qualitative Methods. SAGE.

Sandelowski, M. (1995). Sample size in qualitative research. Research in Nursing \& Health, 18(2), 179-183.

Smith, \& Liehr. (2013). Middle Range Theory for Nursing: Third Edition. Springer Publishing Company.

Tuohy, D., Cooney, A., Dowling, M., Murphy, K., \& Sixsmith, J. (2013). An overview of interpretive phenomenology as a research methodology. Nurse Researcher, 20(6), $17-20$.

van Manen, M. (2011). Phenomenology Online » Orientations in Phenomenology.

Retrieved April 13, 2014, from

http://www.phenomenologyonline.com/inquiry/orientations-in-phenomenology/ 


\section{CHAPTER 4}

\section{RESULTS}

This chapter includes a manuscript of the results of this dissertation research, followed by a brief reflection on the use of photo-elicitation as a method of inquiry with adolescent and young adult childhood cancer survivors. 


\title{
THE EXPERIENCE OF CHEMOTHERAPY-INDUCED PERIPHERAL
} NEUROPATHY AMONG CHILDOOD CANCER SURVIVORS

Mohrmann, C. (2017). The experience of chemotherapy-induced peripheral neuropathy among childhood cancer survivors. (Manuscript in preparation).

\begin{abstract}
As the number of childhood cancer survivors (CCS) is increasing, it is imperative to understand the late-effects of childhood cancer therapy to optimize their health and quality of life. Chemotherapy-induced peripheral neuropathy (CIPN) is an unpleasant side effect of chemotherapy which impacts the peripheral nervous system and results in a variety of sensory and motor abnormalities. While CIPN is poorly understood in general, there is a particularly poor understanding of the experience of CIPN among CCS, which leads to lack of appropriate support for maximizing function and quality of life. This qualitative study uses narrative analysis with a phenomenological influence to understand the lived experience of CIPN among five CCS. Semi-structured interviews and photoelicitation were used. The lived experience of CIPN is characterized by "a condition of disconnection" with three subthemes: (1) disconnection between mind and body, (2) disconnection between anticipated potential and reality, and (3) disconnection between survivors and support. The condition of disconnection leads to a variety of negative physical and emotional performance outcomes. These findings support the need for the development of interventions to 're-build the connections' CCS are lacking, as well as focused clinical assessments to identify this under-appreciated condition.
\end{abstract}




\section{Introduction}

Childhood cancer survivorship is an emerging field, as 5-year survival rates have dramatically increased over the past few decades to now over $80 \%$ overall, compared to only $63 \%$ in the 1970 's (Armenian, Landier, Hudson, Robison, \& Bhatia, 2013). With a new, growing, and aging population of survivors, new categories of late complications are being discovered each year. Unfortunately, over $80 \%$ of childhood cancer survivors will experience a serious, disabling, or life-threatening health condition by age 45 (Hudson et al., 2013). As a result, there is an increased importance placed on identification of long-term health conditions that result from childhood cancer therapy and continue to impact function or quality of life during survivorship. Acknowledging that knowledge acquisition in this field has greatly improved over the past decades, there are still health conditions experienced by childhood cancer survivors (CCS) that have not been identified and studied. Chemotherapy-induced peripheral neuropathy (CIPN) is a troublesome symptom experienced by many patients during and after the treatment of cancer, but little is known about this experience among CCS in order to promote optimal quality of life after the completion of treatment for cancer.

Many patients still experience symptoms of peripheral neuropathy long after exposure to neurotoxic agents (Armstrong, Almadrones, \& Gilbert, 2005). A recent metaanalysis of over 4,000 adult patients demonstrated that the prevalence of CIPN one month after the completion of therapy was $68 \%$, and CIPN often persisted beyond six months with a prevalence of $30 \%$ (Seretny et al., 2014). While data are sparse regarding the incidence of CIPN among CCS, it is commonly estimated to be between $25-60 \%$ (Mohrmann, Armer, \& Hayashi, 2016). There is no agreed-upon diagnostic criteria for 
peripheral neuropathy in CCS, which in itself presents a great challenge to the study of neuropathy in children and adolescents (Gilchrist, 2012). There is evidence in the adult literature to support CIPN effects on vocation, life roles, emotional health, social interactions, sleep, and sexual functioning; even when symptoms are less severe, the impact of those symptoms can have clinically significant impact on a patient's quality of life (Bakitas, 2007; Driessen, de Kleine-Bolt, Vingerhoets, Mols, \& Vreugdenhil, 2012; Eckhoff, Knoop, Jensen, \& Ewertz, 2015; Ezendam et al., 2014; Tofthagen, 2010a, 2010b; Tofthagen, Overcash, \& Kip, 2012; Wampler et al., 2007). Patient-reported outcomes and clinical significance of functional impacts have not been found to date in the pediatric literature.

When neuropathy involves the motor fibers, patients experience symptoms such as weakness, fasciculation, or muscle atrophy (Chung, Prasad, \& Lloyd, 2014). Sensory neuropathy causes numbness, tingling, and/or altered perception of pain (Chung et al., 2014). Functionally, children with peripheral neuropathy may not be able to open a jar, button their pants, hold a pencil in school, or walk with a normal gait. Those experiencing toxicity during therapy may require dose modifications of the chemotherapeutic agent, increased need for pain medications, and other supportive care interventions. Unfortunately, strong evidence is lacking as to the best treatment for CIPN in children, likely due to the poor overall understanding of this condition (Gilchrist, 2012; Kottschade et al., 2010). This poor understanding includes the trajectory of the CIPN experience during and after therapy, few identified risk factors for developing acute or chronic CIPN, and no identified studies investigating the quality of life or daily lived experience of CCS with this chronic condition. In order to inform the development of diagnostic 
strategies and improve management of this chronic condition, the following research questions were asked: (1) What is the lived experience of painful or function-altering CIPN after the completion of therapy for childhood cancer?; (2) How does chronic CIPN affect school and/or vocational performance after the completion of therapy for childhood cancer?; (3) How does chronic CIPN affect the quality of life of CCS? In order to fully evaluate the scope of the symptom experience, the updated Theory of Unpleasant Symptoms was used as a guide for data collection and analysis (Lenz, Pugh, Milligan, Gift, \& Suppe, 1997).

\section{Methods}

\section{Design}

A narrative study with a phenomenological influence was performed at a large, Midwestern academic medical center. Narrative inquiry within nursing is generally founded on the belief that stories help people share meaning in their life and help clinicians understand how people experience the world (Emden, 1998; Sandelowski, 1991). Phenomenological studies aim to understand the lived experience of a certain phenomenon from the perspective of those living that certain experience, since Husserl proposed that the human experience is valuable and worthy of scientific study (Lopez \& Willis, 2004). This research utilized photo-elicitation, as guided by Hermeneutical photography. In Hermeneutical photography, "the images captured with photography invite human beings to speak about these experiences with reflective depth. Photographs not only gather interpretations of images of experience, but also enrich and extend the communications of those experiences" (Hagedorn, 1994, p. 46).

\section{Participants}


All participants were recruited from the Late Effects Clinic for childhood cancer survivors. All participants met the following inclusion criteria: (1) participant has a history of childhood cancer diagnosed before the age of 21 ; (2) has completed therapy for cancer at least 1 year prior to study enrollment and is still experiencing CIPN; (3) participant is currently between the ages of 14-30; (4) participant's previous cancer treatment included neurotoxic chemotherapy, such as a vinca alkaloids, platinum containing compounds, taxanes, and/or proteasome inhibitors; and (5) participant is cognitively able to participate in an in-depth interview. Purposive sampling was used and recruitment continued until saturation was reached, which was considered the point at which no new themes or patterns emerged (Sandelowski, 1995).

\section{Data Collection Procedures}

Institutional review board approval was granted by the University of Missouri. Recruitment took place within a private exam room in the Late Effects Clinic, or via phone call. All study procedures were explained and the participant's questions were answered. All participants provided their informed consent prior to any study procedures. After informed consent was provided, participants received a packet that included a copy of the consent form; instructions for taking photographs; a 27-exposure disposable camera; and a pre-addressed, pre-stamped return envelope. Participants were instructed to take photographs that helped to explain their experience of living with CIPN; participants did not need to take all 27 possible photographs. Once the photographic portion was complete, cameras were returned by mail and participants were contacted to schedule an interview. A semi-structured interview guide was used for the interview which included review of the participant-generated photographs. The SHOWeD method was used as a 
model to generate photographic data as a part of the semi-structured interview (Catalani \& Minkler, 2010). SHOWeD stands for: “(a) What do you See here? (b) What's really Happening here? (c) How does this relate to Our lives? (d) Why does this problem, concern, or strength Exist? (e) What can we DO about it?" (Catalani \& Minkler, 2010, p. 438). During the participant's interview, each photograph was discussed in detail after the completion of the semi-structured portion.

\section{Analysis}

Data analysis was ongoing during data collection. Each interview was recorded and transcribed verbatim by contracted transcriptionist, and reviewed for accuracy by the researcher. As a part of the phenomenological approach, during the interviews the researcher was analyzing the participant's expression of their lived experience and then asking focused questions to generate more data (Richards \& Morse, 2012). All photographs were developed in film, as well as CD format. Transcripts and photographs were stored in NVivo software for data analysis. The researcher read each transcript multiple times and reviewed corresponding photographs to immerse herself within the data. The 'interpretive engagement' framework was used to analyze participant-generated images (Drew \& Guillemin, 2014). Participants' discussion and interpretation of the images is the first step in analyzing the photographic data. Subsequently, the researcher's reflection and assessment of the images further the analysis. The last step is recontextualizing, considering theoretical frameworks and the audience's perspective. Initial coding of the transcribed interviews began with extracting interpretive statements. The interpretive statements were re-organized and categorized until one major theme and three subthemes emerged; a detailed description of the phenomenon was developed. After 
reviewing the codes, re-organizing, and memo-ing, it became apparent that the TOUS would provide a "framework for organizing the data for re-representation" (Sandelowski, 1993, 216). Therefore, data were also sorted into categories as guided by the Theory of Unpleasant Symptoms.

\section{Methodological Rigor}

The researcher recognized personal values and bias prior to study initiation. Traditional bracketing with attempts to achieve 'transcendental subjectivity' was not attempted, as the researcher believes is not possible to remove previous knowledge of the research topic altogether (Miller, 2003; Richards \& Morse, 2012). In addition, the researcher believes research is done by an individual within a personal context, similar to phenomenological contemporaries Heidegger and van Manen; therefore, traditional bracketing is unnecessary (Lopez \& Willis, 2004). Reflective memo-ing was performed after each level of coding to further refine the themes and to ensure that themes were consistent with the researcher's reflection on the representation of the data. To improve trustworthiness, member-checking was completed after the final themes had emerged. No recommendations for modifications were made, but rather, confirmation that the developed themes were representative of the research participant's experience. Final themes were shared with clinicians caring for CCS in a long-term follow-up clinic to allow for expert review, with no modifications recommended.

\section{Findings: A Condition of Disconnection}

Seven participants consented to participate, but two participants did not complete the photographic portion of the study and thus were not included in the data analysis. A total of five participants ages 18-30 completed both the photographic portion and the 
interview portion of the study. Four of the participants were female. One participant was African American, and the other participants were Caucasian. As a group, these five participants represented a variety of primary cancer diagnoses, three different neurotoxic chemotherapy agent exposures, and radiation therapy, as well as surgical tumor resection. Four participants were employed and two were students; one participant was a student and an employee. Three participants completed face-to-face interviews and two participants requested phone interviews with an average interview time of 22 minutes across all interviews. The experience of living with CIPN among CCS is characterized by the overall theme "a condition of disconnection" with three sub-themes including: (1) disconnection between mind and body; (2) disconnection between anticipated potential and reality; and (3) disconnection between survivors and support (Figure 2).

\section{Disconnection Between Mind and Body}

All participants described peripheral neuropathy in terms of how their mind often perceived a reality different than what their body was experiencing. Participants described four types of mind/body disconnection: (1) feeling what is not present; (2) not feeling what is present; (3) pain disproportionate to the amount of aggravation; and (4) not controlling bodily movements as anticipated. While the symptom description in terms of quality, timing, and intensity varied between participants, and even within participants, each participant's description of the neuropathy experience is characterized by a mind/body disconnection. For example, Participant 1 used the words "tingling" and "numbness" to describe her symptoms, while Participant 6 used the terms "frozen" and “cramping," which is considered between-participant variability (Figure 3). Participant 1 
clarified that the tingling sensation is felt in her hands, while her feet have numbness, which is considered within-participant variability.

Feeling what is not present. Participants used a variety of symptom quality terms to describe sensations their mind perceived, but were not actually elicited by what their bodies were experiencing (Figure 4). Some participants reported this experience as feeling "hypersensitive," while all participants reported this as "weird." Below are two participants' descriptions of feeling what was not present: “...because that's the main pain that I feel the most intense, for me, is that feeling of just copper, hot copper being pressed into the back of my leg." - Participant 1 "It feels like somebody is pricking me with a pin in my hands." - Participant 5

Not feeling what is present. Participants also described numbness in a variety of contexts. Sometimes, numbness is a progression from other symptoms of sensory neuropathy. Participants may feel tingling or burning that fades into numbness. Not feeling what is present was most commonly reported in the hands and feet, consistent with the stocking-glove distribution of peripheral neuropathy. Numbness might be felt after certain activities:

"Yeah. So I think whenever it first started it was mostly my hand would just shake, so there was a lot of shaking mostly down in my ring finger and my pinky. And then that kind of turned more into-- so it still shakes a little bit but it mostly now kind of like a numbness. Sometimes my fingers will go numb and then they'll tingle, especially if I'm doing-- like at work." - Participant 4

A risk associated with lack of sensation is injury. If patients are unable to feel pain, they are unable to appropriately respond to threats to their body. One participant 
described challenges she faced with injury while working long holiday-hours in a retail position. She was on her feet each day and has difficulty finding supportive and appropriate footwear. She was unable to feel her shoe rubbing against her toe over a period of weeks which lead to skin breakdown. Eventually, she required treatment for cellulitis.

"I went to go see my podiatrist the other day and my neuropathy, I almost have, not numbness...I can feel pain, but I don't feel the symptoms before I get to extreme pain." -

\section{Participant 7}

Photograph 1. Cellulitis caused by footwear in presence of CIPN

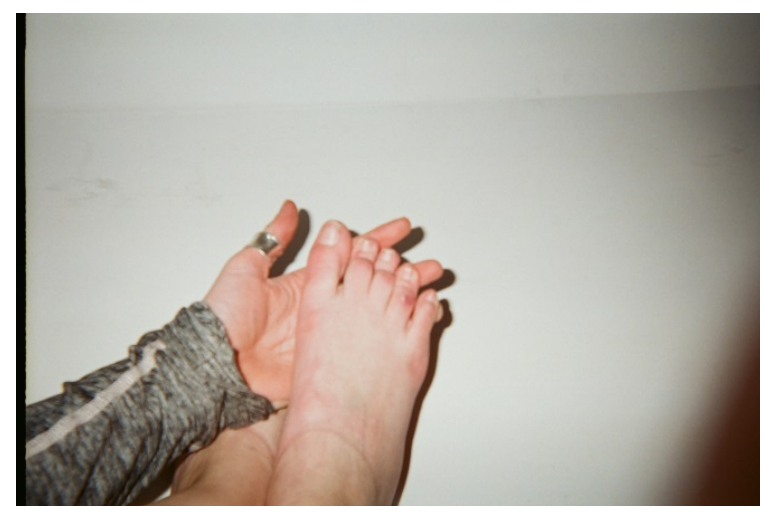

Pain disproportionate to the amount of aggravation. All but one participant

reported they experienced pain. Pain could occur at any time of the day, with or without an identifiable aggravating factor. Common aggravating factors were walking, standing, being in any position for prolonged periods, cold or hot temperature, and footwear.

Unfortunately, pain could also occur upon waking or when trying to sleep.

"Well, I think that that 10-minute walk I had really is what causes me the most pain. But also it's weird because it will happen during the walk, but then I do that at like 2 PM. I will still be having pain at like 8 PM until I go to bed. And it's not like a constant pain, 
but it will come back and I'll feel it four or five times before I go to bed. So it's kind of continual. It will go away but it comes back." - Participant 1

"And then with my feet, they feel numb or if I wear shoes and socks too long or socks, definitely, socks, if I wear socks too long they make my feet hurt." - Participant 5

Photograph 2. Pain caused by simply wearing socks

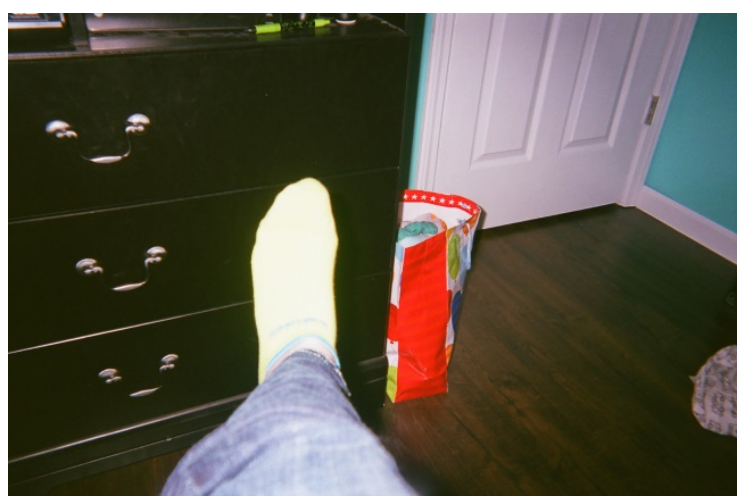

Not controlling bodily movements as anticipated. As either a result of the sensory symptoms experienced, or due to motor neuropathy, there are times where participants with peripheral neuropathy were unable to move and control their bodies as anticipated. As a result, mobility can be limited and role-related tasks were difficult to complete.

"Yeah, like if I sit down too long, and then I get up, my legs are really sore. And sometimes I kind of look like an old lady whenever I get up, and I just get up and then crouch, because my legs, I guess, kind of asleep, but not asleep, more painful than asleep."- Participant 5

'I know that sounds kind of weird, but since you can't control them, they don't feel like they're there, if that makes sense. It's kind of weird, but more of a lack of awareness and really essentially feeling like you're trying to make something happen and it's not-- it almost feels inanimate". - Participant 7 
One participant described feeling disconnected to her body, which sometimes results in feeling off-balance. This lead to difficulties in navigating open space. As a coping mechanism, she found she needed to simply reach out and touch a solid surface to re-connect her mind and body.

Photograph 3. Using touch to re-connect mind and body

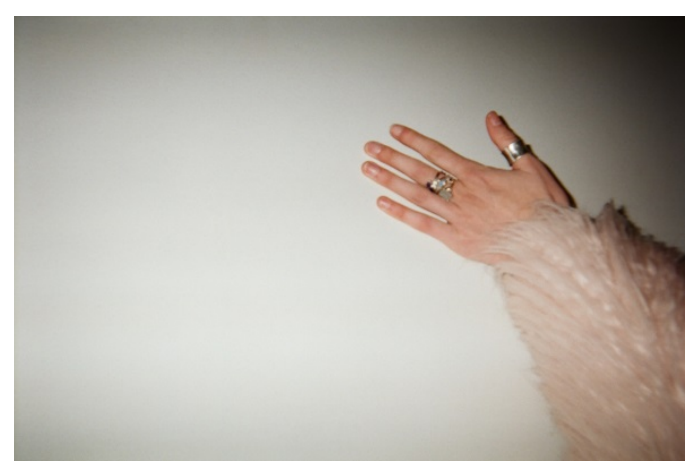

\section{Disconnection Between Anticipated Potential and Reality}

All participants described ways in which their life has changed due to CIPN. The disconnection between their anticipated potential and reality is seen in their perception of the need to perform their daily functions, but their lack of ability to perform those functions as anticipated. Between-participant differences were recognized. Some participants experience only mild discrepancies between their potential and reality. For example, one participant explained only a few functions of her daily life could not be performed as anticipated, while another was unsure if she would be able to simply walk a small distance:

"No. It will only get painful when I've been writing or typing for a long period of time, and then it will just cramp up and my hands will be just stuck like this or something". Participant 3

Photograph 4. "Am I going to be able to get across today?" 


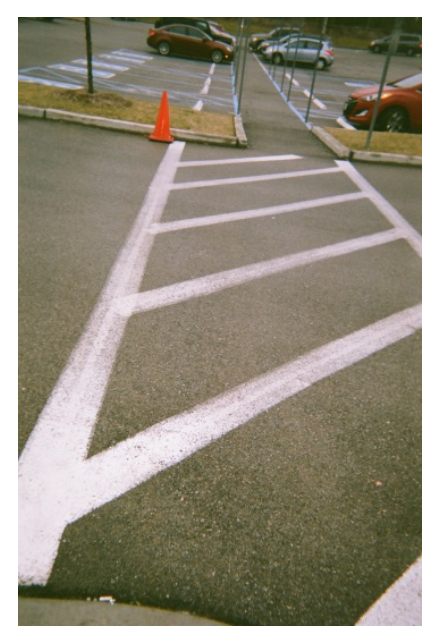

Some participants described the symptoms as much more pervasive, to where many activities of daily living were challenging. At school, participants struggled with walking long distances between classes. At times, they were not able to get to their classroom as anticipated. One participant had to request classroom locations be moved to closer proximity, and another had to resort to only driving around the campus. At home, participants were often unable to complete chores, such as washing dishes or folding laundry. One participant explained that the unexpected timing of the symptoms limited when she was able to take care of her home.

"I guess, on a daily basis you have to do different things around the house, and if you're not feeling well, there are some things that you can't do. And then you feel just kind of worthless, I guess.” - Participant 5

The workplace environment led to participants' increased sensory and motor symptoms, as well as pain. A common experience in many work places, prolonged standing, often elicited pain. The use of equipment can be challenging. Some equipment requires a level of manual dexterity, and participants who felt disconnection in their hands were often unable to control the equipment to complete work-related tasks. Using equipment that functions with repetitive motions or that is heavy can lead to sensory 
symptoms and/or pain. Temperature variability at work also caused pain. One participant described having to work in a freezer as a part of daily responsibilities in the food industry, even though coldness led to extreme pain. As a result, CCS living with CIPN are at risk for under-employment or limited career trajectory. One participant describes turning down a promotion because it would require her to live in a geographic region with frequent snow, and she is unable to easily walk in winter conditions.

Photograph 5. Daunting equipment demonstrating the challenges of work

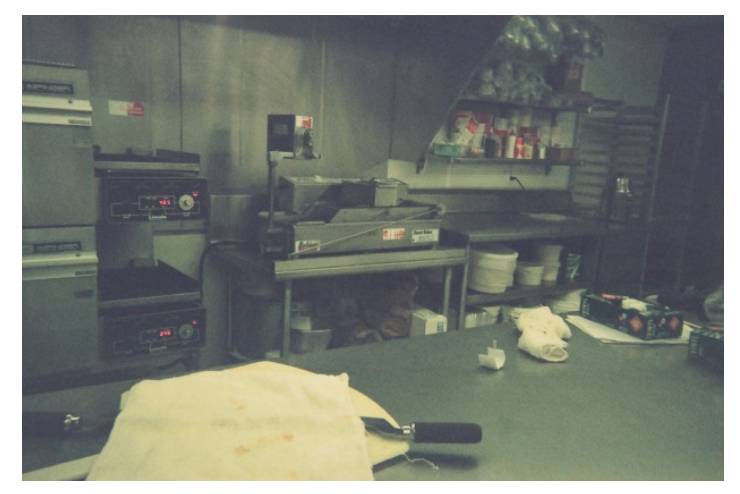

Recreation, romantic relationships, and spiritual expression were also aspects of life where participants often can't perform as expected. Almost all participants gave examples of leisure activities they did before their neuropathy, that have now changed. For example, one participant was limited in how long he could play the drums before his hands hurt; one participant loved participating on the bowling team, but could now only play three games before her hands hurt; one participant loved lacrosse, but could not run without pain, so now she takes yoga classes. Romantic relationships can also be impacted, as physical intimacy can be painful, as well. One participant reported even holding hands caused pain. Spirituality is impacted for those who use their bodies as a part of their spiritual expression, but now have difficulty manipulating their bodily 
movements to maintain a position without pain. One participant reflects that the experience of CIPN has been globally life-altering:

"It's kind of like that weird-- I don't know where I would be. I think I'd be in somewhere completely different if I didn't have neuropathy or the tumors or anything like that. I think it would be a completely different life path." - Participant 7

\section{Disconnection Between Survivors and Support}

All survivors voiced frustration that CIPN is difficult to explain, and therefore, difficult for others in their life to understand. This lack of understanding and appreciation lead to lack of support in a multitude of settings. Additionally, CCS are often having to challenge hierarchal relationships to ask for support. For example, adolescent and young adult survivors of childhood cancers are at a point in their lives where they must fulfill role responsibilities as expected by parents, coaches, teachers, and bosses. They often described situations where they were not empowered or felt they were unequipped to challenge the role expectations held by leaders in their life. At home, when parents and other family members don't comprehend their limited ability to complete chores, the participant may be punished or suffer emotionally from the lack of support.

“Well, I do know, like I was telling you earlier, my mom doesn't really understand it, and she complains all the time...It's hard. It's hard. It kind of makes me mad." - Participant 5

At high school, one participant recalled difficulty participating in required physical activity. She felt that she had a true disability, but since she had the physical appearance that she was capable, she could not describe her limitations to her coaches. One participant described the need to wear supportive footwear at her work setting, but her boss will asked her to change her shoes because they do not portray the image of the 
high-end retail store. Participants felt this lack of ability to explain their limitations and abilities resulted in little modifications to their role responsibilities, and therefore, the survivors had to continue participating in tasks that they knew would elicit or worsen their symptoms. CIPN is described as an "invisible disability" which made it even more difficult for participants to ask for modifications to their expected responsibilities.

“-- and because there's not a lot of words you can use to describe it to get your message across to people, so that they can fully comprehend what it's like for you" - Participant 1

In the community setting, participants expressed challenges they faced when they were judged by people in the community. One participant was often verbally attacked for using handicap parking spaces, since people did not appreciate her disability visibly. In social settings, one participant was kicked out of a bar while socializing with friends. She appeared to be intoxicated due to her abnormal gait caused by her severe bilateral foot drop. She was too embarrassed to explain that she was not intoxicated, but rather, she had a disability. While experiencing judgement from those in the community was less distressing than experiencing lack of support from those who knew them well, it was a message that reinforced their disconnection from needed support.

Photograph 6. "I'm actually disabled, I'm not using my grandmother's tag"

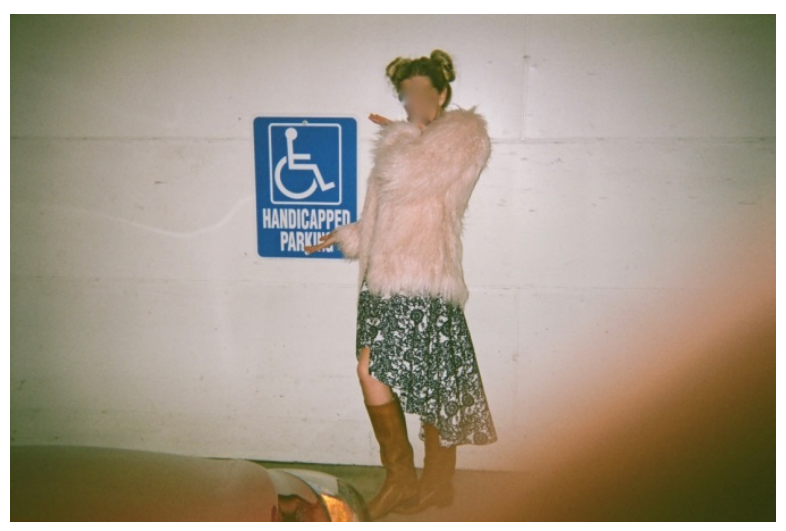


CCS with CIPN also felt disconnected from medical support. CCS sensed that healthcare providers do not understand their condition, and as a result, CCS had low faith in interventions. These CCS had tried a variety of approaches for management, from medication to medical devices. Physical therapy was commonly reported, although few appreciated a direct benefit. One participant reported difficulty finding a physical therapist trained to care for CIPN. In addition, survivors felt that CIPN varied from other types of peripheral neuropathy, such as diabetic neuropathy, and reported a perceived lack of benefit from therapy that was generalized from other neuropathic conditions. As a result, participants often tried to cope on their own by using a variety of self-developed strategies. Some participants relied on exercise and stretching, while almost all had found unique strategies. For example, two participants reported using objects, such as a ball in their pocket or a wall, to touch to regain sensation or a sense of grounding. "And I feel like neuropathy is a very small box that you get put into...And its usually diabetic patients that I get put in a box with...But I get put in this non-cancerous, peripheral neuropathy box that has no bearing”- Participant 7

\section{Discussion}

The purpose of this study was to illustrate the lived experience of CIPN among CCS. Findings show that CIPN is characterized as a condition of disconnection that results in broad functional and emotional impact. CIPN is a highly personal experience, where each participant had unique physical and emotional manifestations of disconnection. CCS may use a variety of symptom quality, timing, and intensity descriptors, while collectively conveying a sense of disconnection between mind and body. Symptom distress among participants is disproportionately low compared to the 
significant impact on physical performance and emotional outcomes. Many participants had resolved to "fight through it," and as a result, presented to their family, friends, community, and healthcare providers with little distress regarding their symptoms. This likely contributed to the disconnect survivors felt exists between their symptoms and the healthcare support they need. In a reciprocal way, participants sensed their healthcare providers under-appreciate the significance of this condition. Many factors have likely contributed to the under-appreciation of CIPN (Markman, 2006). These findings add to this literature by expanding what is known of the physical and emotional impact of CIPN among CCS, specifically in a population of adolescents and young adults.

To our knowledge, this is the first report of emotional implications of living with chronic CIPN among CCS. Disconnection experienced between mind and body causes frustration. Participants felt frustration 'in the moment,' as they attempted to achieve a certain task, but failed as they could not control their bodily movements. Disconnection between expected potential and reality resulted in sadness, and, in the worst outcomes, a feeling of worthlessness. Specifically, in this developmental period, adolescents and young adults can have significant negative outcomes, if they are not able to fulfill their expected social roles (identity vs. role confusion) or make meaningful, connected relationships (identify vs. isolation) (Erikson, 1993). The impact of disrupted normal developmental tasks distinguishes these findings from reports of adults with CIPN (Bakitas, 2007; Tofthagen, 2010a). Disconnection between survivors and support causes hopelessness. Oftentimes, participants report not discussing symptoms with their healthcare providers since they did not expect there were any impactful treatment 
options. Due to the disconnection, CCS are often dealing with the emotional impact of CIPN alone.

The secondary purposes of this study were to demonstrate how CIPN affects school, vocational performance, and quality of life among CCS. All participants identified at least one impact on school and/or vocation, while many experienced a broad impact. In addition to challenges in physically participating in work-associated activities, CCS with CIPN are at risk for a poor career trajectory. This finding adds to previous work on vocational impact among adults with cancer who experience CIPN, by appreciating that the early age of treatment and the development of CIPN leads to earlier time of career impact. It would be anticipated that earlier age at career impact would have a greater impact on their life-time career trajectory. Adult cancer survivors with CIPN have previously reported difficulty with vocation and leisure activities (Bakitas, 2007; Tofthagen, 2010a). This study expands understanding by adding the perspective of developing adolescents and young adults.

\section{Strength and Limitations}

While this study adds to the literature by illuminating a poorly described health condition among CCS, the following limitations must be acknowledged. First, two of the seven participants were lost to follow-up. These two participants were called at the twoweek interval, and further questions regarding the photographic assignment were clarified. Each participant was called after the camera was not returned at the assigned one-month interval. Both confirmed their desire to participate, but had changes in their current life situation that they identified as barriers to completing the photographic portion in a timely manner. Ultimately, the cameras were never returned and interviews 
were not completed. While the researcher believes saturation was achieved, the potential for new findings among these two potential participants cannot be ruled out. Both participants lost to follow-up self-identified as African American, and the lack of their perspectives is an obvious weakness regarding the potential diversity of experiences that cannot be reported. Second, there were practical limitations to collecting photographic data. Unfortunately, two rolls of film were accidentally destroyed by the photo-processor. Fortunately, the participants who generated these photos either remembered significant images, or took notes regarding their photographs, so we could discuss their photographs during the in-depth interview. It must be acknowledged, potentially photographs were taken that were not discussed during the interview. Also, the researcher-generated reflections on those images could not be made.

This research was strengthened by utilizing innovative methods in attempts to understand a phenomenon that is difficult to describe and measure. While previous studies have acknowledged the challenges of identifying and describing CIPN, photographs were unique tools to give voice to the experience that is otherwise not reported. This study also included patients that represent a variety of primary cancer diagnoses, and thus, a variety of chemotherapeutic exposures. Such variety broadens the understanding of this condition among a more-representative sample of CCS compared to previous studies that primarily utilize survivors of childhood leukemia (Jain et al., 2013; Lavoie Smith et al., 2015; Ramchandren et al., 2009). Lastly, the sample included patients many years from the completion of therapy, which provides a unique insight into the chronicity of this condition. 


\section{Conclusion}

CCS experiencing CIPN long after the completion of cancer therapy are at risk for global functional and emotional impact on their daily lives. Symptom variability is present within and between patients, but the following over-arching themes of disconnection summarizes the symptom experience: disconnect between mind and body, disconnect between anticipated potential and reality, and disconnect between survivors and support. Findings from this research support findings from previous studies of adult survivors with CIPN, that while symptoms improve for many patients after treatment has ended, a subset of patients have persistent and significantly impactful symptoms (Driessen et al., 2012; Tofthagen et al., 2012). This research expands on previous findings to illuminate the difference in symptom experience among those treated for cancer at a younger age, and, therefore, dealing with chronic late effects of cancer therapy during crucial periods of development. Future researchers should utilize these findings to guide the development of interventions that support building the connections these survivors lack. Interventions should include emotional support, in addition to focus on improved physical performance. Clinicians caring for CCS should evaluate their patients for CIPN, knowing they are less likely to disclose their struggles with CIPN, and, at a minimum, offer strategies for emotional support to assist those living with this chronic condition as a result of their cancer therapy. 
The second section of Chapter 4 following the results manuscript provides a brief reflection on the use of photo-elicitation as a method of inquiry with adolescent and young adult $\mathrm{CCS}$.

\section{Photo-elicitation as a Method of Inquiry with Adolescents and Young Adults}

The use of arts-based visual methods in healthcare research is on the rise as researchers have found these methods useful not only for knowledge creation, but also for knowledge translation (Fraser \& al Sayah, 2011). Art-based visual methods can include photographs, drawings, paintings, poetry, video, and even performance theatre. Visual or arts-based methods have been used to increase participant control through empowerment, as well as to understand patient experiences that cannot be elicited through traditional qualitative or quantitative methods (Boydell, Gladstone, Volpe, Allemang, \& Stasiulis, 2012). The use of arts-based visual methods encourages patients to share stories, beliefs, and life situations which assists healthcare providers by improving understanding between patients and healthcare providers, and by ultimately facilitating their clinical decision-making (Frith \& Harcourt, 2007). The dissertation research presented utilized participant-generated images to understand CIPN among CCS due to limitations in previously-reported instruments used to evaluate this condition. Special considerations made due to the use of photo-elicitation, as well as a reflection on the utility of these methods, will be discussed.

\section{Photo-elicitation}

The photo-elicitation method uses photographs taken by the researcher or participants to enhance participant's expression of their experience by creating a comfortable space, improving memory, and invoking comments. This method has also 
been used to lessen the perceived hierarchical relationship between investigator and participant (Epstein, Stevens, McKeever, \& Baruchel, 2008). In this dissertation, there were three possible reasons for the perception of a hierarchical relationship: (1) Researcher vs. Participant, (2) Healthcare Provider vs. Patient, and (3) Adult vs. Adolescent/Young Adult. The researcher believes photo-elicitation was useful in breaking down the perceived hierarchical relationships to improve the quality of data gathered. Once photographs were introduced during the in-depth interview, participant responses seemed longer, and participants often shared more opinions regarding healthcare providers. Participants seemed more empowered when discussing their photographs, compared to the researcher-led part of the interview. Using photographs did improve recall to allow for increased sharing of the participant's experience. There were many occasions where a participant was viewing a photo and admitted they had forgotten the point they wanted to share until they saw the photograph again. Many of these instances provided significant insight to the researcher. From a developmental standpoint, these adolescents and young adults were excited to take photographs and share their experience, and did not act as though the activity was too juvenile.

\section{Data Analysis}

There are aspects of analyzing photographic data where the researchers must be particularly careful and reflective. When using photographs as primary data, the researcher needs to be wary of the ability of the photographer to manipulate and influence an image. Cautious discussion of the photograph with the photographer is necessary to avoid hasty interpretations. For example, one participant was not able to remember why she took a certain photograph, and although I had assumptions as to what the photograph 
represented, I decided to exclude those assumptions in the data analysis to avoid the risk of making an interpretation that did not represent her experience. Interpretations should be systematic, rather than passive. The duality of photographic data is that it may be concrete and have more abstract representation simultaneously (Drew \& Guillemin, 2014). The researcher also needs to consider that there may be "missing photographs." Participants may have significant experiences to share that they are unable to photograph and the researcher should address this potential (Frith \& Harcourt, 2007). This did occur on two occasions during my interviews. For one example, a participant was asked if there were any experiences she could not photograph, and she explained that she wanted to photograph an overhead view of her college campus to illustrate the challenges she experiences walking long distances.

\section{Ethical and Practical Considerations}

In attempts to collect data ethically, I engaged each participant in a discussion regarding the ethics of the photographs prior to the start of their study participation. Also, there was a statement at the end of their instruction sheet for the photographic portion instructing them to avoid taking pictures of illegal activity. Fortunately, no illegal activity was captured in the photographs. In contrast to many projects employing the Photovoice method, my utilization of photo-elicitation required the protection of participant's anonymity (Clark, Prosser, \& Wiles, 2010). Therefore, the decision was made to blur faces in photographs used as a part of the data reporting. From a practical perspective, there were issues with film development. I would recommend using digital photographs when possible. When the project budget allows, smart phones or digital cameras can be 
used with a secure digital drop box to allow for participation from a distance, when necessary.

\section{Conclusion}

Researchers have found visual methods benefit their study in terms of recruitment, retention, and data analysis. As a relatively new method, there are several areas of development needed to strengthen and further promote its use in healthcare. Using visual methods requires a number of ethical considerations that must be fully evaluated by the research team prior to the project implementation. The rationale behind the decision to utilize visual methods has not always been clear, as well as the process for data analysis. The process from "photographs to findings" needs to be demystified and reported clearly in research reports. Researchers must be diligent to ensure their findings are representative of the participant's experience and further methods to evaluate scientific rigor and trustworthiness are required.

Although there are potential improvements to strengthen photographic methods, using photographs in this dissertation research assisted in telling the story of research participants with more insight, emotion, and depth, while empowering research subjects to inform those that provide their healthcare. Photographic methods can break-down barriers for those unable or unlikely to participate in healthcare research, which as a result gives voice to those previously unheard by their healthcare providers. Deeper understanding of these patients' experience can change how care is provided to patients, their families, and their communities. 


\section{References}

Armenian, S. H., Landier, W., Hudson, M. M., Robison, L. L., \& Bhatia, S. (2013). Children's Oncology Group's 2013 blueprint for research: Survivorship and outcomes. Pediatric Blood \& Cancer, 60(6), 1063-1068. https://doi.org/10.1002/pbc. 24422

Armstrong, T., Almadrones, L., \& Gilbert, M. (2005). Chemotherapy-Induced Peripheral Neuropathy. Oncology Nursing Forum, 32(2), 305-311. https://doi.org/10.1188/05.ONF.305-311

Bakitas, M. A. (2007). Background noise: the experience of chemotherapy-induced peripheral neuropathy. Nursing Research, 56(5), 323-331. https://doi.org/10.1097/01.NNR.0000289503.22414.79

Boydell, K. M., Gladstone, B. M., Volpe, T., Allemang, B., \& Stasiulis, E. (2012). The Production and Dissemination of Knowledge: A Scoping Review of Arts-Based Health Research. Forum Qualitative Sozialforschung / Forum: Qualitative Social Research, 13(1). Retrieved from http://www.qualitativeresearch.net/index.php/fqs/article/view/1711

Catalani, C., \& Minkler, M. (2010). Photovoice: A Review of the Literature in Health and Public Health. Health Education \& Behavior, 37(3), 424-451. https://doi.org/10.1177/1090198109342084

Chung, T., Prasad, K., \& Lloyd, T. E. (2014). Peripheral Neuropathy. Neuroimaging Clinics of North America, 24(1), 49-65. https://doi.org/10.1016/j.nic.2013.03.023

Clark, A., Prosser, J., \& Wiles, R. (2010). Ethical issues in image-based research. Arts \& Health, 2(1), 81-93. https://doi.org/10.1080/17533010903495298 
Drew, S., \& Guillemin, M. (2014). From photographs to findings: visual meaningmaking and interpretive engagement in the analysis of participant-generated images. Visual Studies, 29(1), 54-67. https://doi.org/10.1080/1472586X.2014.862994

Driessen, C. M. L., de Kleine-Bolt, K. M. E., Vingerhoets, A., Mols, F., \& Vreugdenhil, G. (2012). Assessing the impact of chemotherapy-induced peripheral neurotoxicity on the quality of life of cancer patients. Supportive Care in Cancer, 20(4), 877-881.

Eckhoff, L., Knoop, A., Jensen, M. B., \& Ewertz, M. (2015). Persistence of docetaxelinduced neuropathy and impact on quality of life among breast cancer survivors. European Journal of Cancer (Oxford, England: 1990), 51(3), 292-300. https://doi.org/10.1016/j.ejca.2014.11.024

Emden, C. (1998). Theoretical perspectives on narrative inquiry. Collegian, 5(2), 30-35. https://doi.org/10.1016/S1322-7696(08)60281-4

Epstein, I., Stevens, B., McKeever, P., \& Baruchel, S. (2008). Photo Elicitation Interview (PEI): Using Photos to Elicit Children's Perspectives. International Journal of Qualitative Methods, 5(3), 1-11.

Erikson, E. H. (1993). Childhood and Society. W. W. Norton \& Company. Ezendam, N. P. M., Pijlman, B., Bhugwandass, C., Pruijt, J. F. M., Mols, F., Vos, M. C., ... van de Poll-Franse, L. V. (2014). Chemotherapy-induced peripheral neuropathy and its impact on health-related quality of life among ovarian cancer survivors: results from the population-based PROFILES registry. Gynecologic Oncology, 135(3), 510-517. https://doi.org/10.1016/j.ygyno.2014.09.016 
Fraser, K. D., \& al Sayah, F. (2011). Arts-based methods in health research: A systematic review of the literature. Arts \& Health, 3(2), 110-145. https://doi.org/10.1080/17533015.2011.561357

Frith, H., \& Harcourt, D. (2007). Using photographs to capture women's experiences of chemotherapy: Reflecting on the method. Qualitative Health Research, 17(10), $1340-1350$.

Gilchrist, L. (2012). Chemotherapy-Induced Peripheral Neuropathy in Pediatric Cancer Patients. Seminars in Pediatric Neurology, 19(1), 9-17. https://doi.org/10.1016/j.spen.2012.02.011

Hagedorn, M. R. (1994). Hermeneutic photography: An innovative esthetic technique for generating data in nursing research. Advances in Nursing Science Esthetics and the Art of Nursing, 17(1), 44-50.

Hudson, M., Ness, K., Gurney, J., Mulrooney, Chemaitilly, Krull, ... Robison. (2013). Clinical ascertainment of health outcomes among adults treated for childhood cancer. JAMA, 309(22), 2371-2381. https://doi.org/10.1001/jama.2013.6296

Jain, P., Gulati, S., Seth, R., Bakhshi, S., Toteja, G. S., \& Pandey, R. M. (2013). Vincristine-induced Neuropathy in Childhood ALL (Acute Lymphoblastic Leukemia) Survivors Prevalence and Electrophysiological Characteristics. Journal of Child Neurology, 883073813491829. https://doi.org/10.1177/0883073813491829

Kottschade, L. A., Sloan, J. A., Mazurczak, M. A., Johnson, D. B., Murphy, B. P., Rowland, K. M., ... Loprinzi, C. L. (2010). The use of vitamin E for the prevention of chemotherapy-induced peripheral neuropathy: results of a 
randomized phase III clinical trial. Supportive Care in Cancer, 19(11), 17691777. https://doi.org/10.1007/s00520-010-1018-3

Lavoie Smith, E. M., Li, L., Chiang, C., Thomas, K., Hutchinson, R. J., Wells, E. M., ... Renbarger, J. (2015). Patterns and severity of vincristine-induced peripheral neuropathy in children with acute lymphoblastic leukemia. Journal of the Peripheral Nervous System: JPNS, 20(1), 37-46. https://doi.org/10.1111/jns.12114

Lenz, E. R., Pugh, L. C., Milligan, R. A., Gift, A., \& Suppe, F. (1997). The MiddleRange Theory of Unpleasant Symptoms: An Update. Advances in Nursing Science, 19(3), 14-27.

Lopez, K. A., \& Willis, D. G. (2004). Descriptive Versus Interpretive Phenomenology: Their Contributions to Nursing Knowledge. Qualitative Health Research, 14(5), 726-735. https://doi.org/10.1177/1049732304263638

Markman, M. (2006). Chemotherapy-induced peripheral neuropathy: underreported and underappreciated. Current Pain and Headache Reports, 10(4), 275-278.

Miller, S. (2003). Analysis of phenomenological data generated with children as research participants. Nurse Researcher, 10(4), 68.

Mohrmann, C., Armer, J., \& Hayashi, R. J. (2016). Challenges Evaluating Chemotherapy-Induced Peripheral Neuropathy in Childhood Cancer Survivors Which Instrument Should Nurses Use? Journal of Pediatric Oncology Nursing, 34(2), 1-9.

Ramchandren, S., Leonard, M., Mody, R. J., Donohue, J. E., Moyer, J., Hutchinson, R., 
\& Gurney, J. G. (2009). Peripheral neuropathy in survivors of childhood acute lymphoblastic leukemia. Journal of the Peripheral Nervous System, 14(3), 184189. https://doi.org/10.1111/j.1529-8027.2009.00230.x

Richards, L., \& Morse, J. M. (2012). README FIRST for a User's Guide to Qualitative Methods. SAGE.

Sandelowski, M. (1991). Telling stories: narrative approaches in qualitative research. Image: Journal of Nursing Scholarship, 23(3), 161-166.

Sandelowski, M. (1993). Theory unmasked: the uses and guises of theory in qualitative research. Research in Nursing \& Health, 16(3), 213-218.

Sandelowski, M. (1995). Sample size in qualitative research. Research in Nursing \& Health, 18(2), 179-183.

Seretny, M., Currie, G. L., Sena, E. S., Ramnarine, S., Grant, R., MacLeod, M. R., ... Fallon, M. (2014). Incidence, prevalence, and predictors of chemotherapyinduced peripheral neuropathy: A systematic review and meta-analysis. $P A I N 囚$, 155(12), 2461-2470. https://doi.org/10.1016/j.pain.2014.09.020

Tofthagen, C. (2010a). Patient perceptions associated with chemotherapy-induced peripheral neuropathy. Clinical Journal of Oncology Nursing, 14(3), E22-28. https://doi.org/10.1188/10.CJON.E22-E28

Tofthagen, C. (2010b). Surviving Chemotherapy for Colon Cancer and Living with the Consequences. Journal of Palliative Medicine, 13(11), 1389-1391. https://doi.org/10.1089/jpm.2010.0124

Tofthagen, C., Overcash, J., \& Kip, K. (2012). Falls in persons with chemotherapyinduced peripheral neuropathy. Supportive Care in Cancer, 20(3), 583-589. 
Wampler, M. A., Topp, K. S., Miaskowski, C., Byl, N. N., Rugo, H. S., \& Hamel, K. (2007). Quantitative and clinical description of postural instability in women with breast cancer treated with taxane chemotherapy. Archives of Physical Medicine and Rehabilitation, 88(8), 1002-1008. 
Figure 2. The Experience of CIPN: A Condition of Disconnection

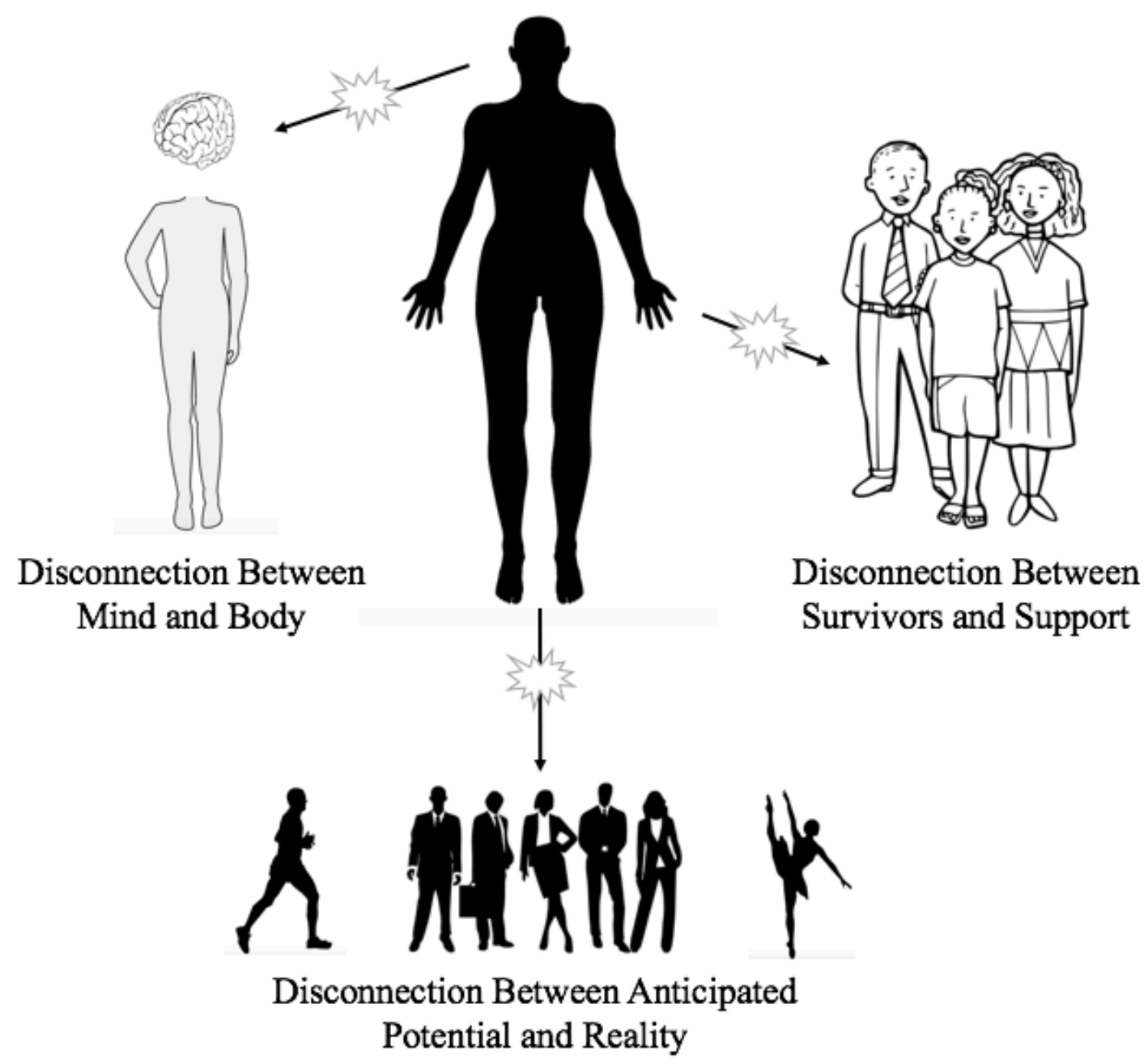


Figure 3. Between- vs. Within-Participant Symptom Variability

\begin{tabular}{|c|c|c|c|c|}
\hline \multicolumn{3}{|c|}{ Between-Participant Variability } & \multicolumn{2}{|c|}{ Within-Participant Variability } \\
\hline $\begin{array}{l}\text { Numbness, } \\
\text { Tingling }\end{array}$ & $\begin{array}{l}\text { Burning, } \\
\text { Electrical }\end{array}$ & $\begin{array}{l}\text { Frozen, } \\
\text { Cramping }\end{array}$ & $\begin{array}{l}\text { Tingling } \\
\text { in Hands }\end{array}$ & $\begin{array}{c}\text { Numbness } \\
\text { in Feet }\end{array}$ \\
\hline
\end{tabular}


Figure 4. Symptom Quality Word Cloud

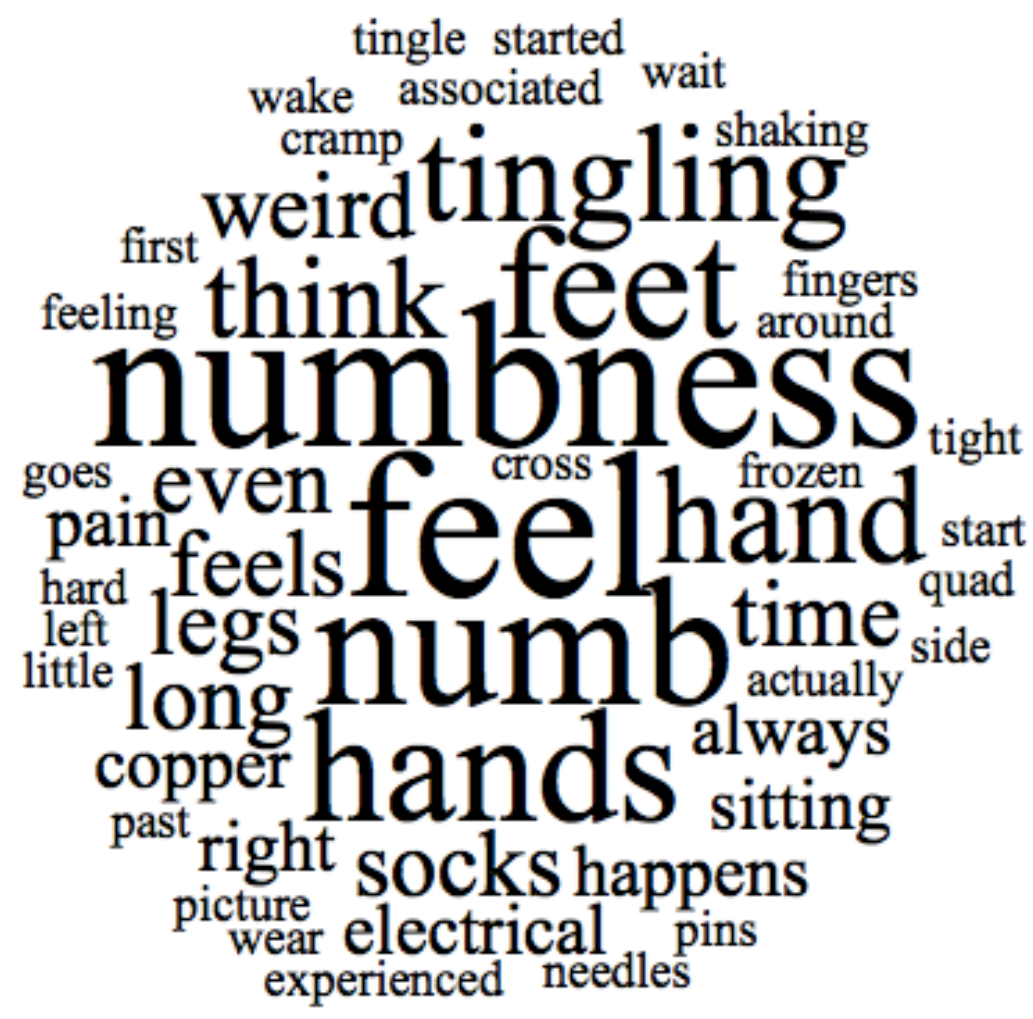




\section{CHAPTER 5}

\section{CONCLUSION}

Treatment for childhood cancer has significantly improved, not only in regards to increased rates of overall survival, but also by utilizing treatment strategies focused on minimizing late effects of childhood cancer therapy (Oeffinger et al., 2006; Salloum et al., 2017; Turcotte et al., 2017). While these commendable efforts have contributed to improved care for childhood cancer patients, late effects of cancer therapy continue to cause significant morbidity and mortality (Cox et al., 2014; Printz, 2015). As a result, a new population has emerged of children, adolescents, and adults who have survived cancer during childhood and now require specialized health screening and health promotion activities. These survivors have unique healthcare needs due to their previous exposure to chemotherapy, radiation, surgery, and other treatment modalities required to cure them of their disease. The needs of this population have been explored during the past few decades with a focus on identifying exposure-based health risks (Armenian, Landier, Hudson, Robison, \& Bhatia, 2013). Armenian et al. (2013) have identified goals for future research of childhood cancer survivors (CCS) that includes continuing to identify the pathophysiology of adverse health outcomes and designing methods to reduce long-term morbidity and mortality.

The persistent experience of peripheral neuropathy symptoms, as induced by chemotherapy, radiation, or surgery, has been identified as an area needing further research (Gilchrist, 2012). There are a limited number of studies that evaluate long-term peripheral neuropathy in children, with almost all studies focused on electrophysiology 
and motor functioning in children with acute lymphoblastic leukemia (Harila-Saari, Huuskonen, Tolonen, Vainionpää, \& Lanning, 2001; Jain et al., 2013; Ness et al., 2013; Ramchandren et al., 2009). Without validated patient assessment instruments, peripheral neuropathy has been difficult for healthcare providers to understand, diagnose, and treat (Gilchrist, Marais, \& Tanner, 2013). In addition, the longer-term impact of peripheral neuropathy is not understood, although there is evidence that symptoms persist far beyond the end of treatment for many childhood cancer survivors (Gilchrist, Tanner, \& Ness, 2017). Understanding the patient's symptom experience of the phenomenon of persistent peripheral neuropathy, and the impact and patient responses to those symptom experiences, will aid in the future development and testing of possible interventions. The dissertation research presented illustrates the lived experience of chronic chemotherapyinduced peripheral neuropathy (CIPN) in a population of long-term CCS, which is characterized as a disease of disconnection. Instrumental to the development of the research plan, as well as the data analysis, was the middle-range Theory of Unpleasant Symptoms (TOUS). This chapter will discuss the benefits of the TOUS for use in CIPN research. A visual model of the symptom experience of CIPN among CCS will be presented. This chapter will conclude with a discussion of how to utilize this model for the development of more sensitive and specific instruments to measure CIPN, treatment strategies, and education.

\section{Utilizing the TOUS for CIPN Research}

Briefly, the TOUS explains the symptom experience in terms of influencing factors that impact a patient's symptom experience, which results in a patient's performance. There are complex, multi-directional relationships between these variables 
(Myers, 2009). In addition, those utilizing this theory must appreciate that symptoms can occur in clusters (Dodd, Miaskowski, \& Lee, 2004). Smith and Liehr (2013) note three strengths of the theory: it may be applied to various symptoms, it acknowledges that symptoms are multidimensional, and it considers that patients are usually experiencing more than one symptom (Smith \& Liehr, 2013). Also, the TOUS's level of abstraction allows for application of the theory to a variety of patient populations for evaluation of their symptom experience. The theorists also believe the level of abstraction is appropriate for the development of nursing interventions (Lenz, Pugh, Milligan, Gift, \& Suppe, 1997). The theory was an appropriate guide for the dissertation research, as the TOUS provides a framework that encompasses aspects of the CIPN symptom experience that have not been found in reported literature to date. Utilizing the TOUS as a framework for the dissertation research allowed for a more detailed assessment to be performed in order to provide new knowledge to the field that did not previously exist.

Previous studies using the TOUS chose a multitude of measurement tools due to the complex interaction between symptoms and their antecedents, and the recommendation by the theorists to measure each symptom individually (Lenz et al., 1997). In-depth interviews were conducted as a part of the dissertation research to gain perspective in the patient's experience with CIPN, and it was essential to develop interview questions carefully to evaluate each symptom, antecedent, and performance measure individually, rather than select a variety of measurement tools. This method was favored, as the assumption was held that there is much about the patient's experience that can be discovered by open-ended questions, rather than using standardized tools. This is especially true in the study of this phenomenon in this population of CCS, because 
standardized tools developed for pediatric neuropathy in general are scant and those developed are small in scope ( Gilchrist, Marais, \& Tanner, 2013; Smith et al., 2013). Previous quantitative studies have used tools to define the significance of neuropathy as interpreted by the measurable changes in nerve conduction studies or decreased degree of dorsiflexion (Ramchandren et al., 2009). These quantitative studies are missing important dimensions of the symptom experience, and therefore, a qualitative study was performed.

The analysis of the findings in the dissertation research was complex, as would be expected when analyzing the multifaceted, bi-directional relationships between multiple variables. The evaluation revealed findings that represent the relationships between the variables, and visual models are a succinct way to explain the identified relationships. The intent of the dissertation research was to identify details of the CCS's experience with neuropathy in greater detail than has been reported previously, and the visual model was created based on the TOUS to clearly display newly-identified factors influencing the symptom experience. This model can be used to develop intervention trials to affect modifiable, negative variables influencing the survivor's experience of peripheral neuropathy.

\section{A Model of CIPN Among CCS}

During the initial phase of data analysis, interpretive statements were extracted. While reviewing and re-organizing the interpretive statements, it became apparent that aspects of the TOUS were present within the data. At that point, the author created codes to represent each theoretical concept within the TOUS. The TOUS functioned to rerepresent the data after the preliminary stages of analysis, carefully, without distorting the data (Sandelowski, 1993). All transcripts were reviewed and significant statements were 
identified that represented all aspects of the TOUS. Reflective memo-ing was performed as each code was reviewed (Birks, Chapman, \& Francis, 2008). After initial memos were reviewed, lists were created within each memo as phrases or terms were identified that helped define or describe each aspect of the TOUS. Diagraming was performing within the TOUS theoretical model to examine relationships among theoretical elements as demonstrated in the phenomenon of CIPN (Finfgeld-Connett, 2014). Lastly, a visual model of the experience of CIPN was created to illustrate the lived experience among CCS (Figure 1). While the symptom experience was found to be highly personal, aspects of the model were captured across CCS' reports to develop the detailed model. Bidirectional relationships between aspects of the theoretical model are represented.

\section{Influencing Factors}

Consistent with the TOUS, psychologic factors, physiologic factors, and situational factors were identified. Psychologic factors stemmed from the lack of understanding surrounding the condition of CIPN. CCS with CIPN expressed their symptoms were difficult to understand, and therefore, difficult to manage. Since CCS had difficulty understanding and predicting their symptoms, their symptom experience was often heightened by activities in their daily life. One CCS detailed her attempts to exercise with the goal of gaining strength she lost as a result of her CIPN, but she didn't understand how to gain the strength and sensation she has lost. Damage to healthy tissues through injury caused by lack of sensation represents a physiologic influencing factor.

A variety of situational factors were identified by CCS that influence their CIPN symptoms. Weather, temperature, physical space, and clothing were aspects of survivors' physical environment that induced or worsened their symptoms. Adverse weather, such 
as rain, ice, snow, and wind, can make walking outside more difficult. Aspects of the physical space either led to pain (cramped spaces) or made mobility more difficult (large distances, low-lighting, and crowds). Interestingly, clothing was identified as a trigger for unpleasant symptoms. Survivors noted they had difficulty finding footwear that was supportive, but not too compressive. Lack of support and too much compression both led to pain in CCS with CIPN symptoms in their feet.

A variety of aspects of CCS work environment can impact the symptom experience. The physicality or repetitiveness of work tasks, prolonged standing, or holding equipment were all reported to worsen symptoms. Lack of social support was a significant factor influencing symptoms. Similar to CCS, those in their social network also had difficulty understanding CIPN, and, therefore, were not supportive of needed modifications to the survivor's role or physical participation. As a result, survivors often continued to participate in activities that negatively influenced their symptoms. Likewise, survivors have not identified healthcare resources to support or improve their symptoms. Lifestyle factors, such as exercise or leisure activity, can unfortunately lead to pain or other negative symptoms as well.

\section{Symptom}

The TOUS has four aspects of the symptom experience: intensity, timing, quality, and distress (Lenz et al., 1997). The intensity of CIPN among CCS varies over time and is significantly impacted by the influencing factors. The timing of CIPN symptoms is often unexpected, although, CCS may anticipate symptoms after certain activities. Some survivors reported symptoms improved since the end of their treatment, while others 
reported a stable or worsening symptom experience. When the symptom was experienced, the duration was widely variable, and, often, unpredictable.

Symptom quality was highly personal. While numbness and tingling were often

reported, a number of symptom quality descriptors were used, and are represented within the visual model. All patients reported the task of describing the symptom quality was often difficult because the sensations were overall so "weird." Symptom distress was overall low. Many patients have identified living with CIPN became a "new normal." One CCS commented the lack of symptoms is now abnormal.

\section{Performance}

Disproportionate to the low level of distress, performance outcomes were highly impacted. Again, while each survivor may experience a unique set of performance outcomes, there is potential for a wide scope of negative performance outcomes. CCS' physical performance can be impacted in many aspects of their daily life, from activities of daily living, to relationships, to spirituality. Many negative cognitive outcomes are also possible. As CCS are unable to fulfill their life-role responsibilities or achieve their vocational goals, they may experience frustration, stress, worthlessness, and other negative emotions.

\section{Implications for Future Research, Practice, and Education}

Using the TOUS to display the experience of CIPN among CCS creates a visual model that may be utilized by researchers and clinicians caring for this population, and highlights unique findings of the dissertation research. The visual model represents a significant number of situational factors that influence the symptom experience that were not identified in the pediatric cancer survivor literature to date. The identification of such 
a large number of influencing factors highlights the value of using a theoretical model to design and interpret interview data. Previous research has most often focused on a single aspect or functional outcome that results from the CIPN experience, rather than a global understanding of the experience. By utilizing the TOUS, previously unknown factors can now be explored and interventions can be designed with an appreciation for the complex interaction between influencing factors, symptoms, and performance for each CCS.

Previously-tested interventions to improve or ameliorate CIPN symptoms have not been widely successful. Pharmacological interventions have not been effective in general and rarely focus on pediatric patients (Tofthagen, Visovsky, \& Hopgood, 2013; Visovsky, Collins, Abbott, Aschenbrenner, \& Hart, 2007). Non-pharmacological interventions have focused on managing an aspect of the CIPN symptom experience, and no large trials to date have been identified that significantly improve symptoms (Visovsky et al., 2007). It has been proposed that methodological and instrumental limitations are contributing to unfavorable results (Poupon et al., 2015). The findings from this research support the theoretically-based approach to symptom assessment and symptom intervention. Essentially, a more holistic approach is needed for this complex symptom experience. Improvement in symptom assessments would include: strategies for evaluating the multi-dimensional experience, evaluation tools that account for a highlypersonalized experience, and evaluation tools that screen for a wide variety of performance outcomes in addition to aspects of the symptom experience alone. Future interventions should take into account the significant number of influencing factors presented in the visual model. Modifiable influencing factors should be a target for intervention, and non-modifiable influencing factors should be a focus for areas in which 
to provide support for coping. Educating patients to understand and describe their symptoms is key for improving support in a variety of social and vocational settings.

The visual model should be considered in conjunction with the three aspects of disconnection presented in the original research findings: disconnection between mind and body; disconnection between anticipated potential and reality; and disconnection between survivors and support (Mohrmann, 2017). Understanding of the disconnection between mind and body is enhanced by the display of the influence of the "symptoms" on patient "performance" in the visual model. Physiologic and psychologic influencing factors further illustrate the complexity of the mind and body disconnection experience. For example, the lack of the survivor's understanding of CIPN, represented in the psychological factor, influences how patients are unable to make sense of the abnormal sensations and unpredictable timing of CIPN represented in the symptom aspect of the model. All survivors reported modification to their lifestyle and a variety of negative emotional performance outcomes, which represent disconnection between anticipated potential and reality. In addition, some of the more unexpected situational factors, such as weather, physical space, or garment compression, lead to worsening symptoms that negatively impacted their performance. Disconnection between survivors and support are seen in many of the situation influencing factors, such as poor social support and lack of healthcare resources.

\section{Conclusion}

Symptom management is an important focus of nursing care and research. CIPN is a troublesome symptom that may persist long after treatment for childhood cancer and significantly impacts the lives of those who live with this symptom. This visual model 
representing the experience of CIPN among CCS, as guided by the TOUS, will aid in the development of future research studies attempting to intervene in the lives of these survivors. This model may be used to guide the development of symptom evaluation in clinical practice, development of instrumentation, design of treatment programs, and creation of patient education. This utilization of the TOUS illustrates how middle-range nursing theories can be translated to nursing research and nursing practice. Testing the proposed relationships in this visual model will serve to strengthen the TOUS for future use. 


\section{References}

Armenian, S. H., Landier, W., Hudson, M. M., Robison, L. L., \& Bhatia, S. (2013). Children's Oncology Group's 2013 blueprint for research: Survivorship and outcomes. Pediatric Blood \& Cancer, 60(6), 1063-1068.

https://doi.org/10.1002/pbc.24422

Birks, M., Chapman, Y., \& Francis, K. (2008). Memoing in qualitative research Probing data and processes. Journal of Research in Nursing, 13(1), 68-75. https://doi.org/10.1177/1744987107081254

Cox, C. L., Nolan, V. G., Leisenring, W., Yasui, Y., Ogg, S. W., Mertens, A. C., ... Robison, L. L. (2014). Noncancer-related mortality risks in adult survivors of pediatric malignancies: the childhood cancer survivor study. Journal of Cancer Survivorship. https://doi.org/10.1007/s11764-014-0353-7

Dodd, M. J., Miaskowski, C., \& Lee, K. A. (2004). Occurrence of Symptom Clusters. JNCI Monographs, 2004(32), 76-78.

https://doi.org/10.1093/jncimonographs/lgh008

Finfgeld-Connett, D. (2014). Use of content analysis to conduct knowledge-building and theory-generating qualitative systematic reviews. Qualitative Research, 14(3), 341-352. https://doi.org/10.1177/1468794113481790

Gilchrist, L. (2012). Chemotherapy-Induced Peripheral Neuropathy in Pediatric Cancer Patients. Seminars in Pediatric Neurology, 19(1), 9-17. https://doi.org/10.1016/j.spen.2012.02.011 
Gilchrist, L., Marais, L., \& Tanner, L. (2013). Comparison of two chemotherapy-induced peripheral neuropathy measurement approaches in children. Supportive Care in Cancer, 1-8. https://doi.org/10.1007/s00520-013-1981-6

Gilchrist, L., Tanner, L. R., \& Ness, K. (2017). Short-term recovery of chemotherapyinduced peripheral neuropathy after treatment for pediatric non-CNS cancer. Pediatric Blood \& Cancer, 64(1), 180-187. https://doi.org/10.1002/pbc.26204

Harila-Saari, A. H., Huuskonen, U. E. J., Tolonen, U., Vainionpää, L. K., \& Lanning, B. M. (2001). Motor nervous pathway function is impaired after treatment of childhood acute lymphoblastic leukemia: A study with motor evoked potentials. Medical and Pediatric Oncology, 36(3), 345-351. https://doi.org/10.1002/mpo.1084

Jain, P., Gulati, S., Seth, R., Bakhshi, S., Toteja, G. S., \& Pandey, R. M. (2013). Vincristine-induced Neuropathy in Childhood ALL (Acute Lymphoblastic Leukemia) Survivors Prevalence and Electrophysiological Characteristics. Journal of Child Neurology, 883073813491829.

https://doi.org/10.1177/0883073813491829

Lenz, E. R., Pugh, L. C., Milligan, R. A., Gift, A., \& Suppe, F. (1997). The MiddleRange Theory of Unpleasant Symptoms: An Update. Advances in Nursing Science, 19(3), 14-27.

Mohrmann. (2017). The experience of chemotherapy-induced peripheral neuropathy among childhood cancer survivors. (Manuscript in preparation).

Myers, J. S. (2009). A Comparison of the Theory of Unpleasant Symptoms and the Conceptual Model of Chemotherapy-Related Changes in Cognitive Function. 
Oncology Nursing Forum, 36(1), E1-E10. https://doi.org/10.1188/09.ONF.E1E10

Ness, K. K., Jones, K. E., Smith, W. A., Spunt, S. L., Wilson, C. L., Armstrong, G. T., ... Gurney, J. G. (2013). Chemotherapy-Related Neuropathic Symptoms and Functional Impairment in Adult Survivors of Extracranial Solid Tumors of Childhood: Results From the St. Jude Lifetime Cohort Study. Archives of Physical Medicine and Rehabilitation. https://doi.org/10.1016/j.apmr.2013.03.009

Oeffinger, K. C., Mertens, A. C., Sklar, C. A., Kawashima, T., Hudson, M. M., Meadows, A. T., ... Robison, L. L. (2006). Chronic Health Conditions in Adult Survivors of Childhood Cancer. New England Journal of Medicine, 355(15), 1572-1582. https://doi.org/10.1056/NEJMsa060185

Poupon, L., Kerckhove, N., Vein, J., Lamoine, S., Authier, N., Busserolles, J., \& Balayssac, D. (2015). Minimizing chemotherapy-induced peripheral neuropathy: preclinical and clinical development of new perspectives. Expert Opinion on Drug Safety, 1-14. https://doi.org/10.1517/14740338.2015.1056777

Printz, C. (2015). Majority of survivors of childhood cancer experience comorbidities. Cancer, 121(14), 2293-2293. https://doi.org/10.1002/cncr.29540

Ramchandren, S., Leonard, M., Mody, R. J., Donohue, J. E., Moyer, J., Hutchinson, R., \& Gurney, J. G. (2009). Peripheral neuropathy in survivors of childhood acute lymphoblastic leukemia. Journal of the Peripheral Nervous System, 14(3), 184189. https://doi.org/10.1111/j.1529-8027.2009.00230.x

Salloum, R., Chen, Y., Yasui, Y., Packer, R., Leisenring, W. M., Wells, E. M., ... Armstrong, G. T. (2017). Temporal trends in late-onset morbidity and mortality 
after medulloblastoma diagnosed across three decades: A report from the Childhood Cancer Survivor Study (CCSS). Journal of Clinical Oncology, 35(15_suppl), 10516-10516.

https://doi.org/10.1200/JCO.2017.35.15_suppl.10516

Sandelowski, M. (1993). Theory unmasked: the uses and guises of theory in qualitative research. Research in Nursing \& Health, 16(3), 213-218.

Smith, E. M. L., Li, L., Hutchinson, R. J., Ho, R., Burnette, W. B., Wells, E., ... Renbarger, J. (2013). Measuring Vincristine-Induced Peripheral Neuropathy in Children With Acute Lymphoblastic Leukemia. Cancer Nursing September/October 2013, 36(5). https://doi.org/10.1097/NCC.0b013e318299ad23

Smith, \& Liehr. (2013). Middle Range Theory for Nursing: Third Edition. Springer Publishing Company.

Tofthagen, C., Visovsky, C. M., \& Hopgood, R. (2013). Chemotherapy-induced peripheral neuropathy: an algorithm to guide nursing management. Clinical Journal of Oncology Nursing, 17(2), 138-144.

https://doi.org/10.1188/13.CJON.138-144

Turcotte, L. M., Liu, Q., Yasui, Y., Arnold, M. A., Hammond, S., Howell, R. M., ... Neglia, J. P. (2017). Temporal Trends in Treatment and Subsequent Neoplasm Risk Among 5-Year Survivors of Childhood Cancer, 1970-2015. JAMA, 317(8), 814-824. https://doi.org/10.1001/jama.2017.0693

Visovsky, C., Collins, M., Abbott, L., Aschenbrenner, J., \& Hart, C. (2007). Putting Evidence Into Practice ${ }^{\circledR}$ : Evidence-Based Interventions for Chemotherapy- 
Induced Peripheral Neuropathy. Clinical Journal of Oncology Nursing, 11(6), 901-913. https://doi.org/10.1188/07.CJON.901-913 
Figure 4. Visual Model: The Experience of CIPN Among CCS

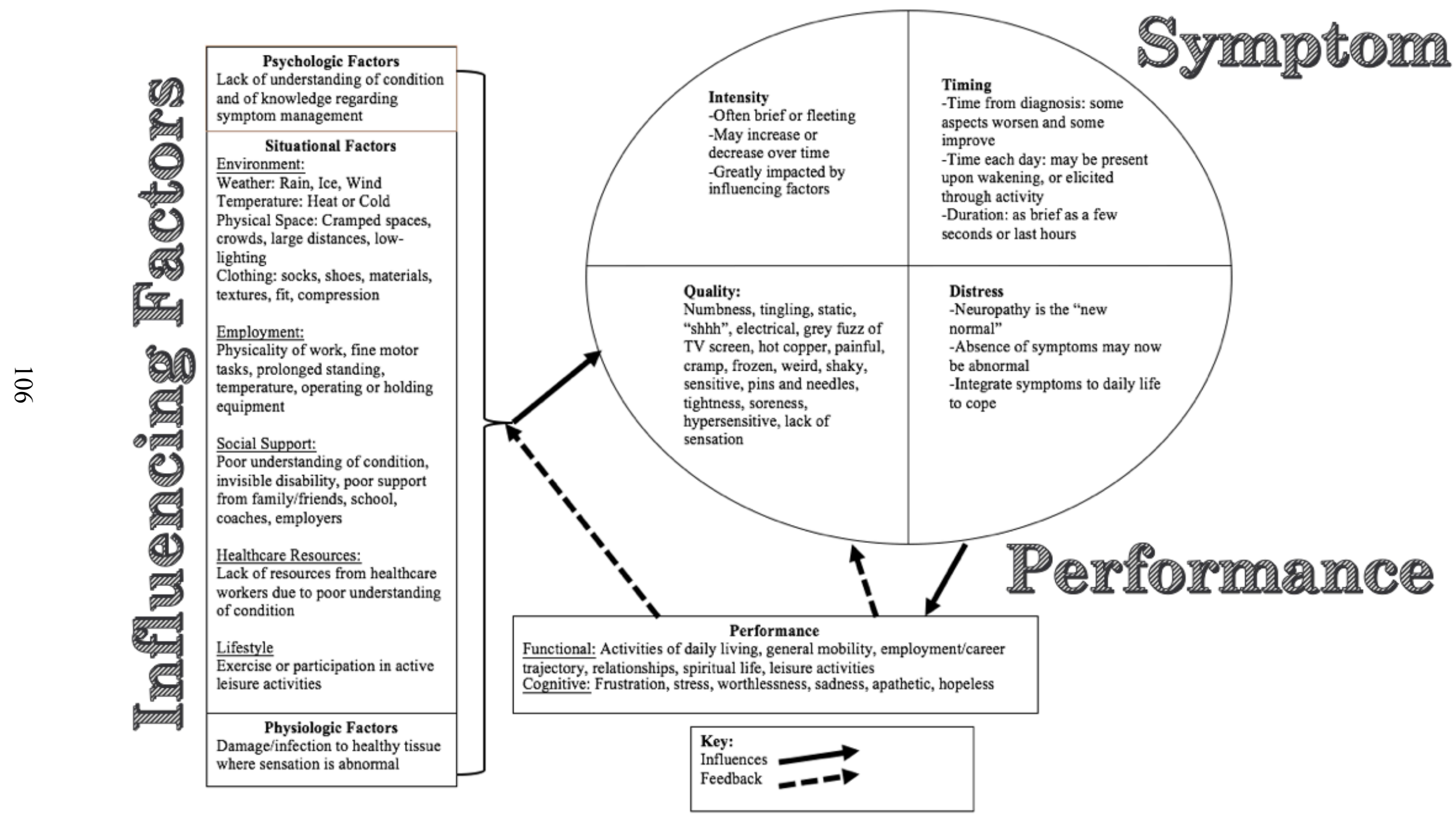




\section{References}

Anghelescu, D. L., Faughnan, L. G., Jeha, S., Relling, M. V., Hinds, P. S., Sandlund, J. T., ... Pui, C.-H. (2011). Neuropathic pain during treatment for childhood acute lymphoblastic leukemia. Pediatric Blood \& Cancer, 57(7), 1147-1153. https://doi.org/10.1002/pbc.23039

Armenian, S. H., Landier, W., Hudson, M. M., Robison, L. L., \& Bhatia, S. (2013). Children's Oncology Group's 2013 blueprint for research: Survivorship and outcomes. Pediatric Blood \& Cancer, 60(6), 1063-1068. https://doi.org/10.1002/pbc.24422

Armstrong, T., Almadrones, L., \& Gilbert, M. (2005). Chemotherapy-Induced Peripheral Neuropathy. Oncology Nursing Forum, 32(2), 305-311. https://doi.org/10.1188/05.ONF.305-311

Aytaç, S., Yetgin, S., \& Tavil, B. (2006). Acute and long-term neurologic complications in children with acute lymphoblastic leukemia. The Turkish Journal of Pediatrics, $48(1), 1-7$.

Bakitas, M. A. (2007). Background noise: the experience of chemotherapy-induced peripheral neuropathy. Nursing Research, 56(5), 323-331. https://doi.org/10.1097/01.NNR.0000289503.22414.79

Barroso, J., Gollop, C. J., Sandelowski, M., Meynell, J., Pearce, P. F., \& Collins, L. J. (2003). The Challenges of Searching for and Retrieving Qualitative Studies. Western Journal of Nursing Research, 25(2), 153-178. https://doi.org/10.1177/0193945902250034 
Beijers, A. J. M., Mols, F., Tjan-Heijnen, V. C. G., Faber, C. G., van de Poll-Franse, L. V., \& Vreugdenhil, G. (2015). Peripheral neuropathy in colorectal cancer survivors: The influence of oxaliplatin administration. Results from the population-based PROFILES registry. Acta Oncologica (Stockholm, Sweden), 54(4), 463-469. https://doi.org/10.3109/0284186X.2014.980912

Bevan, M. T. (2014). A Method of Phenomenological Interviewing. Qualitative Health Research, 24(1), 136-144. https://doi.org/10.1177/1049732313519710

Binner, M., Ross, D., \& Browner, I. (2011). Chemotherapy-Induced Peripheral Neuropathy: Assessment of Oncology Nurses' Knowledge and Practice. Oncology Nursing Forum, 38(4), 448-454.

Birks, M., Chapman, Y., \& Francis, K. (2008). Memoing in qualitative research Probing data and processes. Journal of Research in Nursing, 13(1), 68-75. https://doi.org/10.1177/1744987107081254

Boydell, K. M., Gladstone, B. M., Volpe, T., Allemang, B., \& Stasiulis, E. (2012). The Production and Dissemination of Knowledge: A Scoping Review of Arts-Based Health Research. Forum Qualitative Sozialforschung / Forum: Qualitative Social Research, 13(1). Retrieved from http://www.qualitativeresearch.net/index.php/fqs/article/view/1711

Brown, T., \& Lalor, A. (2009). The Movement Assessment Battery for ChildrenSecond Edition (MABC-2): A Review and Critique. Physical \& Occupational Therapy in Pediatrics, 29(1), 86-103.

https://doi.org/10.1080/01942630802574908 
Calhoun, E. A., Welshman, E. E., Chang, C.-H., Lurain, J. R., Fishman, D. A., Hunt, T. L., \& Cella, D. (2003). Psychometric evaluation of the Functional Assessment of Cancer Therapy/Gynecologic Oncology Group-Neurotoxicity (Fact/GOG-Ntx) questionnaire for patients receiving systemic chemotherapy. Journal of Gynecological Cancer November, 13(6), 741-748.

Cata, J. P., Weng, H.-R., Burton, A. W., Villareal, H., Giralt, S., \& Dougherty, P. M. (2007). Quantitative sensory findings in patients with bortezomib-induced pain. The Journal of Pain, 8(4), 296-306.

Catalani, C., \& Minkler, M. (2010). Photovoice: A Review of the Literature in Health and Public Health. Health Education \& Behavior, 37(3), 424-451. https://doi.org/10.1177/1090198109342084

Chung, T., Prasad, K., \& Lloyd, T. E. (2014a). Peripheral Neuropathy. Neuroimaging Clinics of North America, 24(1), 49-65. https://doi.org/10.1016/j.nic.2013.03.023

Chung, T., Prasad, K., \& Lloyd, T. E. (2014b). Peripheral neuropathy: clinical and electrophysiological considerations. Neuroimaging Clinics of North America, 24(1), 49-65.

Clark, A., Prosser, J., \& Wiles, R. (2010). Ethical issues in image-based research. Arts \& Health, 2(1), 81-93. https://doi.org/10.1080/17533010903495298

Coad, J. (2007). Using art-based techniques in engaging children and young people in health care consultations and/or research. Journal of Research in Nursing, 12(5), 487-497. https://doi.org/10.1177/1744987107081250 
Cornblath, D. R., Chaudhry, V., Carter, K., Lee, D., Seysedadr, M., Miernicki, M., \& Joh, T. (1999). Total neuropathy score validation and reliability study. Neurology, 53(8), 1660-1660.

Cox, C. L., Nolan, V. G., Leisenring, W., Yasui, Y., Ogg, S. W., Mertens, A. C., ... Robison, L. L. (2014). Noncancer-related mortality risks in adult survivors of pediatric malignancies: the childhood cancer survivor study. Journal of Cancer Survivorship. https://doi.org/10.1007/s11764-014-0353-7

De Grandis, D. (2007). Acetyl-L-Carnitine for the Treatment of Chemotherapy-Induced Peripheral Neuropathy: A Short Review. CNS Drugs, 21, 39.

De Luca, C. R., McCarthy, M., Galvin, J., Green, J. L., Murphy, A., Knight, S., \& Williams, J. (2013). Gross and fine motor skills in children treated for acute lymphoblastic leukaemia. Developmental Neurorehabilitation, 16(3), 180-187. https://doi.org/10.3109/17518423.2013.771221

Deitz, J. C., Kartin, D., \& Kopp, K. (2007). Review of the Bruininks-Oseretsky Test of Motor Proficiency, Second Edition (BOT-2). Physical \& Occupational Therapy in Pediatrics, 27(4), 87-102. https://doi.org/10.1080/J006v27n04_06

Dodd, M. J., Miaskowski, C., \& Lee, K. A. (2004). Occurrence of Symptom Clusters. JNCI Monographs, 2004(32), 76-78. https://doi.org/10.1093/jncimonographs/lgh008

Drew, Duncan, \& Sawyer. (2010). Visual Storytelling: A Beneficial But Challenging Method for Health Research With Young People. Qualitative Health Research, 20(12), 1677-1688. https://doi.org/10.1177/1049732310377455 
Drew, S., \& Guillemin, M. (2014). From photographs to findings: visual meaningmaking and interpretive engagement in the analysis of participant-generated images. Visual Studies, 29(1), 54-67. https://doi.org/10.1080/1472586X.2014.862994

Driessen, C. M. L., de Kleine-Bolt, K. M. E., Vingerhoets, A., Mols, F., \& Vreugdenhil, G. (2012). Assessing the impact of chemotherapy-induced peripheral neurotoxicity on the quality of life of cancer patients. Supportive Care in Cancer, 20(4), 877-881.

Eckhoff, L., Knoop, A., Jensen, M. B., \& Ewertz, M. (2015). Persistence of docetaxelinduced neuropathy and impact on quality of life among breast cancer survivors. European Journal of Cancer (Oxford, England: 1990), 51(3), 292-300. https://doi.org/10.1016/j.ejca.2014.11.024

Emden, C. (1998). Theoretical perspectives on narrative inquiry. Collegian, 5(2), 30-35. https://doi.org/10.1016/S1322-7696(08)60281-4

Epstein, I., Stevens, B., McKeever, P., \& Baruchel, S. (2008). Photo Elicitation Interview (PEI): Using Photos to Elicit Children's Perspectives. International Journal of Qualitative Methods, 5(3), 1-11.

Erikson, E. H. (1993). Childhood and Society. W. W. Norton \& Company. Ezendam, N. P. M., Pijlman, B., Bhugwandass, C., Pruijt, J. F. M., Mols, F., Vos, M. C., ... van de Poll-Franse, L. V. (2014). Chemotherapy-induced peripheral neuropathy and its impact on health-related quality of life among ovarian cancer survivors: results from the population-based PROFILES registry. Gynecologic Oncology, 135(3), 510-517. https://doi.org/10.1016/j.ygyno.2014.09.016 
Finfgeld-Connett, D. (2014). Use of content analysis to conduct knowledge-building and theory-generating qualitative systematic reviews. Qualitative Research, 14(3), 341-352. https://doi.org/10.1177/1468794113481790

Fraser, K. D., \& al Sayah, F. (2011). Arts-based methods in health research: A systematic review of the literature. Arts \& Health, 3(2), 110-145. https://doi.org/10.1080/17533015.2011.561357

Friis, R. H., \& Sellers, T. (2013). Epidemiology for Public Health Practice. Burlington, MA: Jones \& Bartlett Publishers.

Frith, H., \& Harcourt, D. (2007). Using photographs to capture women's experiences of chemotherapy: Reflecting on the method. Qualitative Health Research, 17(10), $1340-1350$.

Gilchrist, L. (2012). Chemotherapy-Induced Peripheral Neuropathy in Pediatric Cancer Patients. Seminars in Pediatric Neurology, 19(1), 9-17. https://doi.org/10.1016/j.spen.2012.02.011

Gilchrist, L., Marais, L., \& Tanner, L. (2013). Comparison of two chemotherapy-induced peripheral neuropathy measurement approaches in children. Supportive Care in Cancer, 1-8. https://doi.org/10.1007/s00520-013-1981-6

Gilchrist, L., \& Tanner, L. (2013). The pediatric-modified total neuropathy score: a reliable and valid measure of chemotherapy-induced peripheral neuropathy in children with non-CNS cancers. Supportive Care in Cancer, 21(3), 847-856. https://doi.org/10.1007/s00520-012-1591-8 
Gilchrist, L., Tanner, L. R., \& Ness, K. (2017). Short-term recovery of chemotherapyinduced peripheral neuropathy after treatment for pediatric non-CNS cancer. Pediatric Blood \& Cancer, 64(1), 180-187. https://doi.org/10.1002/pbc.26204

Gomber, S., Dewan, P., \& Chhonker, D. (2010). Vincristine induced neurotoxicity in cancer patients. The Indian Journal of Pediatrics, 77(1), 97-100. https://doi.org/10.1007/s12098-009-0254-3

Hagedorn, M. R. (1994). Hermeneutic photography: An innovative esthetic technique for generating data in nursing research. Advances in Nursing Science Esthetics and the Art of Nursing, 17(1), 44-50.

Harila-Saari, A. H., Huuskonen, U. E. J., Tolonen, U., Vainionpää, L. K., \& Lanning, B. M. (2001). Motor nervous pathway function is impaired after treatment of childhood acute lymphoblastic leukemia: A study with motor evoked potentials. Medical and Pediatric Oncology, 36(3), 345-351. https://doi.org/10.1002/mpo.1084

Harila-Saari, A. H., Vainionpää, L. K., Kovala, T. T., Tolonen, E. U., \& Lanning, B. M. (1998). Nerve lesions after therapy for childhood acute lymphoblastic leukemia. Cancer, 82(1), 200-207. https://doi.org/10.1002/(SICI)10970142(19980101)82:1<200::AID-CNCR25>3.0.CO;2-5

Hartman, A., van den Bos, C., Stijnen, T., \& Pieters, R. (2006). Decrease in motor performance in children with cancer is independent of the cumulative dose of vincristine. Cancer, 106(6), 1395-1401. https://doi.org/10.1002/cncr.21706 
Hudson, M., Ness, K., Gurney, J., Mulrooney, Chemaitilly, Krull, ... Robison. (2013). Clinical ascertainment of health outcomes among adults treated for childhood cancer. JAMA, 309(22), 2371-2381. https://doi.org/10.1001/jama.2013.6296

Jacob, E. (2004). Neuropathic pain in children with cancer. Journal of Pediatric Oncology Nursing: Official Journal of the Association of Pediatric Oncology Nurses, 21(6), 350-357. https://doi.org/10.1177/1043454204270251

Jain, P., Gulati, S., Seth, R., Bakhshi, S., Toteja, G. S., \& Pandey, R. M. (2013). Vincristine-induced Neuropathy in Childhood ALL (Acute Lymphoblastic Leukemia) Survivors Prevalence and Electrophysiological Characteristics. Journal of Child Neurology, 883073813491829. https://doi.org/10.1177/0883073813491829

Keusch, F., Rao, R., Chang, L., Lepkowski, J., Reddy, P., \& Choi, S. W. (2014). Participation in clinical research: perspectives of adult patients and parents of pediatric patients undergoing hematopoietic stem cell transplantation. Biology of Blood and Marrow Transplantation: Journal of the American Society for Blood and Marrow Transplantation, 20(10), 1604-1611. https://doi.org/10.1016/j.bbmt.2014.06.020

Kottschade, L. A., Sloan, J. A., Mazurczak, M. A., Johnson, D. B., Murphy, B. P., Rowland, K. M., ... Loprinzi, C. L. (2010). The use of vitamin E for the prevention of chemotherapy-induced peripheral neuropathy: results of a randomized phase III clinical trial. Supportive Care in Cancer, 19(11), 17691777. https://doi.org/10.1007/s00520-010-1018-3 
Lavoie Smith, E. M., Li, L., Chiang, C., Thomas, K., Hutchinson, R. J., Wells, E. M., ... Renbarger, J. (2015). Patterns and severity of vincristine-induced peripheral neuropathy in children with acute lymphoblastic leukemia. Journal of the Peripheral Nervous System: JPNS, 20(1), 37-46. https://doi.org/10.1111/jns.12114

Lehtinen, S. S., Huuskonen, U. E., Harila-Saari, A. H., Tolonen, U., Vainionpää, L. K., \& Lanning, B. M. (2002). Motor nervous system impairment persists in long-term survivors of childhood acute lymphoblastic leukemia. Cancer, 94(9), 2466-2473. https://doi.org/10.1002/cncr.10503

Lenz, E. R., Pugh, L. C., Milligan, R. A., Gift, A., \& Suppe, F. (1997). The MiddleRange Theory of Unpleasant Symptoms: An Update. Advances in Nursing Science, 19(3), 14-27.

Lenz, E. R., Suppe, F., Gift, A., Pugh, L., \& Milligan, R. (1995). Collaborative development of middle-range nursing theories: toward a theory of unpleasant symptoms. ANS. Advances in Nursing Science, 17(3), 1-13.

Leone, M., Viret, P., Bui, H. T., Laverdière, C., Kalinova, É., \& Comtois, A.-S. (2013). Assessment of gross motor skills and phenotype profile in children 9-11 years of age in survivors of acute lymphoblastic leukemia. Pediatric Blood \& Cancer, n/an/a. https://doi.org/10.1002/pbc.24731

Lopez, K. A., \& Willis, D. G. (2004). Descriptive Versus Interpretive Phenomenology: Their Contributions to Nursing Knowledge. Qualitative Health Research, 14(5), 726-735. https://doi.org/10.1177/1049732304263638 
Markman, M. (2006). Chemotherapy-induced peripheral neuropathy: underreported and underappreciated. Current Pain and Headache Reports, 10(4), 275-278.

Miller, S. (2003). Analysis of phenomenological data generated with children as research participants. Nurse Researcher, 10(4), 68.

Mohrmann. (2017). The experience of chemotherapy-induced peripheral neuropathy among childhood cancer survivors. Manuscript in Preparation.

Mohrmann, C., Armer, J., \& Hayashi, R. J. (2016). Challenges Evaluating Chemotherapy-Induced Peripheral Neuropathy in Childhood Cancer Survivors Which Instrument Should Nurses Use? Journal of Pediatric Oncology Nursing, $34(2), 1-9$.

Mols, F., Beijers, T., Lemmens, V., van den Hurk, C. J., Vreugdenhil, G., \& van de PollFranse, L. V. (2013). Chemotherapy-induced neuropathy and its association with quality of life among 2- to 11-year colorectal cancer survivors: results from the population-based PROFILES registry. Journal of Clinical Oncology: Official Journal of the American Society of Clinical Oncology, 31(21), 2699-2707. https://doi.org/10.1200/JCO.2013.49.1514

Monteiro Caran, E. M., Dias, C. G., Seber, A., \& Petrilli, A. S. (2005). Clinical aspects and treatment of pain in children and adolescents with cancer. Pediatric Blood \& Cancer, 45(7), 925-932. https://doi.org/10.1002/pbc.20523

Motl, R. W., \& McAuley, E. (2009). Symptom Cluster as a Predictor of Physical Activity in Multiple Sclerosis: Preliminary Evidence. Journal of Pain and Symptom Management, 38(2), 270-280. https://doi.org/10.1016/j.jpainsymman.2008.08.004 
Myers, J. S. (2009). A Comparison of the Theory of Unpleasant Symptoms and the Conceptual Model of Chemotherapy-Related Changes in Cognitive Function. Oncology Nursing Forum, 36(1), E1-E10. https://doi.org/10.1188/09.ONF.E1E10

Ness, K. K., Hudson, M. M., Pui, C.-H., Green, D. M., Krull, K. R., Huang, T. T., ... Morris, E. B. (2012). Neuromuscular impairments in adult survivors of childhood acute lymphoblastic leukemia. Cancer, 118(3), 828-838. https://doi.org/10.1002/cncr.26337

Ness, K. K., Jones, K. E., Smith, W. A., Spunt, S. L., Wilson, C. L., Armstrong, G. T., ... Gurney, J. G. (2013). Chemotherapy-Related Neuropathic Symptoms and Functional Impairment in Adult Survivors of Extracranial Solid Tumors of Childhood: Results From the St. Jude Lifetime Cohort Study. Archives of Physical Medicine and Rehabilitation. https://doi.org/10.1016/j.apmr.2013.03.009

Oeffinger, K. C., Mertens, A. C., Sklar, C. A., Kawashima, T., Hudson, M. M., Meadows, A. T., ... Robison, L. L. (2006). Chronic Health Conditions in Adult Survivors of Childhood Cancer. New England Journal of Medicine, 355(15), 1572-1582. https://doi.org/10.1056/NEJMsa060185

Ortlipp, M. (2008). Keeping and Using Reflective Journals in the Qualitative Research Process. The Qualitative Report, 13(4), 695-705.

Poupon, L., Kerckhove, N., Vein, J., Lamoine, S., Authier, N., Busserolles, J., \& Balayssac, D. (2015). Minimizing chemotherapy-induced peripheral neuropathy: preclinical and clinical development of new perspectives. Expert Opinion on Drug Safety, 1-14. https://doi.org/10.1517/14740338.2015.1056777 
Printz, C. (2015). Majority of survivors of childhood cancer experience comorbidities. Cancer, 121(14), 2293-2293. https://doi.org/10.1002/cncr.29540

Ramchandren, S., Leonard, M., Mody, R. J., Donohue, J. E., Moyer, J., Hutchinson, R., \& Gurney, J. G. (2009). Peripheral neuropathy in survivors of childhood acute lymphoblastic leukemia. Journal of the Peripheral Nervous System, 14(3), 184189. https://doi.org/10.1111/j.1529-8027.2009.00230.x

Reinders-Messelink, H. A., Schoemaker, M. M., Hofte, M., Göeken, L. N. H., Kingma, A., van den Briel, M. M., \& Kamps, W. A. (1996). Fine motor and handwriting problems after treatment for childhood acute lymphoblastic leukemia. Medical and Pediatric Oncology, 27(6), 551-555. https://doi.org/10.1002/(SICI)1096911X(199612)27:6<551::AID-MPO8>3.0.CO;2-K

Reyes-Gibby, C., Morrow, P. K., Bennett, M. I., Jensen, M. P., \& Shete, S. (2010). Neuropathic Pain in Breast Cancer Survivors: Using the ID Pain as a Screening Tool. Journal of Pain and Symptom Management, 39(5), 882-889. https://doi.org/10.1016/j.jpainsymman.2009.09.020

Richards, L., \& Morse, J. M. (2012). README FIRST for a User's Guide to Qualitative Methods. SAGE.

Salloum, R., Chen, Y., Yasui, Y., Packer, R., Leisenring, W. M., Wells, E. M., ... Armstrong, G. T. (2017). Temporal trends in late-onset morbidity and mortality after medulloblastoma diagnosed across three decades: A report from the Childhood Cancer Survivor Study (CCSS). Journal of Clinical Oncology, 35(15_suppl), 10516-10516.

https://doi.org/10.1200/JCO.2017.35.15_suppl.10516 
Sandelowski, M. (1991). Telling stories: narrative approaches in qualitative research. Image: Journal of Nursing Scholarship, 23(3), 161-166.

Sandelowski, M. (1993). Theory unmasked: the uses and guises of theory in qualitative research. Research in Nursing \& Health, 16(3), 213-218.

Sandelowski, M. (1995). Sample size in qualitative research. Research in Nursing \& Health, 18(2), 179-183.

Seretny, M., Currie, G. L., Sena, E. S., Ramnarine, S., Grant, R., MacLeod, M. R., ... Fallon, M. (2014). Incidence, prevalence, and predictors of chemotherapyinduced peripheral neuropathy: A systematic review and meta-analysis. PAIN®, 155(12), 2461-2470. https://doi.org/10.1016/j.pain.2014.09.020

Smith, E. M. L., Li, L., Hutchinson, R. J., Ho, R., Burnette, W. B., Wells, E., ... Renbarger, J. (2013). Measuring Vincristine-Induced Peripheral Neuropathy in Children With Acute Lymphoblastic Leukemia. Cancer Nursing September/October 2013, 36(5). https://doi.org/10.1097/NCC.0b013e318299ad23

Smith, \& Liehr. (2013). Middle Range Theory for Nursing: Third Edition. Springer Publishing Company.

Speck, R. M., DeMichele, A., Farrar, J. T., Hennessy, S., Mao, J. J., Stineman, M. G., \& Barg, F. K. (2012). Scope of symptoms and self-management strategies for chemotherapy-induced peripheral neuropathy in breast cancer patients. Supportive Care in Cancer, 20(10), 2433-2439. https://doi.org/10.1007/s00520-011-1365-8

Stubblefield, M. D., McNeely, M. L., Alfano, C. M., \& Mayer, D. K. (2012). A prospective surveillance model for physical rehabilitation of women with breast cancer. Cancer, 118(S8), 2250-2260. https://doi.org/10.1002/cncr.27463 
Tofthagen, C. (2010a). Patient perceptions associated with chemotherapy-induced peripheral neuropathy. Clinical Journal of Oncology Nursing, 14(3), E22-28. https://doi.org/10.1188/10.CJON.E22-E28

Tofthagen, C. (2010b). Surviving Chemotherapy for Colon Cancer and Living with the Consequences. Journal of Palliative Medicine, 13(11), 1389-1391. https://doi.org/10.1089/jpm.2010.0124

Tofthagen, C., Donovan, K. A., Morgan, M. A., Shibata, D., \& Yeh, Y. (2013). Oxaliplatin-induced peripheral neuropathy's effects on health-related quality of life of colorectal cancer survivors. Supportive Care in Cancer: Official Journal of the Multinational Association of Supportive Care in Cancer, 21(12), 3307-3313. https://doi.org/10.1007/s00520-013-1905-5

Tofthagen, C., Overcash, J., \& Kip, K. (2012). Falls in persons with chemotherapyinduced peripheral neuropathy. Supportive Care in Cancer, 20(3), 583-589.

Tofthagen, C., Visovsky, C. M., \& Hopgood, R. (2013). Chemotherapy-induced peripheral neuropathy: an algorithm to guide nursing management. Clinical Journal of Oncology Nursing, 17(2), 138-144.

https://doi.org/10.1188/13.CJON.138-144

Tuohy, D., Cooney, A., Dowling, M., Murphy, K., \& Sixsmith, J. (2013). An overview of interpretive phenomenology as a research methodology. Nurse Researcher, 20(6), $17-20$.

Turcotte, L. M., Liu, Q., Yasui, Y., Arnold, M. A., Hammond, S., Howell, R. M., ... Neglia, J. P. (2017). Temporal Trends in Treatment and Subsequent Neoplasm 
Risk Among 5-Year Survivors of Childhood Cancer, 1970-2015. JAMA, 317(8), 814-824. https://doi.org/10.1001/jama.2017.0693

US Department of Health and Human Services. (2009). Common terminology criteria for adverse events (CTCAE) version 4.0. National Institutes of Health. Retrieved from http://evs.nci.nih.gov/ftp1/CTCAE/CTCAE_4.03_2010-06-

14_QuickReference_5x7.pdf

Vainionpää, L., Kovala, T., Tolonen, U., \& Lanning, M. (1995). Vincristine therapy for children with acute lymphoblastic leukemia impairs conduction in the entire peripheral nerve. Pediatric Neurology, 13(4), 314-318.

van Brussel, M., Takken, T., Net, J. van der, Engelbert, R. H., Bierings, M., Schoenmakers, M. A., \& Helders, P. J. (2006). Physical function and fitness in long-term survivors of childhood leukaemia. Developmental Neurorehabilitation, 9(3), 267-274.

van Manen, M. (2011). Phenomenology Online» Orientations in Phenomenology. Retrieved April 13, 2014, from http://www.phenomenologyonline.com/inquiry/orientations-in-phenomenology/ Vasquez, S., Guidon, M., McHugh, E., Lennon, O., Grogan, L., \& Breathnach, O. S. (2014). Chemotherapy induced peripheral neuropathy: the modified total neuropathy score in clinical practice. Irish Journal of Medical Science, 183(1), 53-58. https://doi.org/10.1007/s11845-013-0971-5

Vincent, C. V. H. (2005). Nurses' knowledge, attitudes, and practices: Regarding children's pain. MCN: The American Journal of Maternal/Child Nursing, 30(3), $177-183$. 
Visovsky, C., Collins, M., Abbott, L., Aschenbrenner, J., \& Hart, C. (2007). Putting Evidence Into Practice ${ }^{\circledR}$ : Evidence-Based Interventions for ChemotherapyInduced Peripheral Neuropathy. Clinical Journal of Oncology Nursing, 11(6), 901-913. https://doi.org/10.1188/07.CJON.901-913

Wampler, M. A., Topp, K. S., Miaskowski, C., Byl, N. N., Rugo, H. S., \& Hamel, K. (2007). Quantitative and clinical description of postural instability in women with breast cancer treated with taxane chemotherapy. Archives of Physical Medicine and Rehabilitation, 88(8), 1002-1008.

Wickham, R. (2007). Chemotherapy-Induced Peripheral Neuropathy: A Review and Implications for Oncology Nursing Practice. Clinical Journal of Oncology Nursing, 11(3), 361-376. https://doi.org/10.1188/07.CJON.361-376

Wright, M. J., Halton, J. M., Martin, R. F., \& Barr, R. D. (1998). Long-term gross motor performance following treatment for acute lymphoblastic leukemia. Medical and Pediatric Oncology, 31(2), 86-90. https://doi.org/10.1002/(SICI)1096911X(199808)31:2<86::AID-MPO7>3.0.CO;2-V 
Appendix A

\section{Patient Prompts for Photographs}

Thank you for being a part of this study so we can understand what it is like to live with peripheral neuropathy after treatment for cancer!

People with peripheral neuropathy have reported feelings such as numbness, tingling, burning or electrical feelings as well as difficulty with certain activities like writing, driving, working, dressing, or even doing fun activities. Everyone feels differently and we want to know how your symptoms affect your life.

We have asked you to take some pictures over the next month that you feel will help you share your experience. Here are some ideas of pictures you can take. You don't have to take any pictures like this, or you can take a picture of something not on this list - it is up to you!

1. Something that represents what peripheral neuropathy is like in your everyday life.

2. How your symptoms of peripheral neuropathy make you feel.

3. Something that is more difficult for you to do because of peripheral neuropathy.

4. Something you have had to change since you have peripheral neuropathy.

5. How you cope with your symptoms.

6. Something you really love to do.

Please do not take pictures of anything illegal or anything you do not want to share. When you are done taking pictures, please put the camera in the envelope I have given you and send back to me. I will develop the pictures and set up a time to interview you. 
Appendix B

\section{Interview Guide}

\section{Open-ended Questions}

- Tell me about any of the symptoms of peripheral neuropathy you have experienced: numbness, tingling, stabbing, throbbing, electrical, pins and needles sensation.

- Tell me about any of the ways having peripheral neuropathy has changed your life: how you move, how you play, go to school, go to work.

- Tell me about any of the ways peripheral neuropathy makes you feel emotionally.

- Tell me about any pain you experience.

- In your own words, how would you describe your symptoms?

- What is a regular day like for you having these symptoms?

- Is there anything else you want to share with me about your life with these symptoms?

\section{Photo-elicitation Questions}

- Tell me about this picture.

- What is going on in this picture?

- Why did you choose to take this picture?

- How does this picture make you feel?

- What does this picture mean to you?

- How does this picture show me what your life is like with peripheral neuropathy? 
Appendix $\mathrm{C}$

Institutional Review Board

University of Missouri-Columbia

190 Galena Hall; Dc074.00

Columbia, MO 65212

573-882-3181

irbømissouri.edu

September 7, 2016

Principal Investigator: Caroline Mohrmann

Department:

Your IRB Application to project entitled The Experience of Chemotherapy-Induced Peripheral Neuropathy in Childhood Cancer Survivors was reviewed and approved by the MU Institutional Review Board according to the terms and conditions described below:

$\begin{array}{ll}\text { IRB Project Number } & 2005904 \\ \text { IRB Review Number } & 216546 \\ \text { Funding Source } & \text { American Cancer Society } \\ \text { Initial Application Approval Date September 07,2016 } \\ \text { IRB Expiration Date } & \text { September 07,2017 } \\ \text { Level of Review } & \text { Expedited } \\ \text { Project Status } & \text { Active - Open to Enrollment } \\ \text { Expedited Categories } & 45 \text { CFR 46.110.a(f)(6) } \\ \text { Child Category } & 45 \text { CFR 46.110.a(f)(7) } \\ \text { Type of Consent } & 46.404 \\ \text { External Funding } & \text { Consent with Waiver of Documentation } \\ \text { Protocol Version/Date } & \text { Child Assent without Documentation } \\ \end{array}$

The principal investigator (PI) is responsible for all aspects and conduct of this study. The PI must comply with the following conditions of the approval:

1. No subjects may be involved in any study procedure prior to the IRB approval date or after the expiration date.

2. All unanticipated problems, adverse events, and deviations must be reported to the IRB within 5 days.

3. All changes must be IRB approved prior to implementation unless they are intended to reduce immediate risk.

4. All recruitment materials and methods must be approved by the IRB prior to being used.

5. The Continuing Review Report (CRR) must be submitted to the IRB for review and approval at least 30 days prior to the project expiration date. If the study is complete, the 
Completion/Withdrawal Form may be submitted in lieu of the CRR.

6. Maintain all research records for a period of seven years from the project completion date.

7. Utilize the IRB stamped consent documents and other approved research documents located within the document storage section of eCompliance. These documents are highlighted green.

If you are offering subject payments and would like more information about research participant payments, please click here to view the MU Business Policy and Procedure: http://bppm.missouri.edu/chapter $2 / 2 \quad 250 \mathrm{html}$

If you have any questions, please contact the IRB at 573-882-3181 or irbermissouri.edu.

Thank you,

MU Institutional Review Board 


\title{
Appendix D
}

\section{WAIVER OF DOCUMENTATION OF CONSENT}

\author{
Investigator's Name: Caroline Mohrmavx \\ PRONECT \# 2005904
}

\section{STUDY TITLE: THE EXPERIENCE OF CHEMOTHERAPY-INDUCED PERIPHERAL NEUROPATHY IN CHILDHOOD CANCER SURVIVORS}

1. I would like to ask you, or your child, to participate in a study that involves research. If you are a parent or guardian, in the following statements "you" refers to your child.

2. Participation is voluntary and your decision not to participate will not involve any penalty or loss of benefits and will in no way affect the medical care you receive.

3. For this study, you will be given a disposable camera and asked to take pictures that will help you share your experience living with chemotherapy-induced peripheral neuropathy. You will have 1 month to take pictures, and then you will send the camera back to me in an envelope I will give you. I will develop the photos and arrange a time for us to meet so I can interview you about your experience and about the photographs you have taken. The interview should take about an hour. We can arrange the interview to happen at the hospital or we can arrange the interview to take place over the computer. I will record the interview and keep a copy of the photos. I may contact you within 6 months of the interview to see if you agree with what I have learned from the interview, but I may not. After that period, your participation in the study is over.

4. The purpose of our study is to learn what it is like to live with chemotherapy-induced peripheral neuropathy after cancer therapy is over, since this condition is poorly understood and we have few ways to help people living with this condition after their childhood cancer.

5. We are asking approximately 15 subjects to participate in this study.

6. The study staff may withdraw you from the study at any time after explaining to you the reason for withdrawal.

7. While on the study, you are at risk for accidental disclosure of private information. We will not keep any copy of your medical records. We will not share the recording of your interview or the pictures you have taken without your additional permission. You should not take any pictures that you do not want anyone else to see. You should discuss these with the investigator and/or your doctor.

8. You may expect to benefit from taking part in this research to the extent that you are contributing to medical knowledge.

9. If you choose to participate, your recorded interview and the pictures you take will be kept on a secure computer with a password. I won't share this information with other people. I won't share your name with other people. If I let anyone listen to your interview or see any of the pictures you take, I will make sure they are not able to identify you.

10. You won't be charged any money to participate in the study.

11. There is a $\$ 50$ gift card given to you for participation in this study. If you need to travel to the hospital again, you will be offered a $\$ 30$ gas card to help with your travel expenses.

12. If you have any questions regarding your rights as a participant in this research and/or concerns about the study, or if you feel under any pressure to enroll or to continue to participate in this study, you may contact the

IRB USE ONIY

Approval Date: September 7, 2016

Expiration Date: September 7, 2017 
University of Missouri Health Sciences Institutionsl Review Bosrd (which is a group of people who review the research studies to protect participants" rights) at (573) 882-3181.

13. If you have any problems or questions, you may contact Caroline Mohrmann at 314-4546018.

14. I would be happy to answer any questions that you may have.

15. A copy of this script will be given to you to keep. 


\title{
CHILd ASSENT FoRM TO PARTICIPATE IN A RESEARCH STUdY
}

\author{
ASSENT SCRIPT \\ Investigator's Name: Caroline Mohrmavn \\ PRONECT \# 2005904

\section{STUDY TITLE: THE EXPERIENCE OF CHEMOTHERAPY-INDUCED PERIPHERAL NEUROPATHY IN CHILDHOOD CANCER SURVIVORS}

1. I would like to ask you to be a part of a study that involves research.

2. If is your decision to participate or not. If you don"t want to participate it the study, that's OK. You will still be treated the same and get the same medical care.

3. If you want to be in the study, here is what will happen: you will be given a disposable camera and asked to take pictures that will help you share your experience living with chemotherapyinduced peripheral neuropathy. You will have 1 month to take pictures, and then you will send the camera back to me in an envelope I will give you. You can take up to 27 pictures, but you don't have to take any if you don't want. I will develop the photos and set up a time for us to meet so I can ask you more about your pictures and about what it is like to live with neuropathy. We can arrange the interview to happen at the hospital or we can arrange the interview to take place over the computer. I will record the interview and keep a copy of the photos. I may contact you within 6 months of the interview to see if you agree with what I have learned from the interview, but I may not. After that time has passed, you don't have to do anything else for the study.

4. The purpose of our study is to learn what it is like to live with chemotherapy-induced peripheral neuropathy after cancer therapy is over, since we don't know a lot about kids that have neuropathy after their cancer.

5. We are hoping 15 people will be in the study.

6. While you are on the study, we will keep all information about you private, including the pictures you take and what we talk about in the interview. If someone else looks at the pictures or listens to the interview, I'll make sure they can't tell it is you.

7. If you agree to take part in this study, you will be given a $\$ 50$ gift card to Walmart as a way for me to say, "thank you for helping me". If you come back to the hospital for your interview, we will give you a $\$ 30$ gas card to help pay for your gas. You may also feel good about being part of the research study, since you will be helping other kids who have cancer treatment too.

8. You won't be charged any money to participate in the study.

9. If you have any problems or questions, you may call me at 314-454-6018.

10. Do you have any questions about how this study works or what will happen if you are a part of the study?

11. A copy of this script will be given to you to keep.

University of Missouri Child Assent Form Template

Released: April, 2013

HS IRB USE ONLY

Approval Date: September 7, 2016

Expiration Date: September 7, 2017 
VITA

Caroline Mohrmann was born in Memphis, TN. She earned her B.S. in Nursing from Lipscomb University in 2007. She practiced pediatric critical care nursing while earning her M.S. in Nursing from Vanderbilt University in 2009. Her clinical work as an advanced practice nurse at the Washington University School of Medicine at St. Louis Children's Hospital focuses on the care of children with cancer, and specifically, survivors of childhood cancer. She currently resides in St. Louis, Missouri with her husband and daughter. 